UNIVERSIDADE DE SÃO PAULO

ESCOLA DE ENFERMAGEM

ANA PAULA DA CONCEIÇÃO

PREDITORES DA QUALIDADE DE VIDA RELACIONADA À SAÚDE DE PACIENTES COM INSUFICIÊNCIA CARDÍACA

São Paulo 


\title{
PREDITORES DA QUALIDADE DE VIDA RELACIONADA À SAÚDE DE PACIENTES COM INSUFICIÊNCIA CARDÍACA
}

\author{
Versão corrigida da Dissertação apresentada ao Programa de \\ Pós-Graduação em Saúde do adulto da Escola de Enfermagem \\ da Universidade de São Paulo para obtenção do título de \\ Mestra em Ciências
}

Área de Concentração: Enfermagem na Saúde do Adulto Orientadora: $\operatorname{Prof}^{a}{ }^{\mathrm{a}}{ }^{\mathrm{a}}$ Diná de Almeida Lopes Monteiro da Cruz

\section{VERSÃO CORRIGIDA}

A versão original encontra-se disponível na Biblioteca da Escola de Enfermagem da Universidade de São Paulo e na Biblioteca Digital de Teses e Dissertações da Universidade de São Paulo.

SÃO PAULO 
AUTORIZO A REPRODUÇÃO E DIVULGAÇÃO TOTAL OU PARCIAL DESTE TRABALHO, POR QUALQUER MEIO CONVENCIONAL OU ELETRÔNICO, PARA FINS DE ESTUDO E PESQUISA, DESDE QUE CITADA A FONTE.

Assinatura: Data:

Catalogação na Publicação (CIP)

Biblioteca "Wanda de Aguiar Horta"

Escola de Enfermagem da Universidade de São Paulo

Conceição, Ana Paula da

Preditores da qualidade de vida relacionada à saúde de pacientes com insuficiência cardíaca / Ana Paula da Conceição. São Paulo, 2015.

$149 \mathrm{p}$.

Dissertação (Mestrado) - Escola de Enfermagem da Universidade de São Paulo.

Orientadora: Prof. ${ }^{\underline{a}}$ Dr. ${ }^{\underline{a}}$ Diná de Almeida Lopes Monteiro da Cruz

Área de concentração: Enfermagem na Saúde do Adulto

1. Insuficiência cardíaca. 2. Qualidade de vida. 3. Autocuidado. 4. Sono. 5. Enfermagem. 6. Cognição.

7. Depressão. I. Título. 
Nome: Ana Paula da Conceição

Títuo: Preditores da qualidade de vida relacionada à saúde de pacientes com insuficiência cardíaca

Dissertação apresentada à Escola de Enfermagem da Universidade de São Paulo para obtenção do título de Mestre em Ciências

Aprovado em:

\section{Banca Examinadora}

Prof. Dr.:

Julgamento:

Prof. Dr.:

Julgamento:

Prof. Dr.:

Julgamento:
Instituição:

Assinatura:

Instituição:

Assinatura:

Instituição:

Assinatura: 


\section{Dedicatória}

A Deus, por estar presente em todos os momentos...

Zlos meus pais Luiza e Geraldo (in memoriam), pelo exemplo de vida, honestidade, integridade e caráter. Dor terem me ensinado a importância do estudo e por sempre me apoiarem.

Zlo meu querido esposo Flávio Luiz Guimarães, pelo amor, carinho e apoio ao longo desses anos, sempre me apoiando e estando do meu lado.

Alo meu filho Lucas Vinicius, companheiro inseparável e razão do meu viver e a minha afilhada Malu, cuja qual amo muito.

A minha irmã Sonia e ao meu cunhado Xartin, por torcerem sempre por mim e sempre me incentivarem.

Zlos meus queridos amigos de longa data, Daniel, Xirangela, Cleusa e Xara, por estarem sempre presentes, apoiando-me e ajudando nas minhas decisões.

Zlos meus tios Xargaria e Manoel Joaquim Santana, aos primos Aldriana, Erike Bernard, e aos meus sogros Aparecida e Luiz Guimarães (in memoriam), por me ajudarem nos momentos em que mais precisei. 


\section{Agradecimentos Especiais}

À Profa. Dra. Diná de Zlmeida Lopes Xonteiro da Cruz, pela orientação zelosa, atenção e pela dedicação constante ao longo desses dois anos. Delos comentários precisos, pela paciência de ler e veler meus textos, mesmo estando de férias, pelo saber transmitido nas aulas, pelas reuniões imprescindiveis que tornaram este trabalho possivel, enfim, por ter me conduzido nos caminhos da ciência de forma brithante.

À Dra. Andrea Cotait Zyoub, Diretora Técnica da Divisão de Enfermagem do Instituto Dante Pazzanese de Cardiologia, pelo apoio e incentivo incondicionali pelo entusiasmo quando passei no processo seletivo do mestrado, por acreditar em mim, por investir na minha carreira e formação profissional e pelos constantes ensinamentos. Sinto muito orgulho por fazer parte da sua equipe; 


\section{Agradecimentos}

À Mariana Alvina dos Santos, pela parceria durante o desenvolvimento deste estudo;

Ass Drofass. Dras. Rosana Aparecida Spadoti Dantas e Xliako Kimur, meu reconhecimento pelas valiosas contribuições no exame de qualificação;

À Profa. Ana Lucia Siqueira, pelas valiosas contribuições metodológicas;

Às Dra Rika Kobayashsie Drofa Dra. Estela Bianchi. pelo incentivo;

À enfermeira Célia Fliromi Shiotsu, pelos ensinamentos, apoio e incentivo;

İs amigas mais recentes, Christiane Casteli e Gabriela Nunes, pela amizade e constante incentivo;

Zlos enfermeiros chefes, César Zugusto, Luciana Bueno, me substituirem para que eu pudesse realizar as disciplinas e atividades do mestrado;

Às enfermeiras da unidade de internação, Fernanda Ladeia Z1bad, Valéria Rosi Marques da Costa e Lucimara Dereira da Silua, pelo auxilio durante a coleta de dados;

Alos enfermeiros, auxiliares de enfermagem e oficiais administrativos da unidade de internação do $4^{\circ}$ andar, pela convivência carinhosa e pela dedicaçãa e competência com que realizam a assistência de enfermagem e compreensão durante os momentos de ausência; 
À enfermeira chefe do ambulatório, Xichele Zyres, e às enfermeiras Xaria Z Aparecida e Nadja, do Instituto Dante Dazzanese de Cardiologia, por auxiliar durante a coleta de dados;

Zlos integrantes do grupo de Desquisa em Diagnóstico, Intervençõos e Resultados e Enfermagem (DIREnf), pelas valiosas contribuiçôes;

A todos os pacientes que participaram espontaneamente deste trabalho, sem eles essa pesquisa não seria possiveli

A todos aqueles que, de uma forma ou de outra, contribuiram para a realização deste trabalho. 
Talvez não tenha conseguido fazer o methor, mas lutei para que o melhor fosse feito. Não son o que deveria ser, mas Graças a Deus, não son o que era antes. (Xarthin Luther King]. 
Conceição, AP. Preditores da qualidade de vida relacionada à saúde de pacientes com insuficiência cardíaca [dissertação]. São Paulo: Escola de Enfermagem, Universidade de São Paulo; 2014.

\section{Resumo}

A insuficiência cardíaca (IC) é uma condição muito frequente, caracterizada por alta taxa de mortalidade e tem impacto negativo na qualidade de vida relacionada à saúde (QVRS). Este estudo teve como objetivo analisar fatores preditores da QVRS em pacientes com IC. Método: Estudo observacional, transversal, realizado com 409 pacientes com IC em tratamento ambulatorial. Variáveis sociodemográficas e clínicas, incluindo qualidade do sono (Pisttsburgh Sleep Quality Inventory), autocuidado (Self-Care of Heart Failure Index) e qualidade de vida relacionada à saúde (Minnesota Living With Heart Failure Questuionnaire) foram analisadas por meio de testes de associação e regressão logística binária múltipla. Resultados: Dos 409 pacientes avaliados: 224 (54,8\%) eram do sexo masculino, tinham idade média de 57,9 anos (dp = 11,6), escolaridade média de 6,1 anos ( $\mathrm{dp}=4,1)$ e 60,2\% tinham QVRS moderada/ruim. A QVRS moderada ou ruim foi associada a: ser do sexo feminino $(p=0,048)$, apresentar declínio cognitivo ( $p=0,008)$, estar em classe funcional mais elevada ( $p<0,001)$, ter sintomas depressivos ( $p<0,001)$, ser "mau dormidor" ( $p<0,001$ ), ter fadiga e fadiga ocasionada pelo esforço $(p<0,001)$, ter dispneia $(p<0,001)$, noctúria $(p<0,001)$, fazer uso de 7 ou mais tipos de medicamentos ( $p<0,001$ ), tomar os medicamentos 9 vezes ou mais por dia $(p<0,002)$ e ter baixa atividade física habitual $(p<0,041)$. No modelo de análise múltipla, ser "mau dormidor" $(O R=2,5 ; p=0,003)$, inadequada confiança no autocuidado ( $O R=2,5 ; p=0,009)$, estar na classe funcional mais elevada ( $O R=3,7 ; p=0,002)$, ter fadiga $(O R=3,3 ; p=0,009)$ e fadiga ocasionada pelo esforço ( $O R=8,7 ; p=<0,001)$ e fazer uso de 7 ou mais tipos de medicamentos (OR $=3,2 ; p=0,001)$ foram preditores independentes para a QVRS moderada ou ruim. Conclusões: A QVRS de pacientes com IC envolve fatores potencialmente modificáveis por intervenções não farmacológicas. Outros estudos de caráter longitudinal são necessários para confirmar a relevância desses fatores para a QVRS na insuficiência cardíaca.

Palavras chave: Insuficiência cardíaca. Qualidade de Vida. Autocuidado. Sono. Enfermagem. Fadiga. Cognição. Depressão. 
Conceição, AP. Predictors of health-related quality of life in patients with heart failure [dissertation]. São Paulo: Nursing School, University of São Paulo; 2014.

\begin{abstract}
Heart failure is a very common condition characterized by high mortality and has a negative impact on health-related quality of life (HRQOL). This study aimed to analyze potential predictors of HRQOL in patients with heart failure. Method: An observational, cross-sectional study conducted with 409 patients with HF in outpatient treatment. Sociodemographic and clinical variables, including sleep quality (Pisttsburgh Sleep Quality Inventory), self-care (Self-care of Heart Failure Index) and health-related quality of life (Minnesota Living With Heart Failure Questionnaire) were analyzed using tests of association and multiple binary logistic regression. Results: Out of 409 patients assessed, 224 (54.8\%) were male, the mean age was 57.9 (SD 11.6) years, mean schooling was 6.1 (SD 4.1) years, and $60.2 \%$ had HRQOL moderate / poor. Moderate or poor HRQOL was associated with: female sex $(\mathrm{p}=$ 0.048), cognitive decline $(p=0.008)$, higher functional class $(p<0.001)$, depressive symptoms ( $p<0.001)$, "bad sleeper" $(p<0.001)$, fatigue and exertion fatigue $(p<0.001)$, dyspnea ( $<<0.001)$, nocturia ( $<<0.001)$, making use of 7 or more kinds of drugs $(p<0.001)$; having nine or more medications taken per day $(p<0.002)$ and low habitual physical activity $(p<0.041)$. In the multivariate analysis model, "bad sleepers" $(O R=2.5, p=0.003)$, inadequate confidence in self-care $(O R=2.5, p=0.009)$, higher functional class $(O R=3.7, p$ $=0.002)$, fatigue $(O R=3.3, p=0.009)$, exertion fatigue $(O R=8.7, p=<0.001)$, use of seven or more kinds of drugs $(O R=3.2, p=0.001)$ were independent predictors of moderate or poor HRQOL. Conclusions: HRQoL in heart failure patients with HF involves factors potentially modifiable by means of non-pharmacological interventions. Other studies of longitudinal design are needed to confirm the relevance of these factors to HRQOL in heart failure.
\end{abstract}

Key words: Heart Failure. Quality of Life. Self-care. Sleep. Nursing. Fatigue. Cognition. Depression. 


\section{LISTA DE TABELAS}

Tabela 1 - Características sociodemográficas da amostra $(N=409)$, São Paulo2014

Tabela 2 - Características clínicas gerais da amostra $(N=409)$, São Paulo - 2014

Tabela 3 - Número e porcentual de participantes segundo comorbidades $(\mathrm{N}=409)$, São Paulo - 2014

Tabela 4 - Número e porcentual de participantes segundo uso de terapia medicamentosa ( $N=409)$, São Paulo - 2014

Tabela 5 - Estatística descritiva do Mini Exame do Estado Mental (MEEM) $(N=409)$, São Paulo -

2014.

Tabela 6 - Número e frequência de pacientes, segundo as respostas aos itens do DUFS (Fadiga) ( $\mathrm{N}=409)$, São Paulo - 2014

Tabela 7 - Número e frequência de pacientes, segundo as respostas aos itens do DEFS (fadiga ao esforço) $(\mathrm{N}=409)$, São Paulo - 2014.

Tabela 8 - Número e frequência de pacientes segundo as respostas aos itens do CES-D ( $\mathrm{N}=409)$, São Paulo -

2014.

Tabela 9 - Estatísticas descritiva da atividade física habitual e dos seus componentes, São Paulo -

2014.

Tabela 10 - Número e porcentagem das respostas dos sujeitos em relação aos componentes do PSQI $(\mathrm{N}=409)$, São Paulo - 2014 .

Tabela 11 - Frequência dos fatores que contribuíram para o componente transtornos do sono $(\mathrm{N}=409)$, São Paulo - 2014.

Tabela 12 - Estatística descritiva das características do sono de acordo com as respostas ao PSQI para os componentes de latência e de eficiência habitual do sono $(N=409)$, São Paulo - 2014.

Tabela 13 - Estatística descritiva dos itens do Minnesota Living with Heart Failure Questionnaire (MLHFQ) (N = 409), São Paulo - 2014.

Tabela 14 - Estatística descritiva dos dos itens e confiabilidade do SCHFI - versão brasileira, São Paulo - 2014 ...

Tabela 15 - Número e porcentual de pacientes, segundo qualidade de vida relacionada à saúde e variáveis sociodemográficas $(N=409)$. São Paulo, 2014. 
Tabela 16 - Número e porcentual de pacientes, segundo Qualidade de vida relacionada à saúde e variáveis clínicas $(\mathrm{N}=409)$. São Paulo - 2014.

Tabela 17 - Número e porcentual de pacientes, segundo Qualidade de vida relacionada à saúde e padrão do sono $(\mathrm{N}=409)$, São Paulo - 201

Tabela 18 - Número e porcentual de pacientes, segundo Qualidade de vida relacionada à saúde e comportamento de autocuidado $(N=409)$, São Paulo - 2014

Tabela 19 - Resultados da análise múltipla para fatores associados à má qualidade de vida relacionada à saúde, São Paulo - 2014 


\section{LISTA DE QUADROS}

Quadro 1 - Descrição dos estudos sobre fatores associados/preditores de qualidade de vida em pacientes com insuficiência cardíaca ............. 24

Quadro 2 - Variáveis avaliadas e instrumentos utilizados.................. 45 


\section{LISTA DE ABREVIATURAS}

$\begin{array}{ll}\text { ADHERE } & \text { Acute Descompensated Heart Failure National Registry } \\ \text { AFH } & \text { Atividade Física Habitual } \\ \text { AFO } & \text { Atividade Fisica Ocupacional } \\ \text { ALL } & \text { Atividades de Lazer e Locomoção } \\ \text { BRA } & \text { Bloqueadores dos Receptores da Angiotensina } \\ \text { CES-D } & \text { Center for Epidemiologic Studies Depression Scale } \\ \text { CF } & \text { Classe Funcional } \\ \text { DEFS } & \text { Dutch Exertion Fatigue Scale } \\ \text { DP } & \text { Desvio Padrão } \\ \text { DUFS } & \text { Dutch Fatigue Scale } \\ \text { EEUSP } & \text { Escola de Enfermagem Universidade de São Paulo } \\ \text { EFL } & \text { Exercícios físicos de lazer } \\ \text { FEVE } & \text { Fração de Ejeção Ventricular Esquerda } \\ \text { HAS } & \text { Hipertensão Arterial Sistêmica } \\ \text { IBGE } & \text { Instituto Brasileiro de Geografia e Estatística } \\ \text { IC } & \text { Insuficiência Cardíaca } \\ \text { ICC } & \text { Índice de Comorbidade de Charlson } \\ \text { ICS } & \text { International Continence Society } \\ \text { IDPC } & \text { Instituto Dante Pazzanese de Cardiologia } \\ \text { IECA } & \text { Inibidores da Enzima Conversora da Angiotensina } \\ \text { LILACS } & \text { Literatura Latino-Americana e do Caribe em Ciências da Saúde } \\ \text { MEEM } & \text { Mini Exame do Estado Mental } \\ \text { MESH } & \text { Medical Subject Headings } \\ \text { MLHFQ } & \text { Minnessota Living With heart Failure Questionnaire } \\ \text { NYHA } & \text { New York Heart Association } \\ \text { OMS } & \text { Organização Mundial de Saúde } \\ \text { OPTIMIZE- } & \text { Organized Program to Initiate Lifesaving Treatment in Hospitalized- } \\ \text { HF } & \text { Heart Failure } \\ \text { OR } & \text { Odds Ratio } \\ \text { PSQI } & \text { Pittsburg Sleep Quality Index } \\ \text { PubMed } & \text { Public Medline } \\ \text { QVRS } & \text { Qualidade de Vida Relacionada à Saúde } \\ \text { QV } & \text { Qualidade de Vida } \\ \text { SAME } & \text { Serviço de Arquivo Médico e Estatística } \\ \text { SCHFI } & \text { Self-Care of Heart Failure Index } \\ \text { SPSS } & \text { Statistical Package for the Social Science } \\ \text { SUS } & \text { Sistema Único de Saúde } \\ \text { TCLE } & \text { Termo de Consentimento Livre e Esclarecido } \\ & \end{array}$




\section{SUMÁRIO}

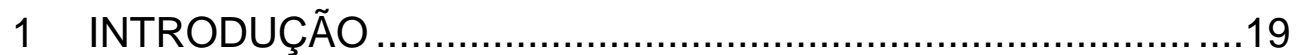

1.1 INSUFICIÊNCIA CARDÍACA E QUALIDADE DE VIDA

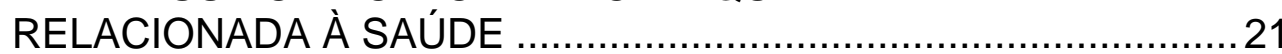

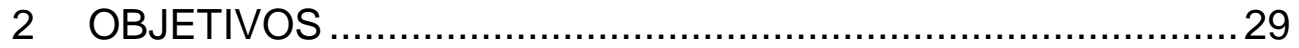

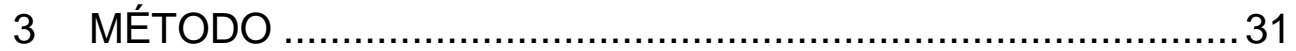

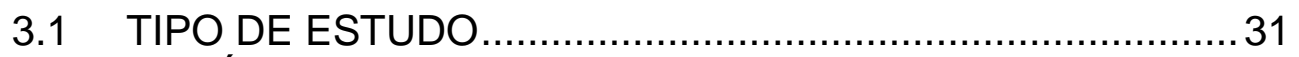

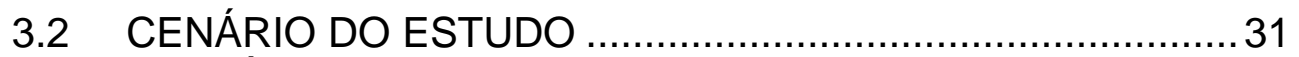

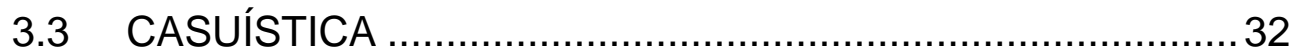

3.4 CRITÉRIOS DE INCLUSÃO E EXCLUSÃO …......................33

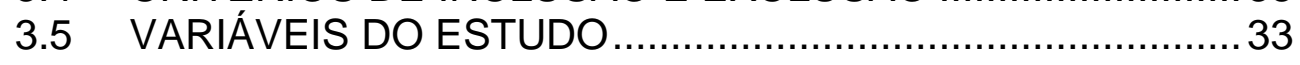

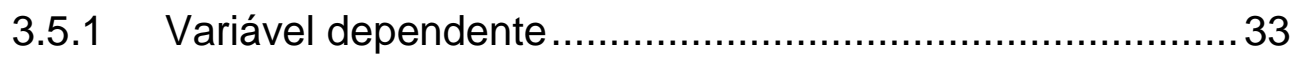

3.5.1.1 Variáveis independentes .............................................. 34

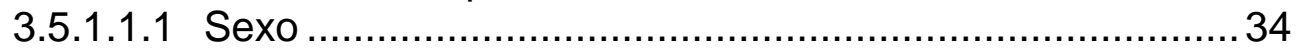

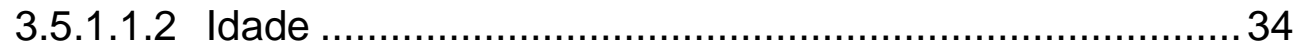

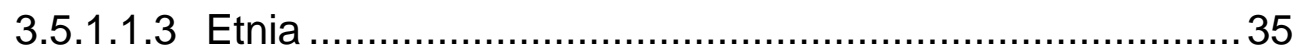

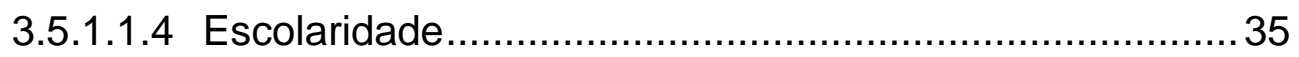

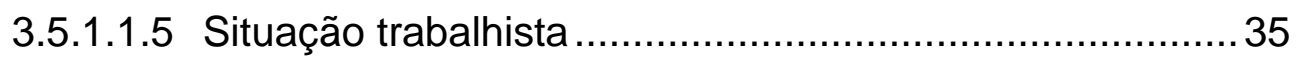

3.5.1.1.6 Convivência marital ................................................... 35

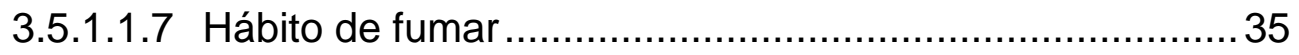

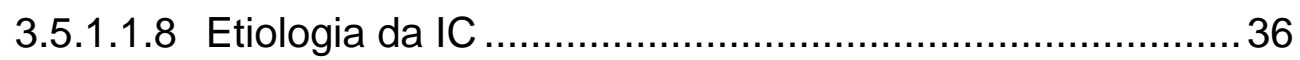

3.5.1.1.9 Fração de ejeção ventricular esquerda ............................36

3.5.1.1.10 Índice de comorbidade de Charlson.............................. 36

3.5.1.1.11 Tempo de experiência com a doença ............................ 37

3.5.1.1.12 Comprometimento cognitivo....................................... 37

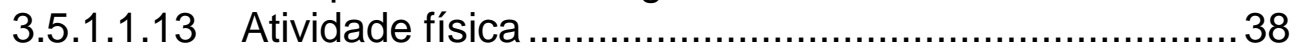

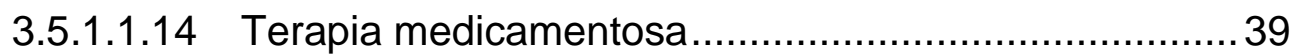

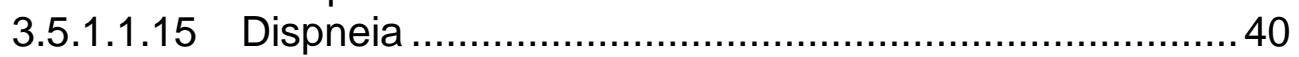

3.5.1.1.16 Fadiga e fadiga ao esforço........................................ 41

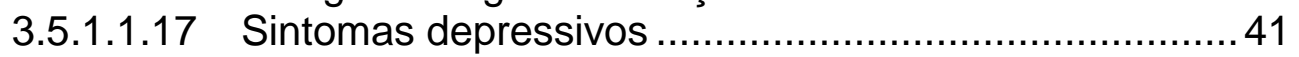

3.5.1.1.18 Nocturia ................................................................ 42

3.5.1.1.19 Classe funcional da IC .......................................... 42

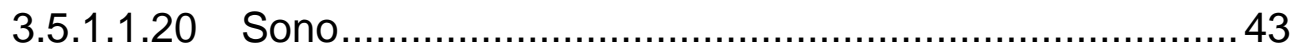

3.5.1.1.21 Comportamento de autocuidado ............................... 44

3.5.1.1.22 Tipo de acompanhamento....................................... 44

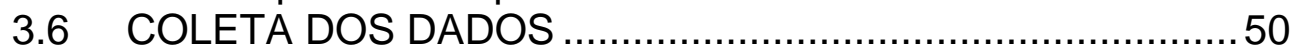

3.7 INSTRUMENTO PARA A COLETA DOS DADOS ..................51

3.8 ANÁLISE ESTATÍSTICA DOS DADOS …............................. 52

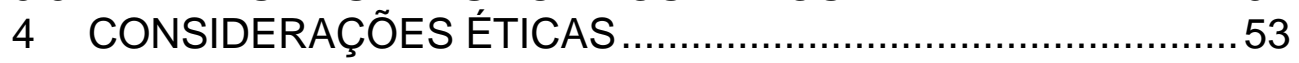

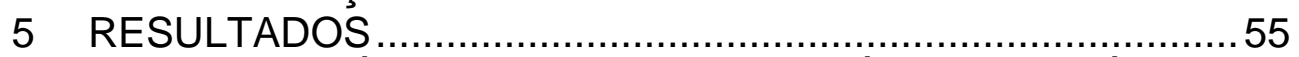

5.1 CARACTERÍSTICAS SOCIODEMOGRÁFICAS E CLÍNICAS55

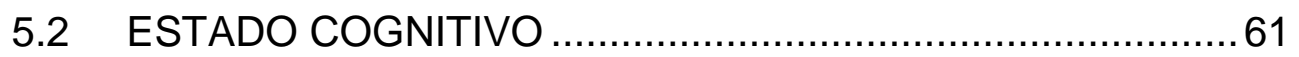

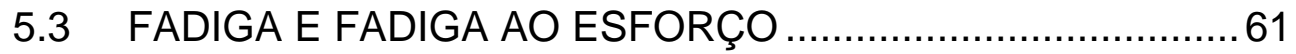

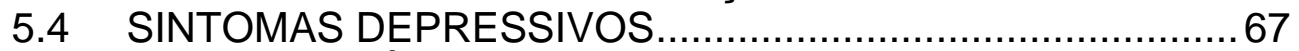

5.5 ATIVIDADE FÍSICA HABITUAL ........................................ 71

5.6 DESCRIÇÃO DO PADRÃO DE SONO............................... 71 
5.7 DESCRIÇÃO DA QUALIDADE DE VIDA RELACIONADA À SAÚDE

5.8 DESCRIÇÃO DO AUTOCUIDADO …............................ 79

5.9 ASSOCIACCÃO DAS VARIÁVEIS SOCIODEMOGRÁFICAS

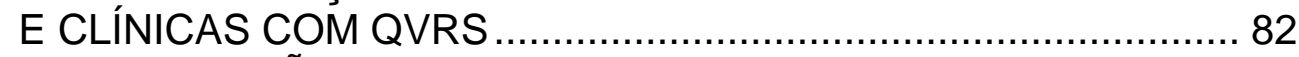

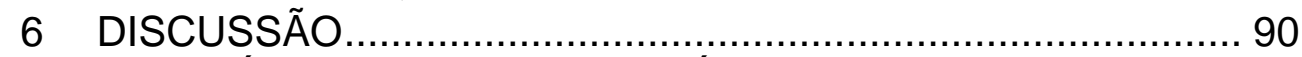

6.1 VARIÁVEIS SOCIODEMOGRÁFICAS ……….................... 90

6.2 VARIÁVEIS CLÍNICAS ..................................................... 91

6.3 PREDITORES DE MÁ QVRS ......................................... 105

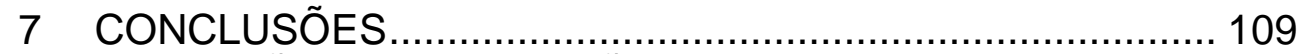

8 LIMITAÇÕES E IMPLICAÇÕES …………........................ 111

8.1 LIMITAÇÕES ........................................................... 111

8.2 IMPLICAÇÕES PARA A ASSISTENCIA, ENSINO E PESQUISA

9 REFERENCIAS

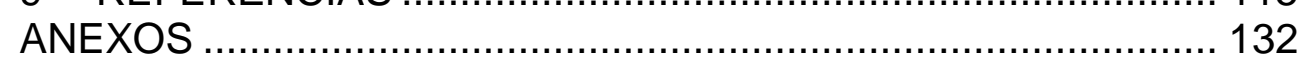


Introdução 


\section{INTRODUÇÃO}

Este estudo buscou analisar fatores potencialmente associados e preditores da qualidade de vida relacionada à saúde (QVRS) de pacientes com Insuficiência Cardíaca (IC).

A IC é uma síndrome clínica caracterizada por disfunção cardíaca que ocasiona suprimento sanguíneo inadequado para atender às necessidades metabólicas tissulares, sendo considerada a via final comum da maioria das doenças do coração (Bocchi et al., 2009; Mesquita and Jorge, 2010). Trata-se de uma doença crônica e debilitante, comum em todos os países desenvolvidos e sua prevalência está em ascensão, em decorrência do incremento na expectativa de vida da população e do avanço das terapias (Bocchi et al., 2009; Mesquita and Jorge, 2010).

Aproximadamente 23 milhões de pessoas possuem insuficiência cardíaca e 2 milhões de novos casos de insuficiência cardíaca são diagnosticados a cada ano no mundo (Nogueira et al. 2010). No Brasil, a IC é uma epidemia cardiovascular emergente, representando o segundo maior número de motivo de internações de adultos no Sistema Único de Saúde (SUS) a partir dos 65 anos e estima-se que 6,4 milhões de brasileiros sofram dessa doença (Araujo et al., 2005; Godoy et al., 2011; Bocchi et al., 2012).

A IC cursa com altos custos com medicamentos, internações hospitalares e grande número de atendimentos de emergência, ocasionando elevados custos para - País, e grande parte dessas internações são decorrentes da exacerbação dos sintomas da doença (Araujo et al., 2005; Godoy et al., 2011). A taxa de mortalidade pela IC é alta, com cerca de $30 \%$ dentro do primeiro ano após o diagnóstico e com terapêutica clínica. (Casida et al., 2011; Godoy et al., 2011; Strueber et al., 2011). As taxas de mortalidade após hospitalização por IC estão em torno de 10,4\% em 30 dias, 20,0\% em um ano, e 42,3\% em cinco anos (Roger, 2013). Segundo Heidenreich et al. (2011), em 2030, cerca de 9 milhões de pessoas terão IC. Mesmo com os avanços no tratamento, a incidência da IC não diminuiu, mas a sobrevivência após início do tratamento teve um aumento global (Kato et al., 2011). 
Diversos fatores influenciam os resultados da IC tais como: sintomas limitantes (Holland et al., 2010; Evangelista et al., 2008), situação econômica (Dunlay et al., 2011), apoio social (de Belvis et al., 2008), adesão à terapia medicamentosa (Hodges, 2009), autocuidado (Riegel et al., 2011), e o principal objetivo do seu tratamento é melhorar a sobrevida e qualidade de vida relacionada à saúde dos pacientes, considerando que estão predispostos a experimentar altos níveis de sofrimento físico e emocional (Kato et al., 2011).

O tratamento da IC é complexo, incluindo polifarmácia, modificações de estilo de vida e necessidade de manutenção e gerenciamento das atividades do autocuidado. A complexidade do tratamento da IC associada à diminuição no funcionamento físico contribui para baixa qualidade de vida relacionada à saúde desses pacientes (Riegel et al., 2009b).

Além da terapia medicamentosa para alívio dos sintomas e melhor evolução da doença, medidas não farmacológicas, como a educação dos pacientes para o autocuidado e manejo da doença, são importantes para melhor controle da doença e melhor qualidade de vida (Rabelo et al., 2007).

Segundo a Atualização da Diretriz Brasileira de Insuficiência Cardíaca, tornase imprescindível a criação de clínicas específicas para melhor manejo desses pacientes (Bocchi et al., 2012). Nessas clínicas, o enfermeiro tem papel importante na equipe multidisciplinar. Sua meta de trabalho deve ser voltada para educação do paciente para o autocuidado, exaltando a importância da aderência ao tratamento farmacológico e não farmacológico, ensinando aos pacientes e seus cuidadores a identificar precocemente sintomas de descompensação clínica, ou eventos passíveis de tratamento e prevenção, além de fornecer estratégias para fortalecer confiança do paciente no autocuidado (Dickson et al., 2008). Estudos apontam que pacientes que participam de programa de autogestão e que estão ativamente envolvidos com o autocuidado apresentam menos internações (Jovicic et al., 2006; Lainscak et al., 2011; McAlister et al.,2004) 


\subsection{INSUFICIÊNCIA CARDÍACA E QUALIDADE DE VIDA RELACIONADA À SAÚDE}

Qualidade de vida pode ser considerada de duas maneiras: Qualidade de Vida (QV) de forma geral e Qualidade de Vida Relacionada à Saúde (QVRS). Segundo a Organização Mundial de Saúde (OMS), a QV é definida como " a percepção do indivíduo em relação à sua posição na vida de acordo com o contexto cultural e os sistemas de valores nos quais vive e em relação a seus objetivos, expectativas, padrões e preocupações" (WHOQOL, 1995). Já a QVRS representa as respostas individuais aos efeitos físicos, mentais e sociais que a doença produz sobre a vida diária, as quais, por sua vez, influenciam sobre a medida em que se pode conseguir satisfação pessoal com as circunstâncias da vida (Fletcher et al., 1992).

A QVRS é um tema bem estudado em pacientes com IC. Estudos apontam que indivíduos com insuficiência cardíaca têm sua QVRS bastante prejudicada em comparação com pessoas saudáveis ou com outras doenças crônicas (Bekelman et al., 2007; Son et al., 2012) e que a QVRS é um fator independente de pior sobrevida em pacientes com IC (Kato et al., 2011).

Vários fatores têm sido estudados e identificados como associados a prejuízos na QVRS. Características sociodemográficas como idade, sexo, etnia, escolaridade, situação trabalhista e convivência marital têm sido consideradas relevantes para a QVRS de pacientes com IC.

Com relação à idade, a maioria dos pacientes com IC são idosos e pesquisadores tem identificado a idade como um preditor de mortalidade e hospitalizações (Wahle et al., 2009). No entanto, a associação entre idade e QVRS não está claramente determinada. Alguns estudos demonstram que a QVRS geral é mais comprometida em adultos idosos (Naveiro-Rilo et al., 2014) quando comparado com adultos mais jovens, porém outras pesquisas não têm encontrado essa associação (Kato et al., 2011; Erceg et al., 2013). Estudo realizado por Moser et al., (2013), com objetivo de determinar as razões das diferenças na QVRS com IC, em idosos em comparação com pacientes mais jovens, a QVRS foi pior no grupo mais 
jovem. Segundo os autores, as expectativas sobre o que constitui uma boa QV dos pacientes mais idosos, pode ser uns dos fatores que contribuem para a melhor QVRS entre pacientes mais velhos. Nesse estudo, os pacientes mais jovens relataram níveis mais elevados de depressão e ansiedade do que o grupo mais velho, o que também pode ter contribuído para os resultados relativos à QVRS (Moser et al., 2013).

Quanto ao gênero, dados da literatura mostram comprometimento da QVRS tanto nos homens como nas mulheres (Heo et al., 2009; Gallicchio et al., 2007), mas na maioria das pesquisas as mulheres apresentaram piores escores de QVRS quando comparadas com os escores apresentados pelas pessoas do sexo masculino (Barbosa et al., 2014; Chu et al., 2014; Naveiro-Rilo et al., 2014).

Nível educacional também é considerado uma variável importante para investigação da QVRS de pacientes com IC. Estudos têm demonstrado que pacientes com baixa escolaridade apresentam pior qualidade de vida relacionada à saúde quando comparado com aqueles com melhores níveis de escolaridade (Barbareschi et al., 2011).

Quanto à situação econômica, estudos têm mostrado associação positiva com a QVRS (Chu et al., 2014). Segundo Heo et al. (2009), pacientes que apresentam dificuldades econômicas devido à perda de seus empregos e aumento do gasto com medicamentos para tratamento da IC relatam pior QVRS.

Com relação às características clínicas, a gravidade da IC, avaliada por meio da classe funcional NYHA, está associada à QVRS. Os pacientes em classes funcionais mais elevadas apresentam pior QVRS (Naveiro-Rilo et al., 2014; Erceg et al., 2013), possivelmente em razão dos efeitos da redução da capacidade funcional (Fotos et al., 2013). Quanto à fração de ejeção ventricular esquerda, alguns estudos não revelam associação com a QVRS (Naveiro-Rilo et al., 2014; Erceg et al., 2013).

Dentre os sintomas físicos da IC, dispneia e fadiga são os mais frequentes e afetam adversamente vários aspectos da vida diária dos pacientes, como limitação da atividade física diária, do trabalho e atividades sociais, sendo um importante preditor de má QVRS (Heo et al., 2008a; Faller et al., 2009; Lesman-Leegte et al., 2009a ; Lee et al., 2014; Huang et al., 2010). 
Os sintomas depressivos e os distúrbios do sono são frequentes nos pacientes com IC, com taxas que variam de 35\% a 76\% (Casida et al., 2011; Santos M. et al., 2011; Strueber et al., 2011) e geralmente estão associados a pior QVRS em comparação com outras doenças crônicas (Redeker and Hilkert, 2005 ;Broström et al., 2007; Gau et al., 2011; Chen et al., 2009; Zambroski et al., 2005).

Múltiplas comorbidades, assim como a complexidade do tratamento, com uso de polifarmácia, também têm sido associadas a pior QVRS nos indivíduos com IC (Naveiro-Rilo et al., 2014; Erceg et al., 2013; Fotos et al., 2013).

Deficits cognitivos ocorrem com frequência em pacientes com IC, e pesquisas têm descrito que esses deficits contribuem para inadequado autocuidado e possivelmente pior QVRS (Cameron et al., 2010).

Para adequado manejo da IC, o reconhecimento precoce de sintomas é essencial para que sejam tratados rapidamente (Dickson et al., 2007). A redução da capacidade para o autocuidado de pacientes com IC está associada ao aumento da morbidade e mortalidade, possivelmente relacionado com os problemas de tomadas de decisões e de adesão ao tratamento (Dickson et al., 2007). Estudos anteriores demostraram associação entre inadequado autocuidado com piores escores de QVRS e que pacientes que participam de programa de autogestão, e que estão ativamente envolvidos com o autocuidado, apresentam menos internações e melhor QVRS (McAlister et al., 2004; Jovicic et al., 2006; Lainscak et al., 2011).

Observa-se uma crescente preocupação dos pesquisadores em identificar os fatores determinantes de QVRS dos pacientes com IC. Em busca bibliográfica realizada em setembro de 2014 no PubMed, sobre o período de um ano, com resumo disponível e excluindo artigo de revisões, utilizando o $\mathrm{MESH}$ como "major topic" com os descritores "Heart failure" e "Quality of life", foram localizados 29 estudos. Destes, dois não estavam disponíveis. A análise dos títulos e resumos mostrou que apenas 8 eram pesquisas que avaliaram fatores associados ou preditores de QVRS de pacientes com IC, o que permitiu explorar as variáveis potencialmente associadas a má QVRS desses pacientes (Quadro 1). Também foi realizada procura no LILACS com os mesmos descritores e mesmo período, 
resultando em 6 estudos que não foram considerados relevantes para este estudo por não incluírem em suas análises fatores associados ou preditores de QVRS. Essa breve revisão mostrou que as variáveis depressão, ansiedade, classe funcional elevada e comorbidades foram as mais comumente avaliadas (Quando 1).

Quadro 1 - Descrição dos estudos sobre fatores associados/preditores de qualidade de vida em pacientes com insuficiência cardíaca

\begin{tabular}{|c|c|c|c|}
\hline Autor/ano & Objetivo & Método & $\begin{array}{l}\text { Variáveis } \\
\text { Preditoras de } \\
\text { má QVRS }\end{array}$ \\
\hline $\begin{array}{l}\text { Bunyamin, Spaderna, \& } \\
\text { Weidner, } 2013\end{array}$ & $\begin{array}{l}\text { Avaliar a contribuição de } \\
\text { comportamentos de } \\
\text { saúde para a qualidade } \\
\text { de vida em pacientes } \\
\text { candidatos a transplante } \\
\text { de coração. }\end{array}$ & $\begin{array}{l}312 \\
\text { pacientes, } \\
82 \% \text { homens, } \\
\text { Idade média } \\
53(\mathrm{dp}=11) \\
\text { anos. } \\
\text { Avaliação da } \\
\text { QVRS: } \\
\text { MLHFQ } \\
\end{array}$ & $\begin{array}{l}\text { Depressão, } \\
\text { ansiedade, } \\
\text { estilo de } \\
\text { coping } \\
\text { vigilante. }\end{array}$ \\
\hline Comín-Colet et al., 2013 & $\begin{array}{l}\text { Avaliar o efeito da } \\
\text { deficiência de ferro e/ou } \\
\text { anemia na QVRS em } \\
\text { pacientes com IC }\end{array}$ & $\begin{array}{l}552 \\
\text { pacientes, } \\
57 \% \text { homens, } \\
\text { idade média } \\
72 \text { (dp = 11) } \\
\text { anos, } \\
\text { CF NYHA } \\
\text { (III/IV) - 40\%. } \\
\text { Avaliação da } \\
\text { QVRS: }\end{array}$ & $\begin{array}{l}\text { Idade, sexo } \\
\text { masculino, CF } \\
\text { NYHA (III/IV), } \\
\text { tempo desde a } \\
\text { última } \\
\text { internação } \\
\text { hospitalar, uso } \\
\text { de diuréticos, } \\
\text { comorbidades } \\
\text { nível de } \\
\text { proteína C } \\
\text { reativa e } \\
\text { deficiência de } \\
\text { ferro. } \\
\end{array}$ \\
\hline Fotos et al., 2013 & 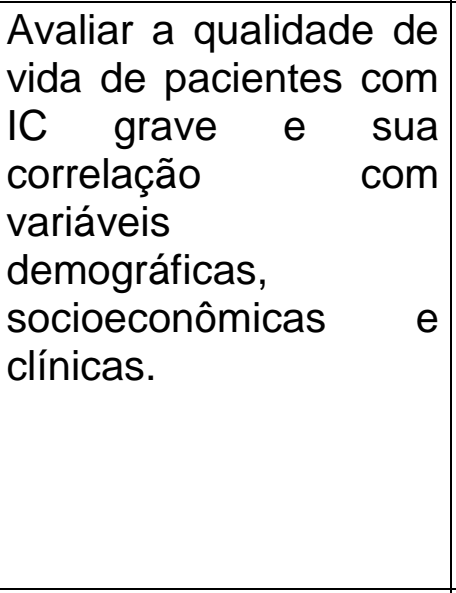 & $\begin{array}{l}199 \\
\text { pacientes, } \\
62,3 \% \\
\text { homens, } \\
80.4 \% \text { com } \geq \\
65 \text { anos, CF } \\
\text { NYHA (III)- } \\
68,3 \% \text { e CF } \\
\text { NYHA (IV)- } \\
31,7 \% \text {. } \\
\text { Instrumento } \\
\text { MLHFQ }\end{array}$ & $\begin{array}{l}\text { Comorbidades } \\
\text { (Insuficiência } \\
\text { renal crônica, } \\
\text { insuficiência } \\
\text { respiratória } \\
\text { crônica, } \\
\text { câncer, } \\
\text { doença } \\
\text { psiquiátrica) e } \\
\text { CF NYHA } \\
\text { mais elevada } \\
\text { ( IV) }\end{array}$ \\
\hline Heo et al., 2013 & 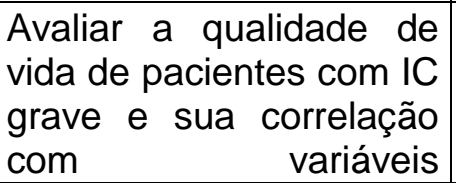 & $\begin{array}{l}199 \text { pacientes, } \\
62,3 \% \\
\text { homens, } \\
80,4 \%\end{array}$ & $\begin{array}{l}\text { Comorbidades } \\
\text { (Insuficiência } \\
\text { renal crônica, } \\
\text { insuficiência }\end{array}$ \\
\hline
\end{tabular}




\begin{tabular}{|c|c|c|c|}
\hline Autor/ano & Objetivo & Método & $\begin{array}{l}\text { Variáveis } \\
\text { Preditoras de } \\
\text { má QVRS }\end{array}$ \\
\hline & $\begin{array}{l}\text { demográficas, } \\
\text { socioeconômicas } \\
\text { clínicas. }\end{array}$ & $\begin{array}{llll}\text { idade } & \geq & 65 \\
\text { anos, } & & \text { CF } \\
\text { NYHA } & \text { (III) } & - \\
68,3 \% & \text { e } & \text { CF } \\
\text { NYHA } & \text { (IV) } & - \\
31,7 \% & & \\
\text { Avaliação } & \text { da } \\
\text { QVRS: } & \\
\text { MLHFQ } & \\
\text { MLFF }\end{array}$ & $\begin{array}{l}\text { respiratória } \\
\text { crônica, câncer, } \\
\text { doença } \\
\text { psiquiátrica) e } \\
\text { CF NYHA (IV). }\end{array}$ \\
\hline $\begin{array}{l}\text { Heo, Lennie, Moser, \& Kennedy, } \\
2014\end{array}$ & $\begin{array}{l}\text { Examinar os vários tipos } \\
\text { de apoio social } \\
\text { associados fósicos e em } \\
\text { sintomas fís } \\
\text { depressivos e qualidade } \\
\text { de vida em pacientes } \\
\text { com IC e os efeitos } \\
\text { mediadores de sintomas } \\
\text { sobre a relação entre o } \\
\text { apoio social e qualidade } \\
\text { de vida }\end{array}$ & $\begin{array}{l}71 \text { pacientes, } \\
66 \% \text { homens, } \\
\text { idade média } \\
\text { de } 72 \text { (dp = } \\
11) \text { anos, CF } \\
\text { NYHA (III) }- \\
48 \% \text { e CF IV } \\
(52 \%) . \\
\\
\text { Avaliação da } \\
\text { QVRS: } \\
\text { MLHFQ }\end{array}$ & $\begin{array}{l}\text { Sintomas } \\
\text { físicos } \\
\text { e sintomas } \\
\text { depressivos. }\end{array}$ \\
\hline Moser et al., 2013 & $\begin{array}{l}\text { Determinar as razões } \\
\text { das diferenças na } \\
\text { Qualidade de vida em } \\
\text { idosos em comparação } \\
\text { com pacientes com IC } \\
\text { mais jovens }\end{array}$ &  & $\begin{array}{c}\text { CF mais } \\
\text { elevada, } \\
\text { ansiedade, } \\
\text { depressão e } \\
\text { capacidade } \\
\text { funcional } \\
\text { limitada. }\end{array}$ \\
\hline Gastelurrutia et al., 2013 & $\begin{array}{l}\text { Avaliar se a fragilidade } \\
\text { afeta a percepção da } \\
\text { qualidade de vida entre } \\
\text { os estratos de idade. }\end{array}$ & $\begin{array}{|lr|}1.405 & \\
\text { pacientes, } & \\
72,2 \% & \\
\text { homens, idade } \\
\text { média } \quad 66,7 \\
\text { anos (dp = } \\
12,4), \quad \text { CF } \\
\text { NYHA(II) } \\
\text { 63,5\%. } \\
\text { Avaliação da } \\
\text { QVRS: } \\
\text { MLHFQ } \\
\end{array}$ & $\begin{array}{c}\text { Idade, sexo } \\
\text { feminino, CF, } \\
\text { número de } \\
\text { comorbidades, } \\
\text { terapia } \\
\text { medicamentosa } \\
\text { da IC. }\end{array}$ \\
\hline $\begin{array}{c}\text { Chung, Moser, Lennie, \& } \\
\text { Frazier, } 2013\end{array}$ & $\begin{array}{l}\text { Determinar a natureza } \\
\text { das relações entre os } \\
\text { sintomas depressivos, } \\
\text { apoio social e QVRS de } \\
\text { pacientes com IC. }\end{array}$ & \begin{tabular}{|lr}
362 pacientes, \\
$68,2 \%$ & \\
homens, idade \\
média $r 0,6$ \\
anos (dp $=$ \\
$11,5)$, & $\mathrm{CF}$
\end{tabular} & $\begin{array}{l}\text { Menor suporte } \\
\text { social e } \\
\text { sintomas } \\
\text { depressivos. }\end{array}$ \\
\hline
\end{tabular}




\begin{tabular}{|l|l|l|l|}
\hline Autor/ano & \multicolumn{1}{|c|}{ Método } & \multicolumn{1}{|c|}{$\begin{array}{c}\text { Variáveis } \\
\text { Preditoras de } \\
\text { má QVRS }\end{array}$} \\
\hline & & $\begin{array}{l}\text { NYHA(III) } \\
\text { Objotivo }\end{array}$ & \\
& & Avaliação da & \\
& & QVRS: & \\
& MLHFQ & \\
\hline
\end{tabular}

Observa-se que o instrumento mais utilizado para avaliação da QV dos pacientes foi o Minnessota Living With heart Failure Questionnaire (MLWHFQ). Esse instrumento baseia-se principalmente no quanto a insuficiência cardíaca interfere na qualidade de vida do paciente (Rector et al., 1995). O MLWHFQ é um instrumento específico para a IC, englobando as dimensões física e emocional e questões adicionais. Estudos anteriores demonstraram que o MLWHFQ tem propriedades psicométricas válidas e confiáveis. Nesses estudos, a QVRS mostrou ser bastante prejudicada na população com IC; os escores médios do MLHFQ variaram de 31,3 $(d p=18,9)$ a 62,7 (dp = 20,3) (Fotos et al., 2013; Moser et al., 2013; Comín-Colet et al., 2013; Chung et al., 2013; Gastelurrutia et al., 2013; Heo et al., 2014).

Identificar as principais variáveis que influenciam a QVRS na IC pode contribuir para a assistência aos pacientes com a finalidade de melhorar a QVRS, o que motivou a realização desse estudo. Acreditamos que a investigação da QVRS de diferentes populações para identificar as variáveis que estão relacionadas à QVRS pode direcionar a assistência à saúde, e pouco se conhece sobre essas relações na população brasileira. 
A hipótese deste estudo fundamentou-se no pressuposto de que a QVRS na IC está associada a vários fatores e a questão norteadora do estudo foi: Qual é a relação entre variáveis sociodemográficas e clínicas com a qualidade de vida relacionada à saúde de pacientes com IC?

A hipótese era a seguinte:

Contribuem para baixa qualidade de vida relacionada à saúde:

- Características sociodemográficas (Idade mais elevada, sexo feminino, baixa escolaridade e situação trabalhista inativa);

- $\quad$ padrão de sono ruim;

- $\quad$ autocuidado inadequado;

- fadiga;

- $\quad$ comprometimento cognitivo;

- $\quad$ sintomas depressivos;

- baixa atividade física;

- $\quad$ uso de polifarmacia 
Objetivos 


\section{OBJETIVOS}

GERAL

- Analisar os fatores associados à qualidade de vida relacionada à saúde de pacientes com insuficiência cardíaca

\section{ESPECÍFICOS:}

- Descrever características sociodemográficas e clínicas de pacientes com IC;

- Descrever o padrão do sono de pacientes com insuficiência cardíaca;

- Descrever o autocuidado de pacientes com insuficiência cardíaca;

- Descrever a qualidade de vida relacionada à saúde de pacientes com insuficiência cardíaca;

- Analisar a associação entre qualidade de vida relacionada à saúde com as variáveis sociodemográficas (sexo, idade, etnia, escolaridade, situação trabalhista, convivência marital) e variáveis clínicas (tipo de atendimento, comorbidades, desempenho cognitivo, dispneia, classe funcional da IC, fração de ejeção, fadiga, sintomas depressivos, atividade física, padrão de sono e autocuidado). 
Método 


\section{MÉTODO}

\subsection{TIPO DE ESTUDO}

Trata-se de um estudo transversal. Em um estudo transversal as medições são feitas em uma única ocasião ou durante um curto período de tempo, sorteando uma amostra da população e examinando as distribuições das variáveis dentro da amostra (Hulley et al., 2008).

Neste estudo foram analisados os dados obtidos na avaliação de linha de base dos potenciais participantes de um ensaio clínico sobre a efetividade de intervenções para melhorar o sono de pacientes com IC (Santos, M, 2014).

\subsection{CENÁRIO DO ESTUDO}

O estudo foi realizado entre abril de 2013 e abril de 2014, no ambulatório do Instituto Dante Pazzanese de Cardiologia (IDPC), uma autarquia do Governo do Estado de São Paulo associada à Universidade de São Paulo para fins de ensino, pesquisa e extensão. Trata-se de um hospital escola especializado em cardiologia, localizado no Município de São Paulo.

O ambulatório pertence à Divisão Clínica, com cerca de 100 salas para atendimento em diversas especialidades cardiológicas. A coleta de dados foi realizada em duas subunidades desse ambulatório, denominadas ambulatório de insuficiência cardíaca e ambulatório de miocárdio, onde são atendidos pacientes com disfunções ventriculares multicausais, e também aqueles em programa de transplante cardíaco. 
Durante o período de coleta de dados do respectivo estudo (abril de 2013 a abril de 2014) foram realizados nessas duas subunidades aproximadamente 17.013 atendimentos.

Os ambulatórios de insuficiência cardíaca e de miocárdio têm enfoque multidisciplinar para o acompanhamento de pacientes clinicamente estáveis, e a consulta de enfermagem é rotineiramente realizada com aqueles pacientes que necessitam de otimização terapêutica, bem como orientações gerais sobre a doença, controle dos sintomas e adesão ao tratamento seguindo as orientações da III Diretriz Brasileira de Insuficiência Cardíaca Crônica(Bocchi et al. 2009).

Porém, devido ao número insuficiente de enfermeiros, esse atendimento não é oferecido para todos os pacientes que usam o serviço. A equipe médica encaminha para 0 atendimento de enfermagem apenas os pacientes que apresentam descompensação clínica, dificuldade de aderência ao regime terapêutico e aqueles com necessidade de otimização e melhor controle do regime terapêutico.

\subsection{CASUÍSTICA}

Participaram do estudo pacientes adultos em tratamento ambulatorial por insuficiência cardíaca.

Para definir o tamanho de amostra para o presente estudo, tomou-se como parâmetro a prevalência de "maus dormidores" (PSQI > 5) do estudo de Santos (2010) que, em uma amostra com 400 pacientes ambulatoriais em tratamento da insuficiência cardíaca, foi de $68,5 \%$. Também se utilizou como parâmetro o escore médio da QVRS de estudos com pacientes semelhantes ao do presente projeto (Carvalho et al., 2009; Santos M. et al., 2011; Servantes et al., 2012; Santos J. et al., 2009; Yeh et al. 2011)

O tamanho de amostra foi calculado para detectar uma diferença de 5 pontos no escore de QVRS entre bons e maus dormidores, supondo um desvio padrão de 12,5 unidades em ambos os grupos. Utilizando um nível de significância de 5\%, 
poder de 95\%, e razão aproximada de 3:2 (estimativa de que para três pacientes, dois são maus dormidores) obtivemos um tamanho amostral de 394 pacientes.

A amostra final de conveniência foi constituída por 409 pacientes para garantir o total calculado no caso de eventuais perdas, o que não ocorreu.

\subsection{CRITÉRIOS DE INCLUSÃO E EXCLUSÃO}

Foram critérios de inclusão: estar regularmente matriculado no ambulatório de IC do IDPC; ter idade maior ou igual a 18 anos; diagnóstico médico confirmado de IC, com classe funcional I, II ou III segundo a classificação do NYHA (Bocchi et al., 2012); condições clínicas que permitissem participar de entrevistas; ter contato telefônico ativo. Dispor de contato telefônico ativo era exigência para o ensaio clínico, razão pela qual foi necessário manter esse critério. Foram excluídos portadores de doenças psiquiátricas, oncológicas, infecciosas com repercussão no estado geral ou de doenças endócrino-metabólicas sem tratamento (por exemplo, diabetes mellitus ou doenças tireoidianas); pacientes em pós-operatório recente (até 60 dias de pós-operatório) de qualquer intervenção cirúrgica; e pacientes que realizavam qualquer tratamento farmacológico/não farmacológico para melhora da qualidade do sono.

\subsection{VARIÁVEIS DO ESTUDO}

\subsubsection{Variável dependente}

Variável dependente: qualidade de vida relacionada à saúde (QVRS).

A qualidade de vida foi avaliada pelo questionário Minnesota Living With Heart Failure Questuionnaire (Rector et al., 1995), com versão validada para a língua portuguesa (Carvalho et al., 2009). Trata-se de um questionário composto por 21 questões relativas às limitações que frequentemente estão associadas ao quanto os sintomas da insuficiência cardíaca impediram o paciente de viver como ele gostaria durante o último mês. As respostas referem-se à percepção do próprio paciente com relação à influência da IC nos aspectos físico (questões 2, 3, 4, 5, 6, 7, 12 e 13), 
emocional (questões 17, 18, 19, 20 e 21) e socioeconômicas (questões 1, 8, 9, 10, $11,14,15$ e 16). A escala de resposta para cada questão varia de zero a cinco pontos, sendo que zero representa nenhuma limitação e cinco representa limitação máxima.

O questionário é quantificado pela soma das respostas dos 21 itens que varia de 0 a 105 pontos. A pontuação alta nos escores indica pior QVRS e a pontuação baixa nos escores indica melhor QVRS. Este questionário possui boas propriedades psicométricas de confiabilidade e validade documentadas na literatura nacional e internacional (Rector et al., 1995; Bennett et al., 2002; Saccomann et al., 2011b). Pontuações menores que 24 pontos representam uma boa qualidade de vida relacionada à saúde; pontuações entre 24 e 45 pontos representam uma moderada qualidade de vida relacionada à saúde, pontuações maiores que 45 representam ruim qualidade de vida relacionada à saúde (Behlouli et al., 2009).

Esta variável foi tratada como variável quantitativa discreta e categorizada em boa qualidade de vida ( $<24$ pontos) e qualidade de vida moderada/ruim $(\geq 24$ pontos).

\subsubsection{Variáveis independentes}

\subsection{Sexo}

A variável sexo foi indicada como feminino ou masculino, de acordo com a aparência do paciente observada pelo pesquisador ou de acordo com a referência que o paciente fizer de si mesmo. Foi tratada como variável nominal (masculino/feminino).

\subsection{Idade}

A idade foi informada pelo paciente no dia da entrevista em anos completos e foi considerada como variável quantitativa discreta e posteriormente categorizada em $<60$ anos e $\geq 60$ anos). 


\subsection{Etnia}

Foi considerada a etnia registrada no prontuário do paciente segundo as categorias descritas pelo Instituto Brasileiro de Geografia e Estatística - IBGE.

Essa variável foi tratada como variável nominal com as categorias agrupadas em brancos e não brancos.

\subsection{Escolaridade}

A escolaridade considerada foi a informação referente ao número de anos de estudo informado pelo sujeito da pesquisa. Foi tratada como variável quantitativa discreta e categorizada em: analfabetos; 1 - 4 anos de estudos; 5-8 anos de estudos; 9 anos ou mais de estudos.

\subsection{Situação trabalhista}

Foi considerada a informação prestada pelo sujeito da pesquisa referente à situação de trabalho atual e considerada segundo as seguintes categorias: empregado/autônomo, aposentado/pensionista, desempregado/estudante/do lar e afastado/auxílio-doença. A variável foi tratada como variável nominal: ativo para "empregado/autônomo"; inativo para "aposentado/pensionista, desempregado/estudante/do lar e afastado/auxílio-doença”.

\subsection{Convivência marital}

Foi considerada a informação prestada pelo sujeito da pesquisa referente à convivência marital ou não. A variável foi tratada como nominal (sim/não).

\subsection{Hábito de fumar}

Foram considerados fumantes os indivíduos que fizeram uso do fumo nos últimos doze meses, independentemente da quantidade de cigarros. Foram considerados não fumantes os indivíduos que nunca fumaram e os que pararam de fumar por mais de dozes meses anteriores à avaliação, independentemente da quantidade de cigarros fumados.

Foi tratada como variável nominal (fumante/não fumante). 


\subsection{Etiologia da IC}

Foi(ram) considerado(s) diagnóstico(s) médico registrado(s) no prontuário do paciente. Essa variável foi tratada como variável nominal e agrupada em duas categorias: cardiomiopatia isquêmica e não isquêmica. Como etiologia isquêmica considerou-se aqueles com disfunção contrátil explicada pela extensão da doença coronariana ou pelo grau de isquemia miocárdica. Para a etiologia não isquêmica foram inseridas cardiomiopatia dilatada, cardiomiopatia alcoólica, cardiomiopatia hipertrófica, cardiomiopatia restritiva e cardiomiopatia reumática.

\subsection{Fração de ejeção ventricular esquerda}

Os valores dessa variável foram obtidos por meio de consulta ao prontuário. Foi tratada como variável quantitativa e categorizada em primeiro quartil valores $\leq$ 29 , segundo quartil 30-37, terceiro quartil $38-47$ e quarto quartil $\geq 48$.

\subsection{0 Índice de comorbidade de Charlson}

O Índice de Comorbidade de Charlson (ICC) é um método de classificação de gravidade que utiliza dados dos diagnósticos secundários para atribuir um risco de morte ao paciente (Charlson et al., 1987). Esse método foi desenvolvido a partir de uma coorte de 604 pacientes em um hospital nos Estados Unidos para predizer a mortalidade em um ano (Charlson et al., 1987). O ICC foi validado em uma coorte de 685 mulheres com câncer de mama, acompanhadas por dez anos, sendo difundido e empregado em diversos trabalhos (Charlson et al., 1987). Esse método consiste em uma lista de 19 condições clínicas anotadas como diagnóstico secundário, com o objetivo de medir a gravidade do caso e avaliar o seu efeito sobre o prognóstico do paciente. Para cada uma dessas condições é atribuída uma pontuação representada por um peso que varia entre um e seis. (Charlson et al., 1987). Para gerar um escore único, a idade do paciente também tem um peso: a partir dos 50 anos, cada período de dez anos corresponde a um ponto adicional no índice. Para o cálculo desse escore foi utilizado o algoritmo desenvolvido por Quan et al.,(2004), que definiu os códigos da CID-10 para cada condição clínica do índice de Charlson (Quan et al., 2004).

Foram consideradas as comorbidades relatadas pelo paciente ou descritas no prontuário. Essa variável foi tratada como variável contínua e classificada em três 
categorias: baixo (escore 1-2), moderado (3-4) e elevado ( $\geq 5$ ) índice de comorbidade.

\subsection{Tempo de experiência com a doença}

Foi considerada a informação prestada pelo sujeito da pesquisa referente ao tempo em anos de descoberta e tratamento da IC e/ou consulta ao prontuário, sendo considerado a data do primeiro registro do diagnóstico de IC. O Para fins de análise, o tempo de doença foi registrado em meses de doença. Foi tratada como variável quantitativa e categorizada em primeiro quartil valores $\leq 29$ meses, segundo quartil 30-37 meses, terceiro quartil 38-47 meses e quarto quartil $\geq 48$ meses.

\subsection{Comprometimento cognitivo}

Para avaliar o declínio cognitivo utilizou-se o Mini Exame do Estado Mental (MEEM). O MEEM foi elaborado por Folstein et al., (1975) e permite a avaliação de função cognitiva e rastreamento de quadros demenciais. Tem sido usado em ambientes clínicos para a detecção de declínio cognitivo, para o seguimento de quadros demenciais e no monitoramento de resposta ao tratamento. Desde a sua criação, suas características psicométricas têm sido avaliadas, tanto na sua versão original, quanto nas inúmeras traduções/adaptações para vários idiomas e países (Hill et al., 1993; Bertolucci et al., 1994; Lindesay et al., 1997).

O MEEM é composto por diversas questões tipicamente agrupadas em 7 categorias, cada uma delas desenhada com o objetivo de avaliar "funções" cognitivas específicas: orientação para tempo (5 pontos), orientação para local (5 pontos), registro de 3 palavras (3 pontos), atenção e cálculo (5 pontos), lembrança das 3 palavras (3 pontos), linguagem (8 pontos) e capacidade construtiva visual (1 ponto). O escore do MEEM pode variar de um mínimo de 0 até um total máximo de 30 pontos e quanto mais alto o escore, melhor o estado cognitivo. A escala é simples de usar e pode ser facilmente administrada em 5-10 minutos. O MEEM foi traduzido por Bertolucci e col., (1994), cujos quais observaram que o escore total do MEEM dependia do nível educacional dos 530 indivíduos avaliados na triagem médica de um hospital-escola de São Paulo (Bertolucci et al., 1994). Eles propuseram a utilização de pontos de corte diferenciados de acordo com a escolaridade para detectar a presença de comprometimento cognitivo. Brucki et al. (2003) propuseram 
adaptação do teste para que este servisse para o uso em ambiente hospitalar, consultório ou estudos populacionais. Os pontos de corte utilizados no estudo foram 20 pontos para analfabetos, 25 para indivíduos com 1-4 anos de estudo, 26 para indivíduos com 5-8 anos de estudo, 28 para indivíduos com 9-11 anos de estudo e 29 para indivíduos com escolaridade superior a 11 anos. (Brucki et al., 2003).

Essa variável foi tratada como quantitativa discreta e categorizada em com comprometimento cognitivo e sem comprometimento cognitivo, conforme proposto por (Brucki et al., 2003).

\subsection{Atividade física}

A avaliação da atividade física será feita por meio da aplicação do questionário de Atividade Física Habitual de Baecke (Baecke et al., 1982).

Este instrumento analisa a atividade física dos participantes, dos últimos 12 meses, durante a atividade ocupacional (AFO) - questões 1 a 8, prática de esportes e exercícios físicos de lazer (EFL) - questões 9-12, e as atividades executadas nas horas de lazer e de locomoção (ALL) - questões 13 a 16, fornecendo três escores que são somados no final para gerar o escore total de atividade física habitual $(\mathrm{AFH})$.

A questão 1 leva em conta o tipo de ocupação, classificada em três níveis de gasto energético: leve, moderado e vigoroso. Para essa classificação recomenda-se utilizar o compêndio de atividades físicas de Ainsworth. Neste estudo iremos utilizar a Versão em Português do Compêndio de Atividades Físicas (Farinatti , 2003).

Para os aposentados ou licenciados considera-se outra atividade ocupacional. No caso de não existir outra atividade, recomenda-se adotar o escore 1 para a questão 1.

Para as atividades domésticas, recomenda-se adotar o nível moderado (3) na questão 1.

Nos casos em que o respondente não tem atividade ocupacional, a recomendação é classificar como esforço moderado as repostas dos itens relativos às atividades físicas ocupacionais. $\mathrm{O}$ instrumento tem sido empregado em pesquisas 
epidemiológicas num contexto mundial (Delvaux et al., 2001; Evenson et al., 2002; Florindo et al., 2004)

No Brasil, foi traduzido e validado, apresentando boas estimativas de confiabilidade nos três escores, medidas pelo alfa de Cronbach respectivamente 0,76, 0,77 e 0,71. O questionário de AFH de Baecke está estruturado de forma qualiquantitativa em escala tipo Likert, levando em conta o ponto de vista das pessoas em relação às atividades físicas e é de fácil entendimento e preenchimento (Baecke et al., 1982). O instrumento fornece escores parciais (atividades físicas ocupacionais, exercícios físicos no lazer e atividades físicas de lazer e locomoção) que podem ser somados num escore total. Os escores são calculados com base em fórmulas aplicadas a valores atribuídos às respostas de cada um dos 16 itens.

Foi tratada como variável quantitativa e categorizada em:

Atividade física ocupacional: primeiro quartil valores $\leq 2,25$, segundo quartil valores de 2,25-2,625, terceiro quartil 2,266-3 e quarto quartil $\geq 3,1$.

Exercícios físicos de lazer $(E F L)$ : primeiro quartil valores $\leq 1,25$, segundo quartil valores de 1,26-1,99, terceiro quartil 2-2,49 e quarto quartil $\geq 2,5$.

Atividades de lazer e de locomoção (ALL): primeiro quartil valores $\leq 1,25$, segundo quartil valores de 1,26-1,99, terceiro quartil 2-2,49 e quarto quartil $\geq 2,5$.

Escore total da Atividade Física Habitual (AFH) : primeiro quartil valores $<6$, segundo quartil valores de 6-6,74, terceiro quartil 6,75-7,5 e quarto quartil $\geq 7,51$.

\subsection{Terapia medicamentosa}

Essa variável foi coletada pelo relato do paciente de todos os medicamentos que usou na última semana e confirmado pela prescrição em receituário médico que o paciente portava. No caso de o paciente não lembrar dos medicamentos ou não portar a receita médica, essa informação foi extraída do prontuário. As medicações foram categorizadas em: inibidores da enzima conversora da angiotensina (IECA), bloqueadores dos receptores da angiotensina (BRA), diuréticos, bloqueadores do canal de cálcio, betabloqueadores, vasodilatadores, digitálicos, anticoagulantes, antiagregantes plaquetários, hormônio tireoide, hipoglicemiantes orais, insulina, 
antiácidos, antiarrítmicos e outros.

A variável tipo de medicamento foi tratada como variável nominal (sim/não). Quanto à quantidade de medicamento utilizada pelo paciente, foi tratada como variável quantitativa discreta e categorizada segundo tercil:

Primeiro tercil: 0-4; segundo tercil: 5-6; terceiro tercil: 7-13.

A variável número de tomada de medicamento por dia foi tratada como variável quantitativa discreta e categorizada segundo tercil:

Primeiro tercil: 0-6; segundo tercil: 7-8; terceiro tercil: 9-22.

\subsection{Dispneia}

Dispneia é um termo utilizado para caracterizar uma experiência subjetiva de desconforto para respirar que varia de intensidade. Para avaliar a dispneia será perguntado ao paciente se este sente falta de ar. Nos casos de resposta positiva, o paciente informará se a falta de ar estava presente aos pequenos, médios, grandes ou intensos esforços, considerando a categorização do grau de dispneia conforme a classificação contida no Índice de Dispneia Basal de Mahler (Mahler et al., 1984).

Pequeno - Fica dispneico com atividades físicas leves tais como caminhar no plano, tomar banho ou ficar de pé.

Moderado (médios) - Fica dispneico com atividades físicas moderadas, como subir pequenos aclives, subir menos que 3 lances de escada ou carregando volumes leves no plano.

Grande - Fica dispneico apenas com grandes atividades físicas como subir grandes aclives ou subir mais que 3 lances de escada.

Intenso - Fica dispneico apenas com atividade física intensa, como carregar volumes muito pesados no plano, pesos leves em aclives ou correndo. Sem falta de ar para realização das tarefas habituais.

Foi tratada como variável nominal (presente/ausente). A intensidade da dispneia em relação ao esforço foi tratada como variável ordinal (pequeno, moderado, grande ou intenso). 


\subsection{Fadiga e fadiga ao esforço}

Essa variável será avaliada pelas escalas Dutch Fatigue Scale - DUFS e Dutch Exertion Fatigue Scale - DEFS (Tiesinga et al., 1998). A DUFS mede fadiga definida como "uma sensação opressiva e sustentada de exaustão e de capacidade diminuída para realizar trabalho físico e mental no nível habitual". A DEFS mede fadiga ao esforço definida como a "fadiga que é diretamente relacionada à atividade"(Tiesinga et al., 1998).

As escalas DUFS e DEFS são compostas por 8 e 9 itens respectivamente, com respostas tipo Likert de 5 pontos ( 1 a 5 ). Os escores totais na DUFS podem variar de 8 a 40 pontos e na DEFS de 9 a 45 pontos. Quanto mais altos os escores, maior a intensidade da fadiga ou da fadiga ao esforço. O processo de adaptação para a língua portuguesa e validação das escalas foi realizado por Fini and Cruz (2010), com boas estimativas de confiabilidade em amostra de pacientes com IC $(\mathrm{DUFS}=0,84$ e DEFS $=0,92)$.

Os casos (se havia ou não havia fadiga ou fadiga ao esforço) foram definidos segundo curva ROC (Receive Operator Caracteristic Curve), estimada no estudo de adaptação e validação para o Brasil (Fini and Cruz, 2010). Os pontos de cortes estabelecidos foram DUFS > 14,5 para fadiga e DEFS > 12,5 para fadiga ao esforço.

Foram tratadas como variáveis contínuas e também como variáveis nominais. Para nominal foram utilizados os pontos de corte obtidos no estudo de Fini and Cruz (2010) : DUFS escores $\geq 14,5$ (fadiga presente) e DEFS escores $\geq 12,5$ (fadiga ao esforço presente.

\subsection{Sintomas depressivos}

Será avaliada pela Escala de Depressão CES-D (Center for Epidemiologic Studies Depression Scale). Essa escala constitui instrumento de rastreamento elaborado pelo National Institute of Mental Health visando identificar humor depressivo e vulnerabilidade à depressão em estudos populacionais (Batistoni et al., 2007,2010). A CES-D é uma escala autoaplicável composta de 20 itens, desenvolvidos para mensurar os sintomas depressivos em populações comunitárias. Os entrevistados avaliam os itens com base nos acontecimentos da semana anterior a entrevista, utilizando uma escala de respostas de quatro pontos (Batistoni et al., 
2007).

As respostas a cada uma das questões são dadas segundo a frequência de sintomas depressivos vividos na semana anterior à entrevista ( 0 = raramente ou nunca; 1 = durante pouco ou algum tempo; 2 = ocasionalmente ou durante um tempo moderado; e 3 = durante a maior parte do tempo ou todo o tempo. Os itens da CES-D incluem questões sobre o humor, sintomas somáticos, interações com outras pessoas, funcionamento motor. O escore total varia entre zero e sessenta pontos.

No Brasil, esse instrumento foi validado para a língua portuguesa e obteve bons índices de consistência interna medida pelo alfa de Cronbach $(0,86)$ em sua versão brasileira (Batistoni et al., 2010). O ponto de corte para identificar sintomas depressivos é $\geq 16$ pontos (Batistoni et al., 2007). O interesse neste estudo não é fazer diagnóstico de depressão, mas avaliar a presença de sintomas depressivos. 0 CES-D tem sido usado para essa finalidade em vários estudos na área da enfermagem (Gonçalves and Fagulha, 2004).

Foi tratada como variável quantitativa contínua e posteriormente categorizada em: sem sintomas depressivos (escore $\leq 16$ pontos) e com sintomas depressivos (escore $>16$ pontos).

\subsection{Nocturia}

Definida pela International Continence Society (ICS) como a necessidade de acordar durante a noite para urinar uma ou mais vezes (van Kerrebroeck et al., 2002). Serão obtidas informações sobre a presença ou não de eliminação urinária à noite por meio de pergunta realizada ao paciente com IC, obtendo-se como resposta sim ou não. Caso a resposta seja positiva, será questionada a frequência, por noite, da necessidade de urinar.

Foi tratada como variável qualitativa nominal (sim/não) e a frequência da nocturia foi tratada como variável quantitativa ordinal.

\subsection{Classe funcional da IC}

A classe funcional é uma estratificação do grau de limitação imposto pela insuficiência cardíaca para atividades cotidianas do indivíduo, estabelecida pela New 
York Heart Association - NYHA (Bocchi et al., 2012). Essa classificação possui quatro categorias que refletem a gravidade da doença: Classe I - ausência de sintomas (dispneia) durante atividades cotidianas. A limitação para esforços é semelhante à esperada em indivíduos normais; Classe II - sintomas desencadeados por atividades cotidianas; Classe III - sintomas desencadeados em atividades menos intensas que as cotidianas ou pequenos esforços; e Classe IV - sintomas em repouso.

A classe funcional foi determinada pela pesquisadora, segundo a diretriz estabelecida pela New York Heart Association - NYHA (Bocchi et al., 2012), e tratada como qualitativa ordinal (Classe funcional I, II, III).

\subsection{Sono}

Essa variável foi avaliada através da aplicação do Pittsburg Sleep Quality Index - PSQI. Esse instrumento avalia a qualidade do sono em relação ao último mês, tendo como objetivo fornecer uma medida válida, confiável, padronizada, fácil de ser respondida e interpretada para avaliação de qualidade de sono, e permite discriminar os sujeitos avaliados entre bons e maus dormidores (Buysse et al., 1989b).

O questionário consiste em 19 questões autoadministradas e 5 questões respondidas por companheiros de quarto de quem responde o instrumento. Essas últimas são utilizadas somente para informação clínica. As 19 questões são agrupadas em 7 componentes (qualidade subjetiva do sono, latência do sono, duração do sono, eficiência habitual do sono, distúrbios do sono, uso de medicações para dormir e sonolência diurna). O escore de cada componente varia de 0 a 3 . As pontuações desses componentes são então somadas para produzir um escore global, que varia de 0 a 21, e quanto maior a pontuação, pior a qualidade do sono. Um escore global do PSQI > 5 indica que o indivíduo está apresentando grandes dificuldades em pelo menos 2 componentes, ou dificuldades moderadas em mais de 3 componentes.

Essa variável foi tratada como quantitativa contínua e depois categorizada em bons dormidores (os que obtêm escores $\leq 5$ ) e como maus dormidores (escores > que 5 ) (Buysse et al., 1989b). 


\subsection{Comportamento de autocuidado}

Comportamento de autocuidado foi avaliado usando a versão brasileira do Self-Care of Heart Failure Index (SCHFI). A versão adaptada e validada para o Brasil foi denominada de Escala de Autocuidado para pacientes com Insuficiência Cardíaca (EAC-IC) (Avila et al., 2013). O SCHFI é uma medida de autocuidado composta por 22 itens divididos em três subescalas: (1) manutenção do autocuidado composta por 10 itens, (2) manejo do autocuidado composto por 6 itens e (3) confiança no autocuidado composta por 6 itens. As respostas para cada item variam de nunca/raramente a sempre/diariamente para o domínio manutenção do autocuidado, pouco provável a muito provável para o domínio manejo do autocuidado e não confiante a extremamente confiante para o domínio confiança no autocuidado. Os escores para cada domínio variam de 0-100 pontos estimados a partir de transformação dos escores puros. Pontuações mais altas refletem um autocuidado superior e um autocuidado adequado é considerado quando o escore para cada subescala é igual ou superior a 70 pontos (Avila et al., 2013).

Foi tratada como variável quantitativa contínua e categorizada posteriormente em autocuidado adequado ( $\geq 70$ pontos) e autocuidado inadequado ( $<70$ pontos), para cada subescala.

\subsection{Tipo de acompanhamento}

Foi considerada a possibilidade de o paciente ter agendamento para consulta com o médico ou consulta com enfermeiro. Essa variável foi tratada como nominal (sim/não) e categorizada em consulta com médico ou consulta com médico e enfermeiro).

No Quadro 2 segue resumo das variáveis, escalas utilizadas, suas variações e interpretação. 
Quadro 2 - Variáveis avaliadas e instrumentos utilizados

\begin{tabular}{|c|c|c|}
\hline Variável & Escala utilizada & $\begin{array}{l}\text { Variações dos escores } \\
\text { e interpretação }\end{array}$ \\
\hline QVRS & $\begin{array}{c}\text { Minnesota Living with } \\
\text { Heart Failure } \\
\text { Questionnarie }\end{array}$ & $\begin{array}{l}\text { Questionário composto } \\
\text { por } 21 \text { questões relativas } \\
\text { ao quanto a IC impediu o } \\
\text { paciente de viver como } \\
\text { ele gostaria durante o } \\
\text { último mês. Varia entre } 0 \\
\text { a } 105 \text { pontos. Pontuações } \\
<24 \text { pontos representam } \\
\text { uma boa qualidade de } \\
\text { vida; pontuações } \geq 24 \\
\text { representam qualidade de } \\
\text { vida moderada/ruim. }\end{array}$ \\
\hline Sexo & - & Masculino e feminino \\
\hline Idade & & $<60$ anos $\mathrm{e} \geq 60$ anos \\
\hline Etnia & - & $\begin{array}{l}\text { Brancos e não brancos } \\
\text { (negro, pardo e amarelo) }\end{array}$ \\
\hline Escolaridade & - & $\begin{array}{l}0 \text { - Analfabetos; } 1 \text { a } 4 \\
\text { anos de estudos; } 5 \text { a } 8 \\
\text { anos de estudos; } 9 \text { ou } \\
\text { mais anos de estudos }\end{array}$ \\
\hline Situação trabalhista & - & $\begin{array}{l}\text { Ativo } \\
\text { autônomo) ou Inativo (do } \\
\text { lar, estudante, } \\
\text { afastado/auxílio-doença; } \\
\text { aposentado } \\
\text { pensionista) }\end{array}$ \\
\hline Convivência marital & $\begin{array}{ll}- \\
-\end{array}$ & Sim/não \\
\hline Hábito de fumar & - & Sim/não \\
\hline Etiologia da IC & - & $\begin{array}{l}\text { Isquêmica; } \\
\text { Não isquêmica } \\
\text { (cardiomiopatia dilatada, } \\
\text { cardiomiopatia alcoólica, } \\
\text { cardiomiopatia } \\
\text { hipertrófica, } \\
\text { cardiomiopatia restritiva e } \\
\text { cardiomiopatia reumática) }\end{array}$ \\
\hline
\end{tabular}




\begin{tabular}{|c|c|c|}
\hline Variável & Escala utilizada & $\begin{array}{l}\text { Variações dos escores } \\
\text { e interpretação }\end{array}$ \\
\hline $\begin{array}{c}\text { Fração de ejeção } \\
\text { ventricular esquerda }\end{array}$ & - & $\begin{array}{l}\text { Primeiro quartil } \leq 29 \% \text {; } \\
\text { segundo quartil } 30-37 \% \text {; } \\
\text { terceiro quartil } 38-47 \% \text {; } \\
\text { quarto quartil } \geq 48 \% \text {. }\end{array}$ \\
\hline $\begin{array}{c}\text { Índice de comorbidade de } \\
\text { Charlson }\end{array}$ & - & $\begin{array}{l}\text { Baixo (escore } 1-2) \\
\text { moderado }(3-4) ; \\
\text { elevado }(\geq 5) \text { índice de } \\
\text { comorbidade }\end{array}$ \\
\hline $\begin{array}{c}\text { Tempo de experiência } \\
\text { com a doença }\end{array}$ & - & $\begin{array}{l}\text { Primeiro quartil valor } \leq 29 \\
\text { meses; segundo quartil } \\
30-37 \quad \text { meses; terceiro } \\
\text { quartil } 38-47 \text { meses; e } \\
\text { quarto quartil } \geq 48 \text { meses. }\end{array}$ \\
\hline $\begin{array}{l}\text { Comprometimento } \\
\text { cognitivo }\end{array}$ & $\begin{array}{l}\text { Mini Exame do Estado } \\
\text { Mental (MEEM) }\end{array}$ & 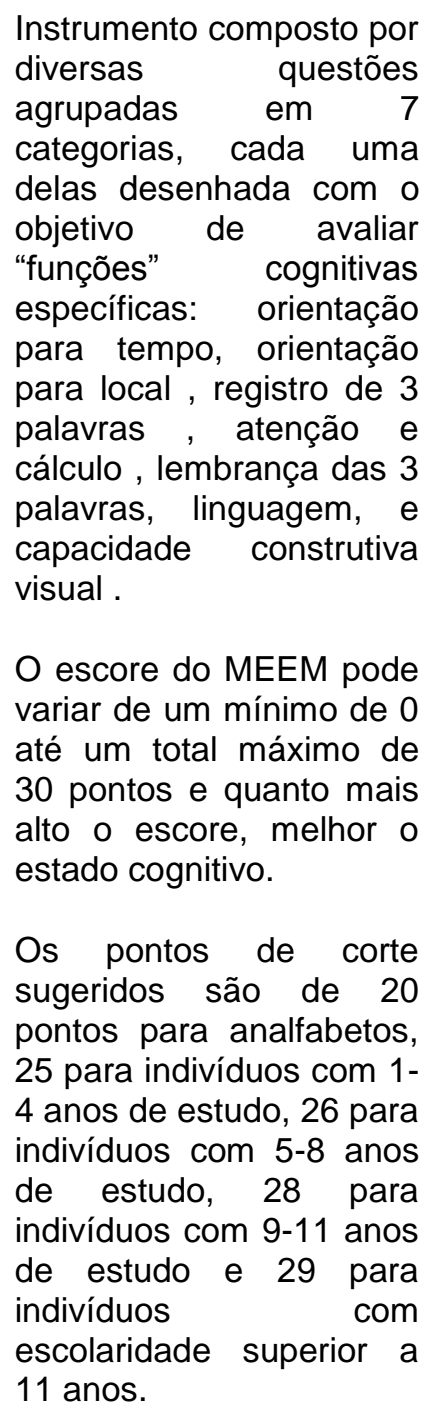 \\
\hline
\end{tabular}




\begin{tabular}{|c|c|c|}
\hline Variável & Escala utilizada & $\begin{array}{l}\text { Variações dos escores } \\
\text { e interpretação }\end{array}$ \\
\hline Dispneia & - & $\begin{array}{l}\text { Sim/não. Grau de } \\
\text { dispneia foi categorizada } \\
\text { em pequeno, moderado, } \\
\text { grande e intenso }\end{array}$ \\
\hline Atividade física habitual & $\begin{array}{c}\text { Questionário de } \\
\text { avaliação de Atividade } \\
\text { Física Habitual de } \\
\text { Baecke. }\end{array}$ & 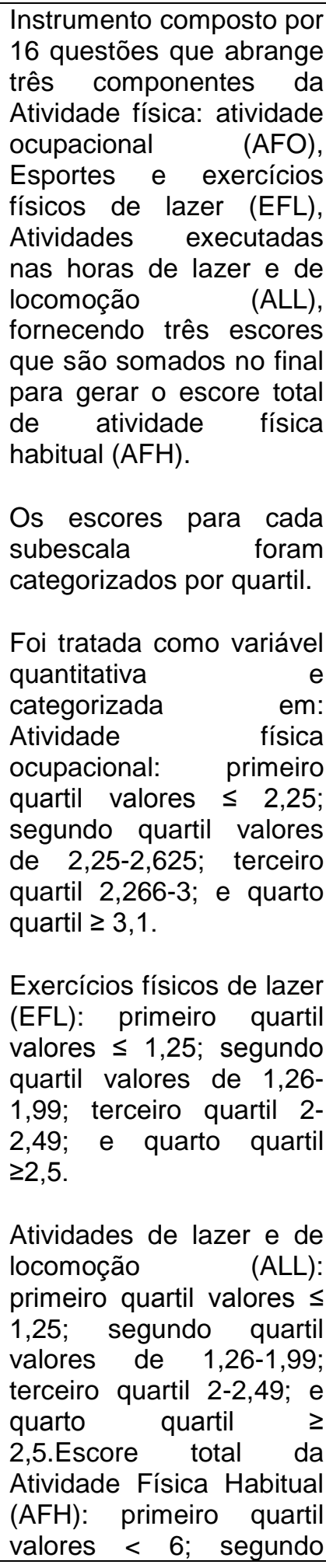 \\
\hline
\end{tabular}




\begin{tabular}{|c|c|c|}
\hline Variável & Escala utilizada & $\begin{array}{l}\text { Variações dos escores } \\
\text { e interpretação }\end{array}$ \\
\hline & & $\begin{array}{l}\text { quartil valores de } 6-6,74 \text {; } \\
\text { terceiro quartil } 6,75-7,5 ; \text { e } \\
\text { quarto quartil } \geq 7,51 \text {. }\end{array}$ \\
\hline Classe funcional da IC & - & $\begin{array}{l}\begin{array}{l}\text { Classe I - ausência de } \\
\text { sintomas } \\
\text { (dispneia) } \\
\text { durante atividades }\end{array} \\
\text { cotidianas; Classe II - } \\
\text { sintomas desencadeados } \\
\text { por atividades cotidianas; } \\
\text { Classe III - sintomas } \\
\text { desencadeados em } \\
\text { atividades } \\
\text { intensas que menos } \\
\text { cotidianas ou pequenos } \\
\text { esforços; Classe IV - } \\
\text { sintomas em repouso. } \\
\text { (Bocchi et al. 2012) }\end{array}$ \\
\hline Tipo de acompanhamento & - & $\begin{array}{l}\text { Médico/médico e de } \\
\text { enfermagem }\end{array}$ \\
\hline \multirow[t]{2}{*}{$\begin{array}{l}\text { Fadiga e fadiga ao } \\
\text { esforço }\end{array}$} & $\begin{array}{c}\text { Dutch Fatigue Scale - } \\
\text { DUFS }\end{array}$ & $\begin{array}{l}\text { A escala DUFS possui } 8 \\
\text { itens. Os escores nos } \\
\text { itens podem ser somados } \\
\text { num escore total que } \\
\text { varia de } 8 \text { a } 40 \text { (quanto } \\
\text { mais alto o escore, maior } \\
\text { a intensidade da fadiga). }\end{array}$ \\
\hline & $\begin{array}{l}\text { Dutch Exertion Fatigue } \\
\text { Scale - DEFS }\end{array}$ & $\begin{array}{l}\text { A DEFS, que mensura } \\
\text { fadiga ao esforço, possui } \\
9 \text { itens, que podem ser } \\
\text { somados num escore } \\
\text { total que varia de } 9 \text { a } 45, \\
\text { indicando a intensidade } \\
\text { da fadiga ao esforço } \\
\text { (quanto maior o escore, } \\
\text { maior a intensidade). Os } \\
\text { pontos de corte serão: } \\
\text { DUFS escores } \geq 14,5 \\
\text { (fadiga substancial) } \\
\text { DEFS escores } \geq 12,5 \\
\text { (fadiga substancial ao } \\
\text { esforço). }\end{array}$ \\
\hline Terapia medicamentosa & - & $\begin{array}{lr}\text { As medicações } & \text { foram } \\
\text { categorizadas } & \text { em: } \\
\text { inibidores da enzima } \\
\text { conversora }\end{array}$ \\
\hline
\end{tabular}




\begin{tabular}{|c|c|c|}
\hline Variável & Escala utilizada & $\begin{array}{l}\text { Variações dos escores } \\
\text { e interpretação }\end{array}$ \\
\hline & & 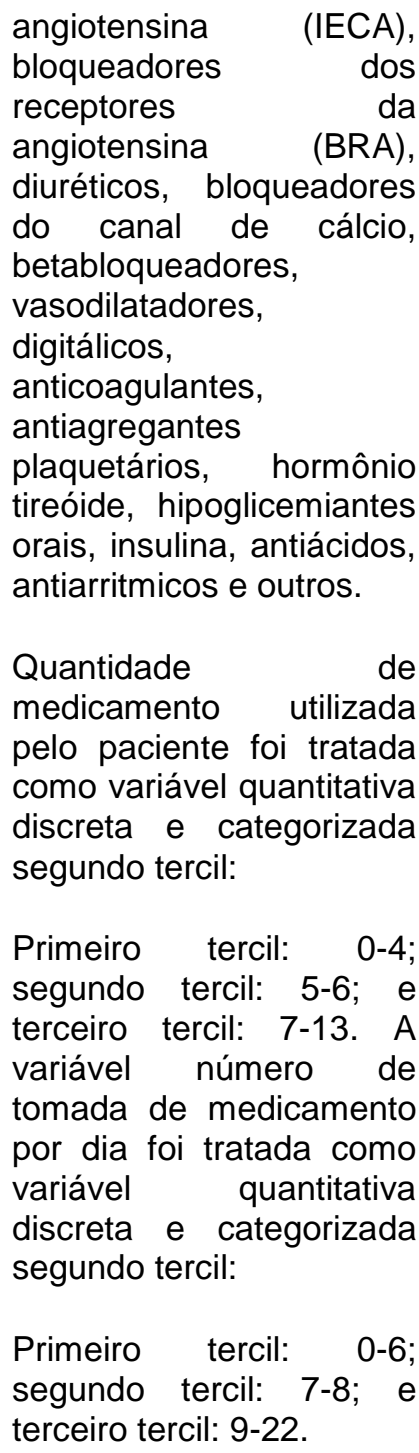 \\
\hline Sono & $\begin{array}{l}\text { Índice de qualidade de } \\
\text { sono de Pittsburgh - } \\
\text { PSQI }\end{array}$ & $\begin{array}{l}\text { O questionário consiste } \\
\text { de } 19 \text { questões auto- } \\
\text { administradas, } \\
\text { agrupadas em } 7 \\
\text { componentes com pesos } \\
\text { distribuídos numa escala } \\
\text { de } 0 \text { a } 3 \text {. } \\
\text { As pontuações desses } \\
\text { componentes são então } \\
\text { somadas para produzir } \\
\text { um escore global, que } \\
\text { varia de } 0 \text { a } 21 \text {, e quanto } \\
\text { maior a pontuação, pior a } \\
\text { qualidade do sono. } \\
\text { Como bons dormidores } \\
\text { são categorizados os que } \\
\text { obtém escores } \leq 5 \text { e }\end{array}$ \\
\hline
\end{tabular}




\begin{tabular}{|c|l|l|}
\hline Variável & \multicolumn{1}{|c|}{ Escala utilizada } & $\begin{array}{l}\text { Variações dos escores } \\
\text { e interpretação }\end{array}$ \\
\hline \multirow{2}{*}{$\begin{array}{c}\text { Comportamento de } \\
\text { Autocuidado }\end{array}$} & $\begin{array}{l}\text { Self-care of Heart } \\
\text { Failure Index (SCHFI), } \\
\text { versão Brasileira. }\end{array}$ & $\begin{array}{l}\text { como maus dormidores } \\
\text { os com escores > que 5 }\end{array}$ \\
& $\begin{array}{l}\text { Escala composta por 22 } \\
\text { itens divididos em três } \\
\text { subescalas: Manutenção } \\
\text { do autocuidado, Manejo } \\
\text { dorautocuidado e } \\
\text { Confiança no } \\
\text { autocuidado. } \\
\text { Os escores para cada } \\
\text { domínio variam de a a } \\
100 ; \quad \text { Autocuidado } \\
\text { adequado é considerado } \\
\text { quando o escore para } \\
\text { cada subescala é } \\
\text { superior a 70 pontos. }\end{array}$ \\
\hline
\end{tabular}

\subsection{Coleta dos dados}

A coleta dos dados foi realizada por entrevista, pela pesquisadora e por quatro coletadores enfermeiros previamente treinados pela pesquisadora para a coleta de dados. No treinamento, os coletadores observaram a pesquisadora aplicando o instrumento em três pacientes e, logo após, a pesquisadora observou os coletadores durante a coleta. As dúvidas eram então discutidas a fim de calibrar a execução do procedimento e tornar a coleta homogênea. O treinamento ocorreu até o esgotamento das dúvidas relacionados ao instrumento e coleta.

Os pacientes avaliados durante o treinamento foram incluídos na amostra do estudo.

O ambulatório funciona de segunda à sexta-feira, com atendimentos das $7 \mathrm{~h}$ às $16 \mathrm{~h}$. Os prontuários dos pacientes com agendamento no dia eram solicitados no dia anterior à consulta ao Serviço de Arquivo Médico e Estatística (SAME) e dispostos nos ambulatórios no dia da consulta. Para sistematizar a coleta de dados, 
diariamente, a pesquisadora e/ou coletadores consultavam os prontuários dos pacientes que seriam atendidos naquele dia, iniciando sempre pelo último prontuário, evitando dessa forma que o paciente fosse interrompido no meio da coleta de dados, para consulta com médico ou com enfermeiro. Nessa ocasião o pesquisador e/ou coletadores aplicaram o instrumento para seleção dos participantes da pesquisa, que permitia identificar se o paciente atendia aos critérios de participação do estudo.

Se o paciente atendesse aos critérios de participação no estudo, antes da consulta médica ou de enfermagem, ele era convidado a participar do estudo, sendo a ele apresentado o termo de consentimento livre e esclarecido (Anexo A). Nessa apresentação o pesquisador esclareceu ao paciente o objetivo, procedimentos e métodos do estudo, e consultou-o sobre seu interesse e disponibilidade em participar da pesquisa.

Nos casos de anuência do paciente e assinatura do termo de consentimento, o pesquisador realizou a coleta dos dados utilizando um instrumento composto de duas partes. A primeira contendo dados de caracterização sociodemográfica e clínica e uma segunda parte contendo instrumentos para avaliação do sono, desempenho cognitivo, avaliação de sintomas depressivos, qualidade de vida, fadiga, autocuidado e atividade física.

O tempo médio utilizado em cada avaliação foi de aproximadamente 40 minutos.

\subsection{Instrumento para a coleta dos dados}

Para a coleta dos dados foi utilizado instrumento estruturado contendo duas partes: a primeira parte foi para o registro dos dados demográficos e condições clínicas que envolvem o tratamento (Anexo B) e a segunda parte reuniu os instrumentos padronizados conforme descritos nas variáveis (Anexo $\mathrm{C}$ ). 


\subsection{Análise estatística dos dados}

Após a codificação de todas as variáveis em um dicionário de termos, elaborou-se um banco de dados eletrônico (Microsoft Excel 2010) que foi alimentado pela pesquisadora. As respostas dos participantes foram lançadas nesse banco de dados, que posteriormente foi importado para o aplicativo do Statistical Package for the Social Science (SPSS $\AA$ ) for Windows, versão 22. Os dados foram submetidos a análises estatísticas descritivas e inferenciais sob orientação de um profissional estatístico.

A descrição da amostra foi feita em termos de número absoluto e porcentual das variáveis qualitativas, e em termos de médias, medianas e desvio-padrão, mínimo e máximo das variáveis quantitativas.

O coeficiente alfa de Cronbach foi aplicado para verificar a consistência interna dos instrumentos padronizados.

A análise da associação entre a qualidade de vida relacionada à saúde e as demais variáveis foi feita através do teste de associação pelo qui-quadrado e modelo de regressão logística binária múltiplo. Nesta análise, a variável dependente foi a qualidade de vida relacionada à saúde (boa versus moderada/ruim) e, as demais, variáveis independentes. Primeiramente foi feita a análise pelo teste de associação e aquelas variáveis com $p<0,200$ foram selecionadas para o processo de modelagem múltipla. O processo de modelagem múltipla foi o stepwise forward. Nesse processo, inicia-se pela variável mais significativa, do ponto de vista estatístico (menor valor de p) e, a seguir, acrescentam-se demais variáveis, uma a uma, de acordo com a ordem crescente de valor do p. A variável permaneceu no modelo múltiplo quando ficou estatisticamente significativa. $\mathrm{O}$ ajuste do modelo foi verificado pelo teste de Hosmer-Lemeshow.

Em todos os casos fixou-se como nível descritivo $p$ valores menores ou iguais a 0,05 . 


\section{CONSIDERAÇÕES ÉTICAS}

Como os objetivos deste projeto são secundários aos objetivos do estudo sobre intervenção para melhora do sono e os participantes são os mesmos, o TCLE (Anexo A) é o mesmo do estudo de intervenção cujo projeto foi apreciado e aprovado pelo Comitê de Ética da EEUSP (Anexo D) e autorizado pela instituição onde os dados foram coletados ( Anexo $E)$. 
Resultados 


\section{RESULTADOS}

Neste capítulo, estão apresentados os resultados obtidos, perfazendo a sequência da caracterização sociodemográfica, caracterização clínica, caracterização do padrão do sono, do autocuidado, bem como a caracterização da qualidade de vida relacionada à saúde de pacientes com insuficiência cardíaca.

Serão apresentados posteriormente os resultados da associação entre qualidade de vida relacionada à saúde com as variáveis sociodemográficas (sexo, idade, etnia, escolaridade, situação trabalhista e convivência marital) e variáveis clínicas (tipo de atendimento, comorbidades, desempenho cognitivo, dispneia, classe funcional da IC, fração de ejeção, fadiga, sintomas depressivos, atividade física, padrão de sono e autocuidado)

\subsection{CARACTERÍSTICAS SOCIODEMOGRÁFICAS E CLÍNICAS}

As características sociodemográficas e clínicas da amostra estão apresentadas nas Tabelas 1 e 2 . Os dados mostraram que houve predomínio do sexo masculino $(54,8 \%)$, a idade média foi de $57,9(\mathrm{dp}=11,6)$ anos e a escolaridade média de 6,1 (dp = 4,1) anos de estudo. Houve predomínio da etnia branca $(61,3 \%)$ e de convivência marital $(64,5 \%)$. Boa parte $(76,7 \%)$ eram inativos em relação à situação trabalhista, destes, 48,9\% eram aposentados ou pensionistas, 16,1\% desempregados/estudantes/do lar e 11,7\% afastados por doença. Apenas 23,2\% possuíam

situação

trabalhista

ativa. 
A principal etiologia da IC foi cardiomiopatia de origem não isquêmica (88,8\%), sendo 43,9\% cardiomiopatia dilatada, 29,8\% chagásica, 8,3\% hipertrófica e $6,8 \%$ a esclarecer. A classe funcional II foi mais prevalente $(46,7 \%)$, a fração de ejeção ventricular média dos participantes foi de $40,2 \%$ ( $d p=13,6 \%$ ) e Índice de Comorbidade de Charlson 3,9 $(\mathrm{dp}=1,5)$, considerado moderado. Dispneia foi relatada por $83,1 \%$ dos participantes, sendo mais frequente dispneia ao esforço moderado (26,9\%), seguido de dispneia ao esforço grande $(25,4 \%)$. Noctúria foi relatada por $82,6 \%$ da amostra e desses, $60,1 \%$ relataram acordar duas ou mais vezes durante a noite para urinar. $O$ tempo médio de experiência com insuficiência cardíaca foi de 64,6 ( $d p=65,1)$ meses. A maioria dos participantes $(66,3 \%)$ tinha sido atendida apenas por consulta médica e $16,9 \%$ dos pacientes foram categorizados como tabagistas.

Tabela 1 - Características sociodemográficas da amostra ( $N$ = 409), São Paulo- 2014

\begin{tabular}{lcc}
\hline \multicolumn{1}{c}{ Características } & Participantes (n) & $\%$ \\
\hline Gênero (n/\%) & 224 & 54,8 \\
Masculino & 185 & 45,2 \\
Feminino & & \\
Idade (anos) & $57,87(11,6)$ & \\
Média (DP) & 59,00 & \\
Mediana & $18-86$ & \\
Mínima-máxima & \\
Tempo de Estudo (anos) & $6,12(4,1)$ \\
Média (DP) & 5,00 \\
Mediana & $0,0-20,0$ \\
Mínima-máxima & 248 \\
Etnia (n/\%) & \\
Branca &
\end{tabular}




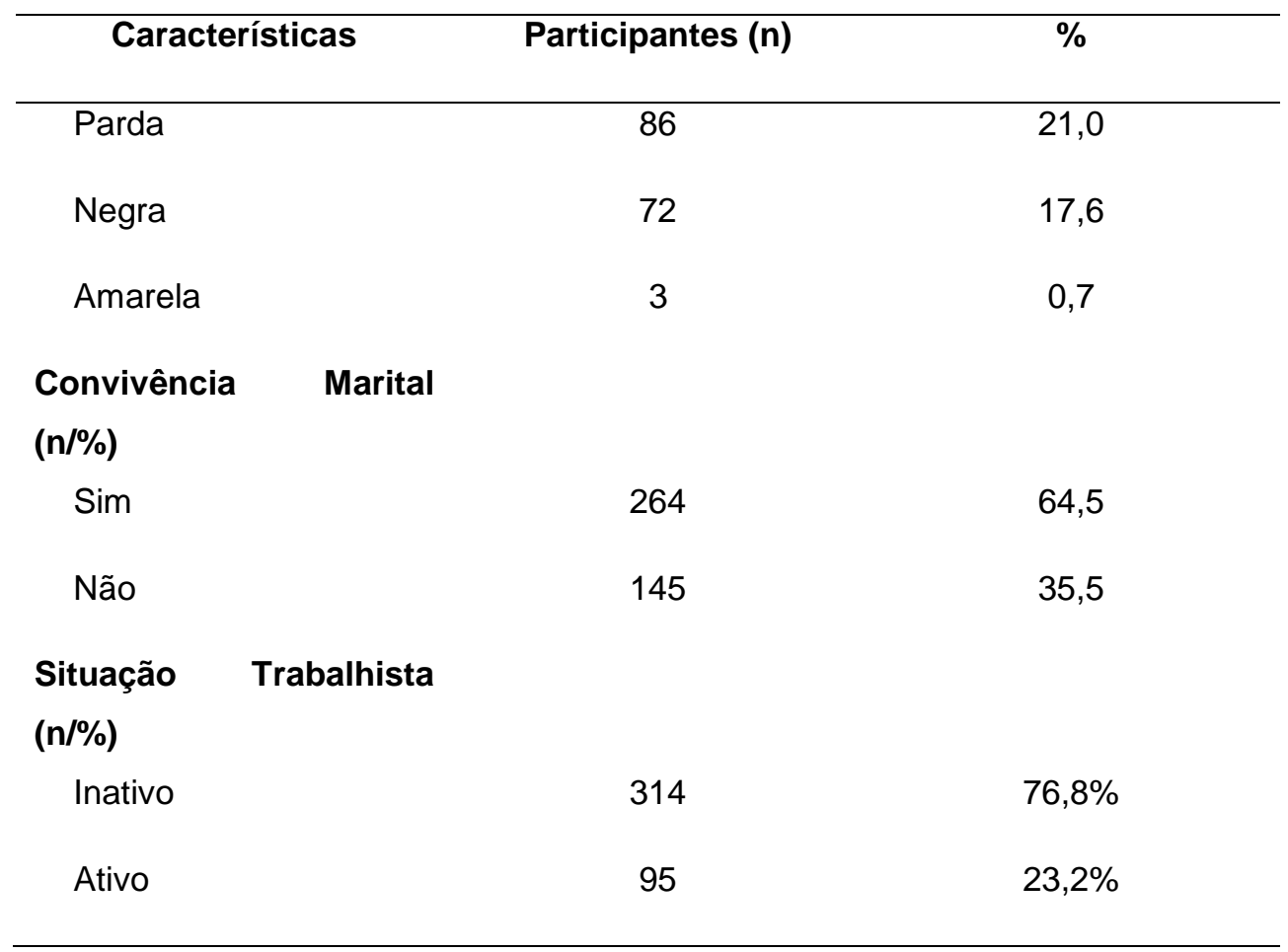

Tabela 2 - Características clínicas gerais da amostra ( $N=409)$, São Paulo 2014

\begin{tabular}{lcc}
\hline Características & $\begin{array}{c}\text { Participantes } \\
\text { (n) }\end{array}$ & $\%$
\end{tabular}

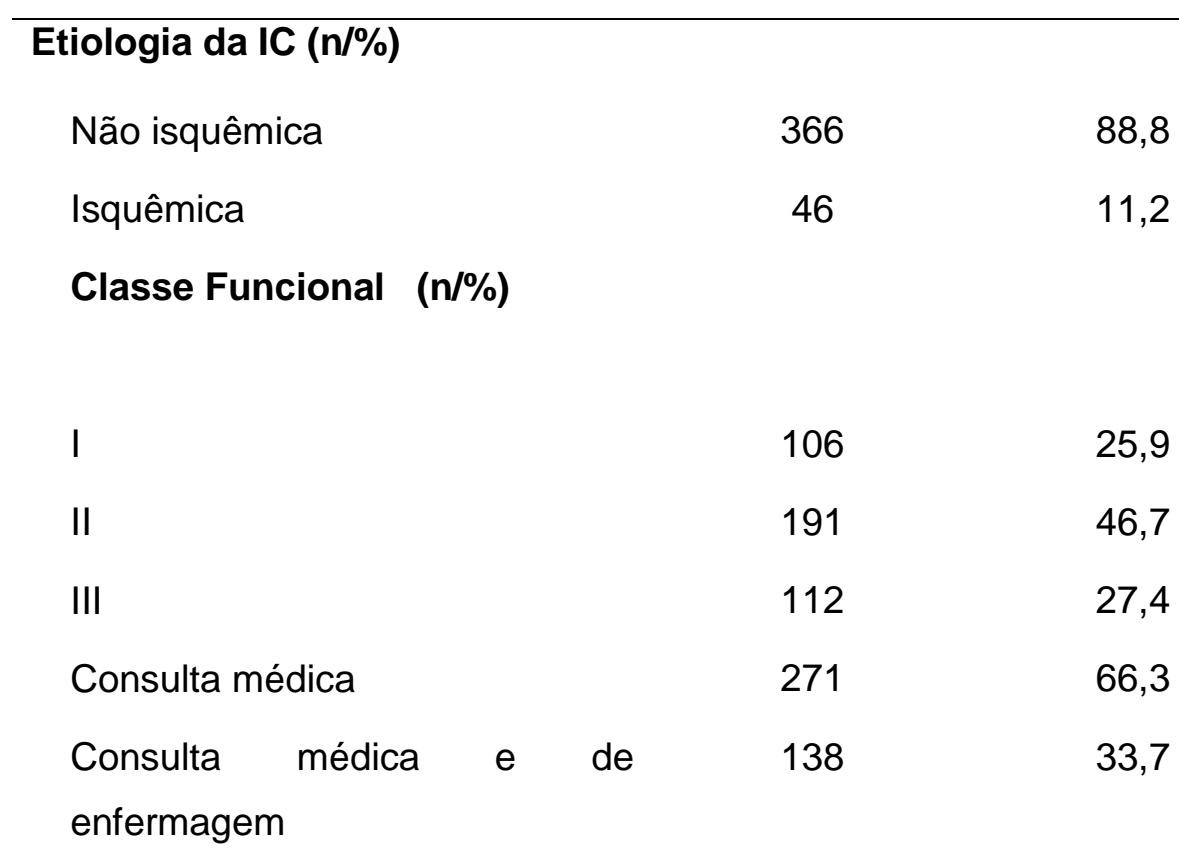

FEVE (\%)* 


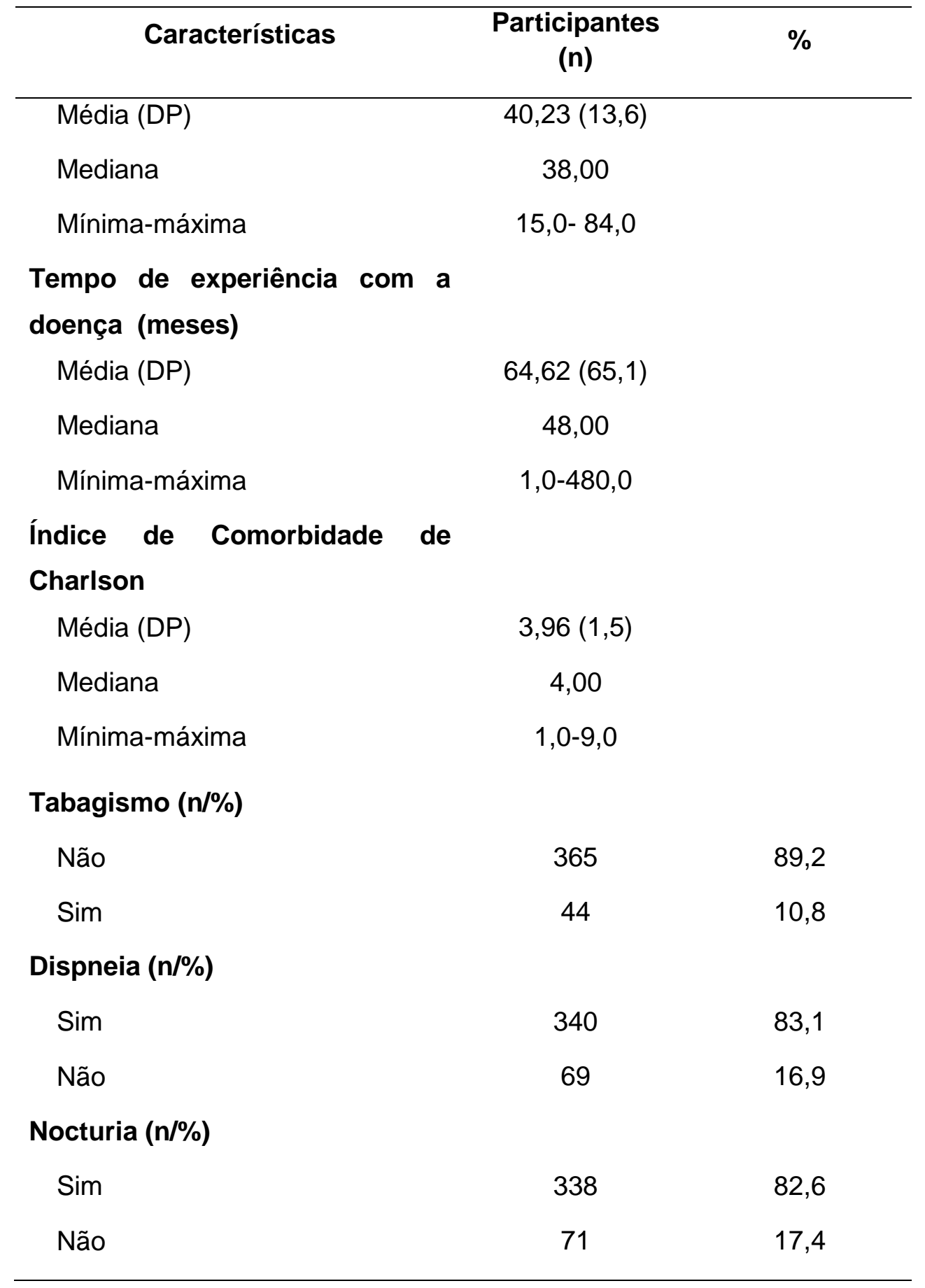

A Tabela 3 mostra as principais comorbidades apresentadas pela amostra. Houve predomínio da HAS $(67,2 \%)$ seguida pela diabetes mellitus $(26,2 \%)$, dislipidemia $(25,4 \%)$ e arritmia cardíaca $(24,4 \%)$. As comorbidades menos frequentes foram neoplasia (1,5\%) - valendo ressaltar que esses pacientes realizaram tratamento cirúrgico/quimioterápico/radioterápico e a doença não estava 
ativa -, doença infecciosa (1\%) sem repercussão hemodinâmica e oclusão arterial crônica $(0,2 \%)$.

Tabela 3 - Frequencia de participantes segundo comorbidades ( $N=409)$, São Paulo - 2014

\begin{tabular}{|c|c|c|}
\hline Comorbidades & $\mathbf{n}$ & $\%^{*}$ \\
\hline Hipertensão arterial sistêmica & 275 & 67,2 \\
\hline Diabetes mellitus & 107 & 26,2 \\
\hline Dislipdemia & 104 & 25,4 \\
\hline Arritmia cardíaca & 100 & 24,4 \\
\hline Marca-passo definitivo & 46 & 11,2 \\
\hline Distúrbio da tireóide & 37 & 9,0 \\
\hline Acidente vascular encefálico isquêmico & 24 & 5,9 \\
\hline Doença arterial coronariana & 22 & 5,4 \\
\hline Insuficiência renal crônica & 21 & 5,1 \\
\hline Doença pulmonar obstrutiva crônica & 15 & 3,7 \\
\hline Depressão & 7 & 1,7 \\
\hline Osteortrose/osteoporose & 7 & 1,7 \\
\hline Neoplasia & 6 & 1,5 \\
\hline Doença infecciosa & 4 & 1,0 \\
\hline Insuficiência venosa & 1 & 0.2 \\
\hline Arterial crônica & & \\
\hline
\end{tabular}

*Porcentual calculada em relação aos 409 pacientes.

A Tabela 4 descreve a prevalência de terapia medicamentosa da amostra. As classes de medicamentos mais prescritas foram: betabloqueadores $(84,1 \%)$, diuréticos $(75,1 \%)$, inibidores da enzima conversora de angiotensina II (48,9\%), antiagregantes plaquetários $(44,7 \%)$, estatinas $(42,5 \%)$, antiácidos $(31,5 \%)$ e 
hipoglicemiantes orais (21,5\%). A média de uso de fármacos foi de 5,3 medicamentos $(\mathrm{dp}=2,3)$, com variação de 0 a 13 medicamentos diferentes por paciente. No que se refere ao número de vezes que os pacientes tomavam seus medicamentos, a variação foi de nenhuma a 22 vezes, com média de 7,6 tomadas $(d p=3,6)$ e mediana de 7,5 tomadas por dia.

Tabela 4 - Frequencia de participantes segundo uso de terapia medicamentosa ( $N=409$ ), São Paulo - 2014

\begin{tabular}{|c|c|c|}
\hline Terapia Medicamentosa & $\mathbf{n}$ & $\%^{*}$ \\
\hline Betabloqueadores & 344 & 84,1 \\
\hline Diuréticos & 307 & 75,1 \\
\hline Inibidores da enzima conversora de angiotensina II & 200 & 48,9 \\
\hline Antiagregantes plaquetários & 183 & 44,7 \\
\hline Estatinas & 174 & 42,5 \\
\hline Bloqueadores dos receptores de angiotensina II & 129 & 31,5 \\
\hline Antiácidos & 129 & 31,5 \\
\hline Hipoglicemiantes orais & 88 & 21,5 \\
\hline Antiarrítmicos & 85 & 20,8 \\
\hline Bloqueadores do canal de cálcio & 62 & 15,2 \\
\hline Anticoagulantes orais & 60 & 14,7 \\
\hline Vasodilatadores & 51 & 12,5 \\
\hline Hormônios Tireóide & 44 & 10,8 \\
\hline Digitálicos & 33 & 8,1 \\
\hline Insulina & 16 & 3,9 \\
\hline Outros** & 12 & 2,8 \\
\hline
\end{tabular}

*Porcentual calculado em relação aos 409 pacientes. ** antieméticos, antialérgicos, antiandrógeno, broncodilatador e corticoide. 


\subsection{ESTADO COGNITIVO}

Considerando-se o estado cognitivo, a Tabela 5 apresenta a estatística descritiva da escala de rastreio de comprometimento cognitivo (MEEM). A escala variou de cinco a trinta pontos, com média igual a 24,29 pontos (dp 4,1) e mediana de 25 pontos. O coeficiente alfa de Cronbach foi de 0,61 . Os resultados da aplicação do MEEM indicaram que $213(52,1 \%)$ pacientes apresentavam comprometimento cognitivo e 196 (47,9\%) sem comprometimento cognitivo. Os itens cálculo, repetição, leitura e desenho foram os que apresentaram medianas mais baixas quando comparada com as pontuações dos demais componentes.

Tabela 5 - Estatística descritiva do Mini Exame do Estado Mental (MEEM) (N = 409), São Paulo - 2014

\begin{tabular}{lccccc}
\hline \multicolumn{1}{c}{ Itens do MEEM } & $\begin{array}{c}\text { Variação } \\
\text { Possível }\end{array}$ & Média (dp) & Mediana & Mínima & Máxima \\
\hline Orientação temporal & $0-5$ & $4,72(0,6)$ & 5,0 & 0,0 & 5,0 \\
Orientação espacial & $0-5$ & $4,66(0,7)$ & 5,0 & 0,0 & 5,0 \\
Memória imediata & $0-3$ & $2,76(0,6)$ & 3,0 & 0,0 & 3,0 \\
Cálculo & $0-5$ & $2,70(1,9)$ & 3,0 & 0,0 & 5,0 \\
Memória de evocação & $0-3$ & $1,81(0,9)$ & 2,0 & 0,0 & 3,0 \\
Nomeação & $0-2$ & $1,97(0,1)$ & 2,0 & 1,0 & 2,0 \\
Repetição & $0-3$ & $0,97(0,2)$ & 1,0 & 0,0 & 3,0 \\
Comando & $0-3$ & $2,79(0,6)$ & 3,0 & 0,0 & 3,0 \\
Leitura & $0-1$ & $0,83(0,4)$ & 1,0 & 0,0 & 1,0 \\
Frase & $0-1$ & $0,58(0,5)$ & 1,0 & 0,0 & 1,0 \\
Desenho & $0-1$ & $0,49(0,5)$ & 0,0 & 0,0 & 1,0 \\
\hline \multicolumn{2}{c}{ Total } & $\mathbf{2 4 , 2 9 ( 4 , 0 )}$ & $\mathbf{2 5 , 0}$ & $\mathbf{5 . 0}$ & $\mathbf{3 0 , 0}$ \\
\hline
\end{tabular}

\subsection{FADIGA E FADIGA AO ESFORÇO}

As Tabelas 6 e 7 apresentam as respostas dos itens das escalas DUFS (avaliação de fadiga) e DEFS (avaliação de fadiga ao esforço). A DUFS (Tabela 6) 
variou de 8 a 40, com pontuação média de 22,41 ( $\mathrm{dp}=8$,3) pontos e mediana de 23,00 pontos. Quanto maior a pontuação, pior a fadiga do paciente. O coeficiente de alfa de Chronbach foi de 0,89 demonstrando boa consistência interna da escala.

Os itens "sensação forte e constante de falta de energia", "observação que precisa de mais energia para dar conta das tarefas", e "sentindo-se sem disposição para fazer as coisas" foram os itens com maior impacto da fadiga nas atividades de vida diária dos pacientes com IC, quando somados os que ocorrem frequentemente e sempre (36,7\%, 44,5 e $36,6 \%$ respectivamente). Apenas $16,6 \%$ dos pacientes disseram conseguir frequentemente ou sempre realizar as suas atividades do dia a dia.

A DEFS (Tabela 7) variou de nove a 45 pontos, média de 23,36 (dp 11,2), mediana de 22 pontos. O coeficiente de alfa de Chronbach foi de 0,95 demonstrando boa consistência interna da escala. Os itens "Você acha fatigante subir e descer escadas?" $(55,7)$ e "Você acha fatigante caminhar por meia hora?" $(41,5)$ foram os itens com frequência predominante entre os que ocorrem sempre ou frequentemente. 
Tabela 6 - Frequência de pacientes, segundo as respostas aos itens do DUFS (Fadiga) (N = 409), São Paulo - 2014

\begin{tabular}{|c|c|c|c|c|c|c|c|c|c|c|c|c|}
\hline \multirow{3}{*}{ Itens DUFS } & \multicolumn{12}{|c|}{ Escores do DUFS } \\
\hline & \multicolumn{2}{|c|}{1} & \multicolumn{2}{|c|}{2} & \multicolumn{2}{|c|}{3} & \multicolumn{2}{|c|}{4} & \multicolumn{2}{|c|}{5} & \multicolumn{2}{|c|}{ Total } \\
\hline & № & $\%$ & № & $\%$ & № & $\%$ & № & $\%$ & № & $\%$ & № & $\%$ \\
\hline $\begin{array}{l}1- \\
\text { Ultimamente } \\
\text { você tido uma } \\
\text { sensação forte e } \\
\text { constante de falta } \\
\text { de energia? }\end{array}$ & 99 & 24,2 & 53 & 13,0 & 118 & 28,9 & 79 & 19,3 & 60 & 14,7 & 409 & 100,0 \\
\hline $\begin{array}{l}2-\text { Ultimamente } \\
\text { você } \\
\text { observado tem que } \\
\text { precisa de mais } \\
\text { energia para dar } \\
\text { conta das suas } \\
\text { tarefas diárias? }\end{array}$ & 96 & 23,5 & 41 & 10,0 & 90 & 22,0 & 108 & 26,4 & 74 & 18,1 & 409 & 100,0 \\
\hline $\begin{array}{lr}3- & \text { Ultimamente } \\
\text { você } \quad \text { tem } & \text { se } \\
\text { sentido } & \text { sem } \\
\text { disposição para } \\
\text { fazer as coisas? }\end{array}$ & 94 & 23,0 & 49 & 12,0 & 116 & 28,4 & 84 & 20,5 & 66 & 16,1 & 409 & 100,0 \\
\hline $\begin{array}{l}\text { 4- Ultimamente } \\
\text { você tem acordado } \\
\text { com a sensação de } \\
\text { estar exausto e } \\
\text { desgastado? }\end{array}$ & 118 & 28,9 & 59 & 14,4 & 105 & 25,7 & 61 & 14,9 & 66 & 16,1 & 409 & 100,0 \\
\hline \begin{tabular}{l} 
5- Ultimamente \\
você tem tido \\
necessidade de \\
\multicolumn{2}{l}{ descansar mais? }
\end{tabular} & 107 & 26,2 & 45 & 11,0 & 108 & 26,4 & 76 & 18,6 & 73 & 17,8 & 409 & 100,0 \\
\hline Ultimamente & 139 & 34,0 & 85 & 20,8 & 117 & 28,6 & 40 & 9,8 & 28 & 6,8 & 409 & 100,0 \\
\hline
\end{tabular}




\begin{tabular}{|c|c|c|c|c|c|c|c|c|c|c|c|c|}
\hline \multirow{3}{*}{ Itens DUFS } & \multicolumn{12}{|c|}{ Escores do DUFS } \\
\hline & \multicolumn{2}{|c|}{1} & \multicolumn{2}{|c|}{2} & \multicolumn{2}{|c|}{3} & \multicolumn{2}{|c|}{4} & \multicolumn{2}{|c|}{5} & \multicolumn{2}{|c|}{ Total } \\
\hline & № & $\%$ & № & $\%$ & № & $\%$ & № & $\%$ & № & $\%$ & № & $\%$ \\
\hline $\begin{array}{l}\text { você tem } \\
\text { conseguido fazer } \\
\text { suas atividades do } \\
\text { dia a dia? }\end{array}$ & & & & & & & & & & & & \\
\hline $\begin{array}{l}\text { 7- Ultimamente seu } \\
\text { interesse por sexo, } \\
\text { sua vontade de ter } \\
\text { relações sexuais } \\
\text { diminuiu? }\end{array}$ & 138 & 33,7 & 32 & 7,8 & 95 & 23,2 & 60 & 14,7 & 84 & 20,5 & 409 & 100,0 \\
\hline $\begin{array}{l}\text { 8- Tem sido mais } \\
\text { difícil se concentrar } \\
\text { em uma coisa por } \\
\text { muito tempo? }\end{array}$ & 125 & 30,6 & 42 & 10,3 & 121 & 29,6 & 65 & 15,9 & 56 & 13,7 & 409 & 100,0 \\
\hline
\end{tabular}


Tabela 7 - Frequência de pacientes, segundo as respostas aos itens do DEFS (fadiga ao esforço) ( $N=409$ ), São Paulo 2014

\begin{tabular}{|c|c|c|c|c|c|c|c|c|c|c|c|c|}
\hline \multirow{3}{*}{$\begin{array}{l}\text { Itens } \\
\text { DEFS }\end{array}$} & \multicolumn{12}{|c|}{ Escores do DEFS } \\
\hline & \multicolumn{2}{|c|}{1} & \multicolumn{2}{|c|}{2} & \multicolumn{2}{|c|}{3} & \multicolumn{2}{|c|}{4} & \multicolumn{2}{|c|}{5} & \multicolumn{2}{|c|}{ Total } \\
\hline & № & $\%$ & № & $\%$ & № & $\%$ & № & $\%$ & № & $\%$ & № & $\%$ \\
\hline $\begin{array}{l}1-\quad \text { Você acha } \\
\text { fatigante caminhar } \\
\text { por } 10 \text { minutos? }\end{array}$ & 170 & 41,6 & 49 & 12,0 & 80 & 19,6 & 45 & 11,0 & 65 & 15,9 & 409 & 100,0 \\
\hline $\begin{array}{l}2-\quad \text { Você acha } \\
\text { fatigante caminhar } \\
\text { por meia hora? }\end{array}$ & 110 & 26,9 & 47 & 11,5 & 70 & 17,1 & 71 & 17,4 & 111 & 27,1 & 409 & 100,0 \\
\hline $\begin{array}{l}\text { 3- Você acha } \\
\text { fatigante ficar em pé } \\
\text { embaixo do chuveiro? }\end{array}$ & 252 & 61,6 & 43 & 10,5 & 57 & 13,9 & 25 & 6,1 & 32 & 7,8 & 409 & 100,0 \\
\hline $\begin{array}{l}\text { 4- Você acha } \\
\text { fatigante subir e } \\
\text { descer escadas? }\end{array}$ & 63 & 15,4 & 26 & 6,4 & 92 & 22,5 & 93 & 22,7 & 135 & 33,0 & 409 & 100,0 \\
\hline 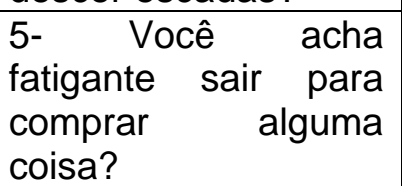 & 139 & 34,0 & 42 & 10,3 & 102 & 24,9 & 46 & 11,2 & 80 & 19,6 & 409 & 100,0 \\
\hline $\begin{array}{l}6-\quad \text { Você acha } \\
\text { fatigante recolher o } \\
\text { lixo da casa? }\end{array}$ & 187 & 45,7 & 46 & 11,2 & 76 & 18,6 & 39 & 9,5 & 61 & 14,9 & 409 & 100,0 \\
\hline $\begin{array}{l}7-\quad \text { Você acha } \\
\text { fatigante passar o } \\
\text { aspirador na casa? }\end{array}$ & 156 & 38,1 & 47 & 11,5 & 76 & 18,6 & 51 & 12,5 & 79 & 19,3 & 409 & 100,0 \\
\hline $\begin{array}{l}\text { 8- Você acha que } \\
\text { visitar } \\
\text { pessoas, em geral, é } \\
\text { fatigante? }\end{array}$ & 182 & 44,5 & 52 & 112,7 & 81 & 19,8 & 40 & 9,8 & 54 & 13,2 & 409 & 100,0 \\
\hline $\begin{array}{l}\text { 9- Você acha } \\
\text { fatigante participar de }\end{array}$ & 183 & 44,7 & 51 & 12,5 & 78 & 19,1 & 38 & 9,3 & 59 & 14,4 & 409 & 100,0 \\
\hline
\end{tabular}




\begin{tabular}{|c|c|c|c|c|c|c|c|c|c|c|c|c|}
\hline \multirow{3}{*}{$\begin{array}{l}\text { Itens } \\
\text { DEFS }\end{array}$} & \multicolumn{12}{|c|}{ Escores do DEFS } \\
\hline & \multicolumn{2}{|c|}{1} & \multicolumn{2}{|c|}{2} & \multicolumn{2}{|c|}{3} & \multicolumn{2}{|c|}{4} & \multicolumn{2}{|c|}{5} & \multicolumn{2}{|c|}{ Total } \\
\hline & № & $\%$ & № & $\%$ & № & $\%$ & № & $\%$ & № & $\%$ & № & $\%$ \\
\hline $\begin{array}{l}\text { encontros sociais } \\
\text { especiais, como uma } \\
\text { festa de aniversário? }\end{array}$ & & & & & & & & & & & & \\
\hline
\end{tabular}




\subsection{SINTOMAS DEPRESSIVOS}

A Tabela 8 apresenta os itens da escala de rastreamento de sintomas depressivos. A pontuação total da escala variou de 0 a 52 pontos, com média de $16,18(\mathrm{dp}=12,6)$ pontos e mediana de 13 pontos. O coeficiente alfa de Chronbach foi de 0,89 , o que demonstra boa consistência interna. Dos pacientes avaliados, 172 (42\%) apresentavam sintomas depressivos. Conforme Tabela $8,52,8 \%$ dos pacientes raramente se sentiam assim, comparando-se a outras pessoas, tendo tanto valor quanto a maioria delas, $51,6 \%$ raramente se sentiam otimistas com relação ao futuro, $51,8 \%$ raramente se sentiam felizes e $51,6 \%$ raramente aproveitavam a vida. 
Tabela 8 - Frequência de pacientes segundo as respostas aos itens do CES-D (N -= 409), São Paulo - 2014.

\begin{tabular}{|c|c|c|c|c|c|c|c|c|c|c|}
\hline \multirow[t]{2}{*}{ Itens do CES- D } & \multicolumn{2}{|c|}{$\begin{array}{c}\text { Raramente } \\
\text { (menos que } 1 \text { dia) }\end{array}$} & \multicolumn{2}{|c|}{$\begin{array}{c}\text { Durante pouco } \\
\text { tempo } \\
\text { (1 ou } 2 \text { dias) }\end{array}$} & \multicolumn{2}{|c|}{$\begin{array}{c}\text { Durante um } \\
\text { tempo moderado } \\
\text { (3 a } 4 \text { dias) }\end{array}$} & \multicolumn{2}{|c|}{$\begin{array}{l}\text { Durante a maior } \\
\text { parte do tempo } \\
\text { (5 a } 7 \text { dias) }\end{array}$} & \multicolumn{2}{|c|}{ Total } \\
\hline & № & $\%$ & № & $\%$ & № & $\%$ & № & $\%$ & № & $\%$ \\
\hline $\begin{array}{l}1-\quad \text { Senti-me incomodado com } \\
\text { coisas que habitualmente não me } \\
\text { incomodam }\end{array}$ & 230 & 56,2 & 51 & 12,5 & 55 & 13,4 & 73 & 17,8 & 409 & 100,0 \\
\hline $\begin{array}{l}\text { 2- Não tive vontade de comer, tive } \\
\text { pouco apetite }\end{array}$ & 237 & 57,9 & 56 & 13,7 & 51 & 12,5 & 65 & 15,9 & 409 & 100,0 \\
\hline $\begin{array}{l}\text { 3- Senti não conseguir melhorar } \\
\text { meu estado de ânimo mesmo com } \\
\text { a ajuda de familiares e amigos }\end{array}$ & 237 & 57,9 & 65 & 15,9 & 42 & 10,3 & 65 & 15,9 & 409 & 100,0 \\
\hline $\begin{array}{l}\text { 4- Senti-me, comparando-me às } \\
\text { outras pessoas, tendo tanto valor } \\
\text { quanto a maioria delas }\end{array}$ & 216 & 52,8 & 29 & 7,1 & 51 & 12,5 & 113 & 27,6 & 409 & 100,0 \\
\hline $\begin{array}{l}5-\quad \text { Senti dificuldade em } \text { me } \\
\text { concentrar no que estava fazendo }\end{array}$ & 183 & 44,7 & 103 & 25,2 & 58 & 14,2 & 65 & 15,9 & 409 & 100,0 \\
\hline 6- Senti-me deprimido & 229 & 56,0 & 76 & 18,6 & 41 & 10,0 & 63 & 15,4 & 409 & 100,0 \\
\hline $\begin{array}{l}\text { 7- Senti que tive de fazer esforço } \\
\text { para dar conta das minhas tarefas } \\
\text { habituais }\end{array}$ & 180 & 44,0 & 97 & 23,7 & 52 & 12,7 & 80 & 19,6 & 409 & 100,0 \\
\hline 8- Senti-me otimista com relação & 211 & 51,6 & 62 & 15,2 & 52 & 12,7 & 84 & 20,5 & 409 & 100,0 \\
\hline
\end{tabular}




\begin{tabular}{|c|c|c|c|c|c|c|c|c|c|c|}
\hline \multirow[t]{3}{*}{ Itens do CES- D } & \multicolumn{2}{|c|}{$\begin{array}{c}\text { Raramente } \\
\text { (menos que } 1 \text { dia) }\end{array}$} & \multicolumn{2}{|c|}{$\begin{array}{c}\text { Durante pouco } \\
\text { tempo } \\
\text { (1 ou } 2 \text { dias) }\end{array}$} & \multicolumn{2}{|c|}{$\begin{array}{c}\begin{array}{c}\text { Durante um } \\
\text { tempo moderado }\end{array} \\
\text { (3 a } 4 \text { dias) }\end{array}$} & \multicolumn{2}{|c|}{$\begin{array}{c}\text { Durante a maior } \\
\text { parte do tempo } \\
\text { (5 a } 7 \text { dias) }\end{array}$} & \multicolumn{2}{|c|}{ Total } \\
\hline & № & $\%$ & № & $\%$ & № & $\%$ & № & $\%$ & № & $\%$ \\
\hline & & & & & & & & & & \\
\hline $\begin{array}{l}\text { 9- Considerei que a minha vida } \\
\text { tinha sido um fracasso }\end{array}$ & 320 & 78,2 & 32 & 7,8 & 23 & 5,6 & 34 & 8,3 & 409 & 100,0 \\
\hline 10- Senti-me amedrontado & 298 & 72,9 & 56 & 13,7 & 17 & 4,2 & 38 & 9,3 & 409 & 100,0 \\
\hline 11- Meu sono não foi repousante & 167 & 40,8 & 94 & 23,0 & 64 & 15,6 & 84 & 20,5 & 409 & 100,0 \\
\hline 12- Estive feliz & 212 & 51,8 & 58 & 14,2 & 75 & 18,3 & 64 & 15,6 & 409 & 100,0 \\
\hline 13- Falei menos que o habitual & 278 & 68,0 & 63 & 15,4 & 31 & 7,6 & 37 & 9,0 & 409 & 100,0 \\
\hline 14- Senti-me sozinho & 256 & 62,6 & 52 & 12,7 & 35 & 8,6 & 66 & 16,1 & 409 & 100,0 \\
\hline $\begin{array}{l}\text { 14- As pessoas não foram } \\
\text { amistosas comigo }\end{array}$ & 313 & 76,5 & 60 & 14,7 & 11 & 2,7 & 25 & 6,1 & 409 & 100,0 \\
\hline $\begin{array}{l}\text { 15- As pessoas não foram } \\
\text { amistosas comigo }\end{array}$ & 313 & 76,5 & 60 & 14,7 & 11 & 2,7 & 25 & 6,1 & 409 & 100,0 \\
\hline 16- Aproveitei minha vida & 211 & 51,6 & 55 & 13,4 & 46 & 11,2 & 97 & 23,7 & 409 & 100,0 \\
\hline 17- Tive crises de choro & 287 & 70,2 & 59 & 14,4 & 31 & 7,6 & 32 & 7,8 & 409 & 100,0 \\
\hline 18- Senti-me triste & 204 & 49,9 & 96 & 23,5 & 45 & 11,0 & 64 & 15,6 & 409 & 100,0 \\
\hline
\end{tabular}




\begin{tabular}{|c|c|c|c|c|c|c|c|c|c|c|}
\hline \multirow[t]{2}{*}{ Itens do CES- D } & \multicolumn{2}{|c|}{$\begin{array}{c}\text { Raramente } \\
\text { (menos que } 1 \text { dia) }\end{array}$} & \multicolumn{2}{|c|}{$\begin{array}{c}\text { Durante pouco } \\
\text { tempo } \\
\text { (1 ou } 2 \text { dias) }\end{array}$} & \multicolumn{2}{|c|}{$\begin{array}{c}\text { Durante um } \\
\text { tempo moderado } \\
\text { (3 a } 4 \text { dias) }\end{array}$} & \multicolumn{2}{|c|}{$\begin{array}{l}\text { Durante a maior } \\
\text { parte do tempo } \\
\text { (5 a } 7 \text { dias) }\end{array}$} & \multicolumn{2}{|c|}{ Total } \\
\hline & № & $\%$ & № & $\%$ & № & $\%$ & № & $\%$ & № & $\%$ \\
\hline $\begin{array}{l}\text { 19- Senti que as pessoas não } \\
\text { gostavam de mim }\end{array}$ & 331 & 80,9 & 34 & 8,3 & 22 & 5,4 & 22 & 5,4 & 409 & 100,0 \\
\hline $\begin{array}{l}\text { 20- Não consegui levar adiante } \\
\text { minhas coisas }\end{array}$ & 239 & 58,4 & 79 & 19,3 & 43 & 10,5 & 48 & 11,7 & 409 & 100,0 \\
\hline
\end{tabular}




\subsection{ATIVIDADE FÍSICA HABITUAL}

A Tabela 9 descreve os do escores de atividade física habitual (AFH) e seus componentes, isto é, exercício físico de lazer (EFL), atividade física ocupacional (AFO) e atividade de lazer e locomoção (ALL). As consistências internas das escalas variaram amplamente e a maior média foi para a Atividade física ocupacional (AFO).

Tabela 9 - Estatísticas descritivas da atividade física habitual e dos seus componentes, São Paulo - 2014

\begin{tabular}{|c|c|c|c|c|c|c|}
\hline Componentes & $\mathbf{N}$ & $\begin{array}{l}\text { Média } \\
\text { (DP) }\end{array}$ & Mediana & Mínimo & Máximo & $\begin{array}{l}\text { Alfa } \\
\text { Cronbach }\end{array}$ \\
\hline $\begin{array}{l}\text { Atividade física } \\
\text { ocupacional (AFO) }\end{array}$ & 409 & $2,74(0,6)$ & 2,75 & 1,37 & 4,37 & 0,60 \\
\hline $\begin{array}{l}\text { Exercício físico de } \\
\text { lazer (EFL) }\end{array}$ & 409 & $1,99(0,7)$ & 2,00 & 1,00 & 4,50 & 0,44 \\
\hline $\begin{array}{l}\text { Atividade de lazer e } \\
\text { locomoção (ALL) }\end{array}$ & 409 & $2,04(0,6)$ & 2,00 & 1,00 & 4,00 & 0,22 \\
\hline $\begin{array}{l}\text { Atividade física } \\
\text { habitual (AFH) }\end{array}$ & 409 & $6,78(1,3)$ & 6,75 & 3,87 & 10,87 & 0,45 \\
\hline
\end{tabular}

\subsection{DESCRIÇÃO DO PADRÃO DE SONO}

As Tabelas 10, 11 e 12 apresentam as respostas dos componentes da escala do PSQI. A escala variou de 1 a 19 pontos, com média igual a 7,88 pontos, com mediana de 7,00, indicativo de má qualidade do sono. O coeficiente de alfa de Chronbach foi de 0,68, o que demonstra razoável consistência interna da escala. Verificou-se, na população estudada, que 286 (68,9\%) pacientes foram classificados como maus dormidores e $123(30,1 \%)$ como bons dormidores, de acordo com a pontuação obtida com o PSQI.

Da análise dos sete parâmetros avaliados pelo PSQI (qualidade do sono, latência do sono, duração do sono, eficiência do sono, distúrbios do sono, uso de medicação para dormir e sonolência diurna) pode-se constatar que os componentes duração do sono e eficiência do sono, apresentaram maior frequência de pacientes 
com escores mais elevados (3), quando comparados com os demais cinco componentes.

Observa-se que os pacientes possuem comprometimento na maioria dos componentes do PSQI, com exceção do componente seis, onde apenas 13 pacientes faziam uso esporádico de algum medicamento para dormir. O tempo médio (em minutos) que geralmente o paciente levou para dormir foi de 33,7 minutos ( $d p=37,7)$, mediana de 20 minutos. O tempo mínimo que o paciente levou para dormir foi de 0 minutos e tempo máximo de 300 minutos.

Tabela 10 - Frequência das respostas dos sujeitos em relação aos componentes do PSQI (N = 409), São Paulo - 2014

\begin{tabular}{|c|c|c|c|}
\hline Componentes & Características & № & $\%$ \\
\hline \multirow[t]{4}{*}{ Qualidade subjetiva do sono } & Muito boa & 29 & 7,1 \\
\hline & Boa & 232 & 56,7 \\
\hline & Ruim & 121 & 29,6 \\
\hline & Muito ruim & 27 & 6,6 \\
\hline \multirow[t]{4}{*}{ Latência do sono } & $\leq 15$ minutos & 27,9 & 27,9 \\
\hline & 16-30minutos & 76 & 18,6 \\
\hline & $31-60$ minutos & 113 & 27,6 \\
\hline & $>60$ minutos & 106 & 25,9 \\
\hline \multirow[t]{4}{*}{ Duração do sono } & $>7$ horas & 102 & 25 \\
\hline & 6 a 7 horas & 169 & 41,3 \\
\hline & $5<6$ horas & 61 & 14,9 \\
\hline & $<5$ horas & 77 & 18,8 \\
\hline \multirow[t]{4}{*}{ Qualidade subjetiva do sono } & Muito boa & 29 & 7,1 \\
\hline & Boa & 232 & 56,7 \\
\hline & Ruim & 121 & 29,6 \\
\hline & Muito ruim & 27 & 6,6 \\
\hline \multirow[t]{3}{*}{ Latência do sono } & $\leq 15$ minutos & 27,9 & 27,9 \\
\hline & 16-30minutos & 76 & 18,6 \\
\hline & $31-60$ minutos & 113 & 27,6 \\
\hline
\end{tabular}




\begin{tabular}{|c|c|c|c|}
\hline Componentes & Características & № & $\%$ \\
\hline & $>60$ minutos & 106 & 25,9 \\
\hline \multirow[t]{4}{*}{ Duração do sono } & $>7$ horas & 102 & 25 \\
\hline & 6 a 7 horas & 169 & 41,3 \\
\hline & $5<6$ horas & 61 & 14,9 \\
\hline & $<5$ horas & 77 & 18,8 \\
\hline \multirow[t]{4}{*}{ Eficiência habitual do sono } & $>85 \%$ & 189 & 46,2 \\
\hline & $75-84 \%$ & 74 & 18,1 \\
\hline & $65-74 \%$ & 40 & 9,8 \\
\hline & $<65 \%$ & 106 & 25,9 \\
\hline \multirow[t]{4}{*}{ Transtornos do sono } & Nenhuma vez & 6 & 1,5 \\
\hline & $<1 \mathrm{vez} /$ semana & 171 & 41,8 \\
\hline & 1 a 2 vezes/semana & 206 & 50,4 \\
\hline & $\geq 3$ vezes/semana & 26 & 6,4 \\
\hline \multirow[t]{4}{*}{ Uso de medicamentos para dormir } & Nenhuma vez & 396 & 96,8 \\
\hline & $<1 \mathrm{vez} /$ semana & 5 & 1,2 \\
\hline & 1 a 2 vezes/semana & 4 & 1,0 \\
\hline & $\geq 3$ vezes/semana & 4 & 1,0 \\
\hline \multirow[t]{4}{*}{ Disfunção diurna } & Nenhuma vez & 200 & 48,9 \\
\hline & $<1 \mathrm{vez} /$ semana & 86 & 21,0 \\
\hline & 1 a 2 vezes/semana & 87 & 21,3 \\
\hline & $\geq 3$ vezes/semana & 36 & 8,8 \\
\hline Total & & 409 & 100,0 \\
\hline
\end{tabular}


Tabela 11 - Frequência dos fatores que contribuíram para o componente transtornos do sono ( $N=409)$, São Paulo - 2014

\begin{tabular}{|c|c|c|c|c|c|c|c|c|c|c|c|}
\hline & \multirow{3}{*}{ Componentes } & \multicolumn{10}{|c|}{ Escores do PSQI } \\
\hline & & \multicolumn{2}{|c|}{$\begin{array}{l}\text { Nenhuma } \\
\text { vez }\end{array}$} & \multicolumn{2}{|c|}{$\begin{array}{c}\text { Menos que } \\
1 \text { vez/ } \\
\text { semana }\end{array}$} & \multicolumn{2}{|c|}{$\begin{array}{l}1 \text { a } 2 \text { vezes } / \\
\text { semana }\end{array}$} & \multicolumn{2}{|c|}{$\begin{array}{l}3 \text { vezes/ } \\
\text { semana } \\
\text { ou mais }\end{array}$} & \multicolumn{2}{|c|}{ Total } \\
\hline & & № & $\%$ & № & $\%$ & № & $\%$ & № & $\%$ & № & $\%$ \\
\hline & $\begin{array}{l}\text { Não conseguiu } \\
\text { adormecer em } \\
\text { até } 30 \mathrm{~min}\end{array}$ & 138 & 33,7 & 36 & 8,8 & 42 & 10,0 & 194 & 47,4 & 409 & 100,0 \\
\hline $2-$ & $\begin{array}{l}\text { Acordou no meio } \\
\text { da noite ou de } \\
\text { manhã }\end{array}$ & 70 & 17,1 & 35 & 8,6 & 49 & 12,0 & 255 & 62,3 & 409 & 100,0 \\
\hline 3- & $\begin{array}{l}\text { Precisou levantar } \\
\text { para ir ao } \\
\text { banheiro }\end{array}$ & 55 & 13,4 & 34 & 8,3 & 32 & 7,8 & 288 & 70,4 & 409 & 100,0 \\
\hline 4- & $\begin{array}{l}\text { Não conseguiu } \\
\text { respirar } \\
\text { confortavelmente }\end{array}$ & 241 & 58,9 & 34 & 8,3 & 46 & 11,2 & 88 & 21,5 & 409 & 100,0 \\
\hline $5-$ & $\begin{array}{l}\text { Tossiu ou roncou } \\
\text { forte }\end{array}$ & 244 & 59,7 & 30 & 7,3 & 27 & 6,6 & 108 & 26,4 & 409 & 100,0 \\
\hline $6-$ & Sentiu muito frio & 341 & 83,4 & 12 & 2,9 & 8 & 2,0 & 48 & 11,7 & 409 & 100,0 \\
\hline & $\begin{array}{l}\text { Sentiu muito } \\
\text { calor }\end{array}$ & 175 & 42,8 & 14 & 3,4 & 24 & 5,9 & 196 & 47,9 & 409 & 100,0 \\
\hline & $\begin{array}{l}\text { Teve sonhos } \\
\text { ruins }\end{array}$ & 290 & 70,9 & 44 & 10,8 & 37 & 9,0 & 38 & 9,3 & 409 & 100,0 \\
\hline & Teve dor & 259 & 63,3 & 37 & 9,0 & 28 & 6,8 & 85 & 20,8 & 409 & 100,0 \\
\hline & - Outras razões & 285 & 69,7 & 34 & 8,3 & 29 & 7,1 & 61 & 14,9 & 409 & 100,0 \\
\hline
\end{tabular}


Tabela 12 - Estatística descritiva das características do sono de acordo com as respostas ao PSQI para os componentes de latência e de eficiência habitual do sono ( $N=409)$, São Paulo - 2014

\begin{tabular}{lccccc}
\hline \multicolumn{1}{c}{ Variáveis } & Média & $\begin{array}{c}\text { Desvio } \\
\text { padrão }\end{array}$ & Mediana & Mínima & Máxima \\
& & & & \\
\hline Horário de deitar & $22 \mathrm{~h} 33$ & $1 \mathrm{~h} 35$ & $23 \mathrm{~h}$ & $00 \mathrm{~h}$ & $23 \mathrm{~h}$ \\
Horário de despertar & $6 \mathrm{~h} 55$ & $1 \mathrm{~h} 53$ & $6 \mathrm{~h}$ & $00 \mathrm{~h}$ & $14 \mathrm{~h}$ \\
Latência do sono & $33,7 \mathrm{~min}$ & $20,0 \mathrm{~min}$ & $37,7 \mathrm{~min}$ & $0,0 \mathrm{~min}$ & $300,0 \mathrm{~min}$ \\
Duração do sono & $6 \mathrm{~h} 11 \mathrm{~min}$ & $1 \mathrm{~h} 4 \mathrm{~min}$ & $6 \mathrm{~h}$ & $1 \mathrm{~h}$ & $11 \mathrm{~h}$ \\
$\begin{array}{l}\text { Tempo despendido } \\
\text { no leito }\end{array}$ & $6 \mathrm{~h} 17 \mathrm{~min}$ & $1 \mathrm{~h} 7 \mathrm{~min}$ & $6 \mathrm{~h}$ & $1 \mathrm{~h}$ & $11 \mathrm{~h}$ \\
Eficiência habitual do & $79,1 \%$ & $22,3 \%$ & $83,3 \%$ & $12,5 \%$ & $180 \%$ \\
sono (\%) & & & & & \\
\hline
\end{tabular}

*Valor da eficiência do sono é obtido dividindo-se o tempo de "horas de sono" estimado pelo sujeito pelo número de horas despendido no leito, calculado a partir das respostas sobre horário de deitar e de despertar

\subsection{DESCRIÇÃO DA QUALIDADE DE VIDA RELACIONADA À SAÚDE}

A Tabela 13 apresenta as respostas dos itens da escala do MLHFQ. Os escore de cada item pode variar de zero a cinco pontos e o escore global de 0 a 105 pontos. A média do escore global na amostra deste estudo foi igual a 34,95 pontos. O coeficiente de alfa de Chronbach foi de 0,92, demonstrando boa consistência interna da escala.

Dos 409 pacientes, 39,9\% apresentaram boa qualidade de vida relacionada à saúde, 25,7\% moderada qualidade de vida relacionada à saúde e 34,5\% má qualidade de vida relacionada à saúde.

Os resultados evidenciaram que dificuldade para caminhada e subida de escadas (média 2,62 e dp = 2,0 pontos), falta de ar (média de 2,26 dp = 1,9 pontos), fadiga (média 2,47 dp = 1,9 pontos) foram os itens com pontuações mais elevadas, que impediam os pacientes de viver como gostariam. 
Os participantes referiram também que os sintomas da insuficiência cardíaca tiveram pouco efeito sobre "sentir um peso para familiares e amigos" (média 1,13 dp $=1,8$ pontos), perda de controle sobre sua vida (média $1,18 \mathrm{dp}=1,7$ pontos), e fazêlos sentir-se preocupados e deprimidos (média 1,64 e dp = 1,9 pontos). Também relataram que os sintomas da IC não ocasionaram hospitalização (média 0,47 e dp = 1,3 pontos) e que não tiveram efeito colateral das medicações (média 0,82 $d p=1,4$ pontos).

A confiabilidade para as duas subescalas foram 0,91 para a dimensão física e 0,83 para dimensão emocional. 
Tabela 13 - Estatística descritiva dos itens do Minnesota Living with Heart Failure Questionnaire (MLHFQ) (N = 409), São Paulo - 2014

\begin{tabular}{|c|c|c|c|c|c|}
\hline Itens do MLHFQ & Média (dp) & Mediana & Mínima & Máxima & Alfa de Cronbach \\
\hline Dimensão física & $15,89(12,3)$ & 14,00 & 0,00 & 40,00 & 0,91 \\
\hline $\begin{array}{l}\text { 2. Obrigando você a sentar ou deitar para } \\
\text { descansar durante o dia }\end{array}$ & $1,84(1,9)$ & 1,00 & 0,00 & 5,00 & \\
\hline $\begin{array}{l}\text { 3. Tornando sua caminhada e subida de } \\
\text { escadas difíceis }\end{array}$ & $2,62(2,0)$ & 3,00 & 0,00 & 5,00 & \\
\hline 4. Tornando seu trabalho doméstico difícil & $2,10(1,99)$ & 2,00 & 0,00 & 5,00 & \\
\hline 5. Tornando suas saídas de casa difíceis & $1,85(1,9)$ & 1,00 & 0,00 & 5,00 & \\
\hline 6. Tornando difícil dormir bem à noite & $1,74(1,9)$ & 1,00 & 0,00 & 5,00 & \\
\hline $\begin{array}{l}\text { 7. Tornando difíceis seus relacionamentos ou } \\
\text { atividades com familiares e amigos }\end{array}$ & $1,03(1,6)$ & 0,00 & 0,00 & 5,00 & \\
\hline 12. Causando falta de ar & $2,26(1,9)$ & 2,00 & 0,00 & 5,00 & \\
\hline $\begin{array}{l}\text { 13. Deixando você cansado, fatigado ou com } \\
\text { pouca energia }\end{array}$ & $2,47(1,9)$ & 3,00 & 0,00 & 5,00 & \\
\hline Dimensão Emocional & $7,89(7,1)$ & 6,00 & 0,00 & 25,00 & 0,83 \\
\hline $\begin{array}{l}\text { 17. Fazendo você se sentir um peso para } \\
\text { familiares e amigos }\end{array}$ & $1,13(1,8)$ & 0,00 & 0,00 & 5,00 & \\
\hline $\begin{array}{l}\text { 18. Fazendo você sentir falta de autocontrole } \\
\text { na sua vida }\end{array}$ & $1,18(1,7)$ & 0,00 & 0,00 & 5,00 & \\
\hline 19. Fazendo você se preocupar & $2,09(1,9)$ & 2,00 & 0,00 & 5,00 & \\
\hline $\begin{array}{l}\text { 20. Tornando difícil você se concentrar ou se } \\
\text { lembrar das coisas }\end{array}$ & $1,82(1,8)$ & 2,00 & 0,00 & 5,00 & \\
\hline 21. Fazendo você se sentir deprimido & $1,64(1,9)$ & 0,00 & 0,00 & 5,00 & \\
\hline
\end{tabular}




\begin{tabular}{|c|c|c|c|c|c|}
\hline Itens do MLHFQ & Média (dp) & Mediana & Mínima & Máxima & Alfa de Cronbach \\
\hline $\begin{array}{l}\text { Demais itens } \\
\text { 1. Causou inchaço em seus tornozelos e } \\
\text { pernas }\end{array}$ & $1,48(1,8)$ & 0,00 & 0,00 & 5,00 & \\
\hline $\begin{array}{l}\text { 8. Tornando seu trabalho para ganhar a vida } \\
\text { difícil }\end{array}$ & $1,65(2,1)$ & 0,00 & 0,00 & 5,00 & \\
\hline $\begin{array}{l}\text { 9. Tornando seus passatempos, esportes e } \\
\text { diversão difíceis }\end{array}$ & $2,01(2,0)$ & 2,00 & 0,00 & 5,00 & \\
\hline 10. Tornando sua atividade sexual difícil & $1,69(2,1)$ & 0,00 & 0,00 & 5,00 & \\
\hline $\begin{array}{l}\text { 11. Fazendo você comer menos as comidas } \\
\text { de que você gosta }\end{array}$ & $1,74(1,8)$ & 1,00 & 0,00 & 5,00 & \\
\hline 14. Obrigando você a ficar hospitalizado & $0,47(1,3)$ & 0,00 & 0,00 & 5,00 & \\
\hline $\begin{array}{l}\text { 15. Fazendo você gastar dinheiro com } \\
\text { cuidados médicos }\end{array}$ & $1,28(1,7)$ & 0,00 & 0,00 & 5,00 & \\
\hline $\begin{array}{l}\text { 16. Causando em você efeitos colaterais das } \\
\text { medicações }\end{array}$ & $0,82(1,4)$ & 0,00 & 0,00 & 5,00 & \\
\hline Total & $34,95(25,3)$ & 31,00 & 0.00 & 97,00 & 0,93 \\
\hline
\end{tabular}




\subsection{DESCRIÇÃO DO AUTOCUIDADO}

A Tabela 14 apresenta as estatísticas descritivas para o comportamento de autocuidado dos pacientes com IC. As pontuações para manutenção do autocuidado ( édia $=49,28 \mathrm{dp}=14,2$ ), manejo do autocuidado (média $=40,86 \mathrm{dp}=20,6$ ) e confiança no autocuidado (média $=56,50 \mathrm{dp}=21,6$ ) foram todas abaixo de 70 pontos, indicando um baixo comportamento de autocuidado. As proporções de pacientes com autocuidado adequado (escore $\geq 70$ pontos) foram: manutenção $(6,4 \%)$, manejo $(10,2 \%)$ e confiança $(21,5 \%)$.

Em relação ao comportamento de manutenção de autocuidado, os itens que apresentaram pontuações mais baixas foram: "Solicita alimentos com pouco sal quando come fora ou visita alguém?" (média de 1,49 e dp = 0,9 pontos), "Realiza alguma atividade física?" (média 1,55 e dp=0,9 pontos) e "Exercita-se por 30 minutos?" (média 1,60 e dp = 1,0 pontos).

Os itens que apresentaram pontuações mais elevadas foram: "É assíduo nas consultas com médico ou enfermeiro" (média 3,40 dp = 1,0 pontos), "Esquece-se ou deixa de tomar algum de seus medicamentos?" (média 3,38 dp =0,8 pontos), "Ingere uma dieta com pouco sal?" (3,17 dp=1,0 pontos).

No comportamento de manejo do autocuidado, os itens com menores pontuações foram: "Ingerir um diurético a mais" (média 1,55 e dp =0,9), "Com que rapidez você os reconheceu como um sintoma de insuficiência cardíaca?" (media $1,76 \mathrm{dp}=1,6)$ e "Pense em um dos recursos que acima que você tentou na última vez em que teve dificuldade para respirar ou tornozelos inchados" (média 1,19 e dp= $1,5)$.

Os itens da subescala confiança no autocuidado com maiores pontuações foram: "seguir o tratamento recomendado" (média 3,01 e dp =0,7) e "avaliar se um medicamento funciona" (média 2,83 e dp =0,8) e o item com menor pontuação foi "fazer algo que pudesse aliviar os sintomas" (média 2,48 e dp =0,9). 
Tabela 14 - Estatística descritiva dos dos itens e confiabilidade do SCHFI - versão brasileira, São Paulo - 2014.

\begin{tabular}{|c|c|c|c|c|c|}
\hline Itens SCHFI & $\mathbf{N}$ & Média (dp) & Mediana & Min./Max. & Alfa Cronbach \\
\hline \multicolumn{6}{|l|}{ Manutenção do Autocuidado } \\
\hline 1. Você se pesa? & 409 & $2,11(0,9)$ & 2,00 & $1,00-4,00$ & \\
\hline $\begin{array}{l}\text { 2.Verifica se os seus tornozelos estão } \\
\text { inchados? }\end{array}$ & 409 & $2,95(1,2)$ & 3,00 & $1,00-4,00$ & \\
\hline $\begin{array}{l}\text { 3.Tenta evitar ficar doente (por exemplo: } \\
\text { vacinar-se contra a gripe, evitar contato } \\
\text { com pessoas doentes)? }\end{array}$ & 409 & $2,50(1,3)$ & 3,00 & $1,00-4,00$ & \\
\hline 4.Realiza alguma atividade física? & 409 & $1,55(0,9)$ & 1,00 & $1,00-4,00$ & \\
\hline $\begin{array}{l}\text { 5.É assíduo nas consultas com médico ou } \\
\text { enfermeiro? }\end{array}$ & 409 & $3,40(1,0)$ & 4,00 & $1,00-4,00$ & \\
\hline 6.Ingere uma dieta com pouco sal? & 409 & $3,17(1,0)$ & 4,00 & $1,00-4,00$ & \\
\hline 7.Exercita-se por 30 minutos? & 409 & $1,60(1,0)$ & 1,00 & $1,00-4,00$ & \\
\hline $\begin{array}{l}\text { 8.Esquece-se ou deixa de tomar algum de } \\
\text { seus medicamentos? }\end{array}$ & 409 & $3,38(0,8)$ & 4,00 & $1,00-4,00$ & \\
\hline $\begin{array}{l}\text { 9.Solicita alimentos com pouco sal quando } \\
\text { come fora ou visita alguém? }\end{array}$ & 409 & $1,49(0,9)$ & 1,00 & $1,00-4,00$ & \\
\hline $\begin{array}{l}\text { 10.Usa um sistema (caixa de comprimido, } \\
\text { lembretes) para ajudá-lo a lembrar de seus } \\
\text { medicamentos? }\end{array}$ & 409 & $2,52(1,4)$ & 3,00 & $1,00-4,00$ & \\
\hline $\begin{array}{l}\text { Escore total - Manutenção do } \\
\text { autocuidado }\end{array}$ & 409 & $49,28(14,2)$ & 49,99 & $20,00-93,32$ & 0,41 \\
\hline \multicolumn{6}{|l|}{ Manejo do autocuidado* } \\
\hline $\begin{array}{l}\text { 11.Com que rapidez você os reconheceu } \\
\text { como um sintoma de insuficiência } \\
\text { cardíaca? }\end{array}$ & 294 & $1,76(1,6)$ & 2,00 & $0,00-4,00$ & \\
\hline 12.Reduzir o sal na sua dieta & 294 & $2,58(1,1)$ & 3,00 & $1,00-4,00$ & \\
\hline 13.Reduzir a ingestão de líquidos & 294 & $2,42(1,1)$ & 3,00 & $1,00-4,00$ & \\
\hline 14.Ingerir um diurético a mais & 294 & $1,55(0,9)$ & 1,00 & $1,00-4,00$ & \\
\hline 15.Contatar seu médico ou enfermeiro & 294 & $2,67(1,2)$ & 3,00 & $1,00-4,00$ & \\
\hline
\end{tabular}




\begin{tabular}{|c|c|c|c|c|c|}
\hline Itens SCHFI & $\mathbf{N}$ & Média (dp) & Mediana & Min./Max. & Alfa Cronbach \\
\hline $\begin{array}{l}\text { para orientação } \\
\text { 16.Pense em um dos recursos acima que } \\
\text { você tentou na última vez em que teve } \\
\text { dificuldade para respirar ou tornozelos } \\
\text { inchados, você tem certeza de que este } \\
\text { recurso o ajudou? }\end{array}$ & 294 & $1,19(1,5)$ & 0,00 & $0,00-4,00$ & \\
\hline $\begin{array}{l}\text { Escore total self - Manejo do } \\
\text { autocuidado }\end{array}$ & 294 & $\begin{array}{l}40,86 \\
(20,6)\end{array}$ & 40,00 & $0,00-95,00$ & 0,50 \\
\hline Confiança no autocuidado & & & & & \\
\hline $\begin{array}{l}\text { 17.Estar livre dos sintomas de insuficiência } \\
\text { cardíaca? }\end{array}$ & 409 & $2,38(0,9)$ & 3,00 & $1,00-4,00$ & \\
\hline 18.Seguir o tratamento recomendado? & 409 & $3,01(0,7)$ & 3,00 & $1,00-4,00$ & \\
\hline $\begin{array}{l}\text { 19.Avaliar a importância de seus } \\
\text { sintomas? }\end{array}$ & 409 & $2,69(0,9)$ & 3,00 & $1,00-4,00$ & \\
\hline $\begin{array}{l}\text { 20.Reconhecer alterações na saúde, caso } \\
\text { elas ocorram? }\end{array}$ & 409 & $2,74(0,8)$ & 3,00 & $1,00-4,00$ & \\
\hline $\begin{array}{l}\text { 21.Fazer algo que possa aliviar seus } \\
\text { sintomas? }\end{array}$ & 409 & $2,48(0,9)$ & 3,00 & $1,00-4,00$ & \\
\hline 22.Avaliar se um medicamento funciona? & 409 & $2,83(0,8)$ & 3,00 & $1,00-4,00$ & \\
\hline Escore total - Confiança no autocuidado & 409 & $56,50(21,6)$ & 61,16 & $0,00-100,00$ & 0,84 \\
\hline
\end{tabular}

* Os dados da subescala Manejo do Autocuidado são menores porque a escala é administrada apenas aos pacientes que apresentam sintomas de insuficiência cardíaca no último mês. 


\subsection{ASSOCIAÇÃO DAS VARIÁVEIS SOCIODEMOGRÁFICAS E CLÍNICAS COM QVRS}

A Tabela 15 apresenta a análise da associação da QV e as variáveis sóciodemográficas. Observa-se que apenas o gênero foi estatisticamente associado à má qualidade de vida; houve maior proporção de mulheres com má qualidade de vida $(65,4 \% \times 55,8 \% p=0,048)$. As demais variáveis não foram significativas ao nível de 0,05. Idade, tempo de estudo e situação trabalhista foram selecionadas para a análise múltipla porque $p<0,20$.

Tabela 15 - Frequência de pacientes, segundo qualidade de vida relacionada à saúde e variáveis sociodemográficas $(N=409)$. São Paulo, 2014

\begin{tabular}{|c|c|c|c|c|c|}
\hline \multirow[b]{2}{*}{ Variável } & \multirow[b]{2}{*}{ Categoria } & \multicolumn{2}{|c|}{ Qualidade de vida } & \multirow[b]{2}{*}{$\begin{array}{l}\text { Total } \\
\text { № (\%) }\end{array}$} & \multirow[b]{2}{*}{$\mathbf{p}^{*}$} \\
\hline & & $\begin{array}{c}\text { Boa } \\
\text { № (\%) }\end{array}$ & $\begin{array}{c}\text { Moderada } \\
\text { / Ruim } \\
\text { № (\%) }\end{array}$ & & \\
\hline \multirow{2}{*}{ Gênero } & Masculino & $99(44,2)$ & $125(55,8)$ & $224(100,0)$ & 0,048 \\
\hline & Feminino & $64(34,6)$ & $121(65,4)$ & $185(100,0)$ & \\
\hline \multirow{2}{*}{ Idade } & $<60$ anos & $76(36,0)$ & $135(64,0)$ & $211(100,0)$ & 0,102 \\
\hline & $\geq 60$ anos & $87(43,9)$ & $111(56,1)$ & $198(100,0)$ & \\
\hline \multirow{2}{*}{ Etnia } & Branco & $98(39,0)$ & $153(61,0)$ & $251(100,0)$ & 0,673 \\
\hline & Não Branco & $65(41,1)$ & $93(58,9)$ & $158(100,0)$ & \\
\hline \multirow{2}{*}{$\begin{array}{c}\text { Convivência } \\
\text { Marital }\end{array}$} & $\operatorname{Sim}$ & $102(38,6)$ & $162(61,4)$ & $264(100,0$ & 0,498 \\
\hline & Não & $61(42,1)$ & $84(57,9)$ & $145(100,0)$ & \\
\hline \multirow{4}{*}{$\begin{array}{l}\text { Tempo de } \\
\text { Estudo }\end{array}$} & Analfabetos & $9(23,7)$ & $29(76,3)$ & $38(100,0)$ & 0,086 \\
\hline & 1-4 anos & $69(45,4)$ & $83(54,6)$ & $152(100,0)$ & \\
\hline & $5-8$ anos & $50(40,7)$ & $73(59,3)$ & $123(100,0)$ & \\
\hline & $\geq 9$ anos & $35(36,5)$ & $61(63,5)$ & $96(100,0)$ & \\
\hline \multirow{2}{*}{$\begin{array}{l}\text { Situação } \\
\text { Trabalhista }\end{array}$} & Ativa & $46(48,4)$ & $49(51,6)$ & $95(100,0)$ & 0,052 \\
\hline & Não Ativo & $117(37,3)$ & $197(62,7)$ & $314(100,0)$ & \\
\hline
\end{tabular}


*p: teste de associação pelo Qui-quadrado

A Tabela 16 apresenta a análise da associação da QVRS e as variáveis clínicas. Observa-se que quase todas foram estatisticamente associadas à má qualidade de vida. Verifica-se que quanto maior a classe funcional, maior a proporção de pacientes com má QVRS ( $p<0,001)$. Pacientes que utilizavam um maior número de medicamentos tinham pior QVRS ( $p<0,001)$, bem como aqueles que tomavam medicamentos acima de 9 vezes ao dia ( $p$,002). Quem teve dispneia ( $p<0,001)$, ou nocturia $(63,9 \% \times 42,3 \% p<0,001)$ tinha pior QVRS. Dentre os pacientes com desempenho cognitivo alto houve maior proporção de QVRS ruim ( $p=0,008)$. Houve associação significativa com fadiga (72,2\% x 12,2\%; $p<0,001)$ e com fadiga ao esforço $(75,3 \% \times 11,3 \%$; $p<0,001)$ em que a maior proporção de QVRS ruim foi entre os pacientes com maiores escores. O paciente com sintomas depressivos também apresentou maior proporção de QVRS ruim $(84,3 \% \times 14,8 \% ; p<0,001)$. As variáveis etiologia da IC e tipo de acompanhamento e atividade física ocupacional não foram significativas (ao nível de 0,05), mas foram selecionadas para a análise múltipla para ajuste do modelo. 
Tabela 16 - Frequência de pacientes, segundo Qualidade de vida relacionada à saúde e variáveis clínicas $(\mathrm{N}=409)$. São Paulo 2014

\begin{tabular}{|c|c|c|c|c|c|}
\hline \multirow[b]{2}{*}{ Variável } & \multirow[b]{2}{*}{ Categoria } & \multicolumn{2}{|c|}{ Qualidade de vida } & \multirow[b]{2}{*}{$\begin{array}{c}\text { Total } \\
\text { № (\%) }\end{array}$} & \multirow[b]{2}{*}{$p^{*}$} \\
\hline & & $\begin{array}{c}\text { Boa } \\
\text { № (\%) }\end{array}$ & $\begin{array}{l}\text { Moderada/ } \\
\text { Ruim } \\
\text { № (\%) } \\
\end{array}$ & & \\
\hline Etiologia da IC & $\begin{array}{l}\text { Isquêmica } \\
\text { Não isquêmica }\end{array}$ & $\begin{array}{c}14(30,4) \\
149(41,0)\end{array}$ & $\begin{array}{l}32(69,6) \\
214(59,0)\end{array}$ & $\begin{array}{l}46(100,0) \\
363(100,0)\end{array}$ & 0,166 \\
\hline $\begin{array}{l}\text { Quantidade de } \\
\text { medicamentos }\end{array}$ & $\begin{array}{l}1 \stackrel{\circ}{\circ}(0-4) \\
2^{\circ} \mathrm{T}(5-6) \\
3^{\circ} \div(7-13)\end{array}$ & $\begin{array}{l}70(50,7) \\
64(41,8) \\
28(24,8)\end{array}$ & $\begin{array}{l}68(49,3) \\
89(58,2) \\
85(75,2)\end{array}$ & $\begin{array}{l}138(100,0) \\
153(100,0) \\
113(100,0)\end{array}$ & $<0,001$ \\
\hline $\begin{array}{c}\text { Tomadas de } \\
\text { medicamentos } \\
\text { /dia }\end{array}$ & $\begin{array}{l}1 \stackrel{\circ}{\circ}(0-6) \\
2^{\circ} \mathrm{T}(7-8) \\
3^{\circ} \div(9-22)\end{array}$ & $\begin{array}{l}74(49,0) \\
45(42,9) \\
43(29,1)\end{array}$ & $\begin{array}{c}77(51,0) \\
60(57,1) \\
105(70,9)\end{array}$ & $\begin{array}{l}151(100,0) \\
105(100,0) \\
148(100,0)\end{array}$ & 0,002 \\
\hline $\begin{array}{c}\text { Tipo de } \\
\text { acompanhamento }\end{array}$ & $\begin{array}{l}\text { Médico } \\
\text { Médico e } \\
\text { enfermeiro }\end{array}$ & $\begin{array}{c}116(42,8) \\
47(34,1)\end{array}$ & $\begin{array}{c}155(57,20 \\
91(65,9)\end{array}$ & $\begin{array}{l}271(100,0) \\
138(100,0)\end{array}$ & 0,088 \\
\hline Classe Funcional & $\begin{array}{l}\text { I } \\
\text { II } \\
\text { III }\end{array}$ & $\begin{array}{l}72(67,9) \\
75(39,3) \\
16(14,3)\end{array}$ & $\begin{array}{c}34(32,1) \\
116(60,7) \\
96(85,7)\end{array}$ & $\begin{array}{l}106(100,0) \\
191(100,0) \\
112(100,0)\end{array}$ & $<0,001$ \\
\hline Fração Ejeção & $\begin{array}{l}1^{\text {a }} Q(0-29) \\
2^{a} Q(30-37) \\
3^{a} Q(38-47) \\
4^{a} Q \geq 48\end{array}$ & $\begin{array}{l}41(40,6) \\
35(38,9) \\
44(39,3) \\
43(41,0)\end{array}$ & $\begin{array}{l}60(59,4) \\
55(61,1) \\
68(60,7) \\
62(59,0)\end{array}$ & $\begin{array}{c}101(100,0) \\
90(100,0) \\
112(100,0) \\
105(100,0)\end{array}$ & 0,989 \\
\hline $\begin{array}{c}\text { Tempo de } \\
\text { experiência com a } \\
\text { doença (meses) }\end{array}$ & $\begin{array}{l}1^{\text {a }} Q(0-21) \\
2^{a} Q(22-45) \\
3^{a} Q(46-92) \\
4^{a} Q \geq 93\end{array}$ & $\begin{array}{l}41(40,2) \\
38(42,7) \\
39(33,9) \\
45(43,7)\end{array}$ & $\begin{array}{l}61(59,8) \\
51(57,3) \\
76(66,1) \\
58(56,3)\end{array}$ & $\begin{array}{c}102(100,0) \\
89(100,0) \\
115(100,0) \\
103(100,0)\end{array}$ & 0,452 \\
\hline $\begin{array}{c}\text { Índice } \\
\text { Comorbidade de } \\
\text { Charlson }\end{array}$ & $\begin{array}{l}\text { Baixo } \\
\text { Moderado } \\
\text { Elevado }\end{array}$ & $\begin{array}{l}25(38,5) \\
76(37,1) \\
62(44,6)\end{array}$ & $\begin{array}{c}40(61,5) \\
129(62,9) \\
77(55,4)\end{array}$ & $\begin{array}{l}65(100,0) \\
205(100,0) \\
139(100,0)\end{array}$ & 0,364 \\
\hline Tabagismo & $\begin{array}{l}\text { Sim } \\
\text { Não }\end{array}$ & $\begin{array}{c}15(34,1) \\
148(40,5)\end{array}$ & $\begin{array}{c}29(65,9) \\
217(59,5)\end{array}$ & $\begin{array}{c}44(100,0) \\
365(100,0)\end{array}$ & 0,409 \\
\hline Dispneia & $\begin{array}{l}\text { Sim } \\
\text { Não }\end{array}$ & $\begin{array}{c}110(32,3) \\
53(77,9)\end{array}$ & $\begin{array}{c}231(67,7) \\
15(22,1)\end{array}$ & $\begin{array}{c}341(100,0) \\
68(100,0)\end{array}$ & $<0,001$ \\
\hline Nocturia & $\begin{array}{l}\text { Sim } \\
\text { Não }\end{array}$ & $\begin{array}{c}122(36,1) \\
41(57,7)\end{array}$ & $\begin{array}{l}216(63,9) \\
30(42,3)\end{array}$ & $\begin{array}{c}338(100,0) \\
71(100,0)\end{array}$ & $<0,001$ \\
\hline $\begin{array}{c}\text { Comprometimento } \\
\text { Cognitivo }\end{array}$ & $\begin{array}{l}\text { Sim } \\
\text { Não }\end{array}$ & $\begin{array}{l}98(46,0) \\
65(33,2)\end{array}$ & $\begin{array}{l}115(54,0) \\
131(66,8)\end{array}$ & $\begin{array}{l}213(100,0) \\
196(100,0)\end{array}$ & 0,008 \\
\hline Fadiga & $\begin{array}{l}<14,5 \text { sem } \\
\text { fadiga } \\
\geq \quad 14,5 \text { com } \\
\text { fadiaa }\end{array}$ & $\begin{array}{l}72(87,8) \\
91(27,8)\end{array}$ & $\begin{array}{c}10(12,2) \\
236(72,2)\end{array}$ & $\begin{array}{l}82(100,0) \\
327(100,0)\end{array}$ & $<0,001$ \\
\hline Fadic & $<12,5 \mathrm{sem}$ & $86(88,7)$ & $11(11,3)$ & $97(100,0)$ & $<0,001$ \\
\hline
\end{tabular}




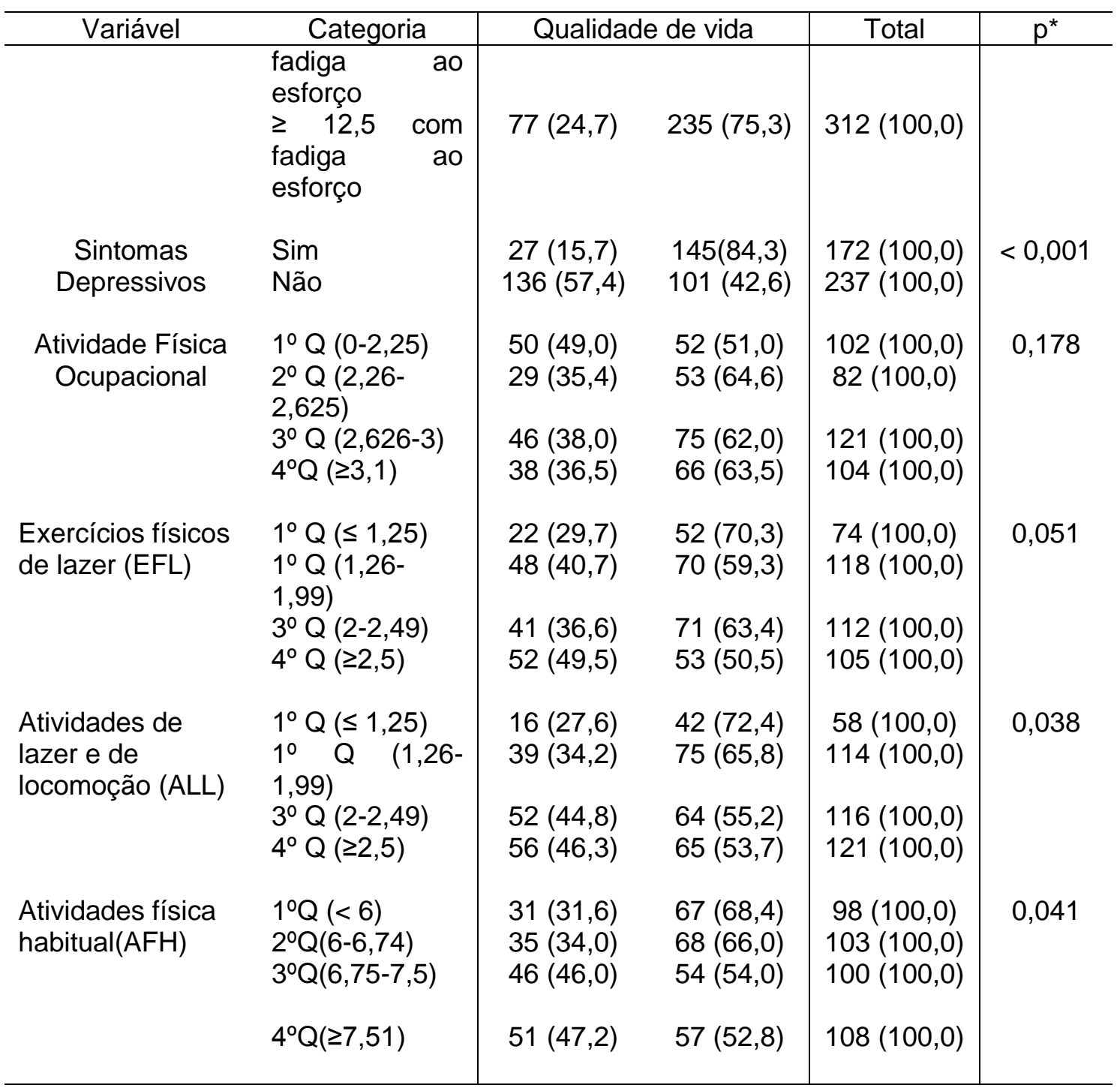

*p: teste de associação pelo Qui-quadrado

Houve associação estatisticamente significativa entre QVRS e padrão do sono (Tabela 17); maior proporção de pacientes com QVRS ruim foi observada entre os pacientes maus dormidores $(70,3 \times 36,6 \%$; $p<0,001)$. 
Tabela 17 - Frequência de pacientes, segundo Qualidade de vida relacionada à saúde e padrão do sono $(N=409)$, São Paulo 2014

\begin{tabular}{|c|c|c|c|c|c|}
\hline \multirow{2}{*}{ Variável } & \multirow{2}{*}{ Categoria } & \multicolumn{2}{|c|}{ Qualidade de vida } & \multirow{2}{*}{$\begin{array}{l}\text { Total } \\
\text { № (\%) }\end{array}$} & \\
\hline & & $\begin{array}{c}\text { Boa } \\
\text { № }(\%)\end{array}$ & $\begin{array}{c}\text { Moderada/ruim } \\
\text { № (\%) }\end{array}$ & & \\
\hline & Bom dormidor & $78(63,4)$ & $45(36,6)$ & $\begin{array}{c}123 \\
(100,0)\end{array}$ & $<0,001$ \\
\hline Padrão do sono & Mau dormidor & $85(29,7)$ & $201(70,3)$ & $\begin{array}{l}286 \\
(100,0)\end{array}$ & \\
\hline
\end{tabular}

${ }^{*}$ p: teste de associação pelo Qui-quadrado

Houve associação estatisticamente significativa entre QVRS e confiança no autocuidado (Tabela 18), maior proporção de pacientes com QVRS ruim foi observada entre os pacientes com inadequada autoconfiança no autocuidado (64,8 X 43,2\%; $p$ < 0,001). Manutenção do autocuidado não foi estatisticamente significante ao nível de 0,05, mas foi selecionada para a análise múltipla porque o teste de associação resultou em $\mathrm{p}<0,20$. 
Tabela 18 - Frequência de pacientes, segundo Qualidade de vida relacionada à saúde e comportamento de autocuidado ( $N$ = 409), São Paulo - 2014

\begin{tabular}{|c|c|c|c|c|c|}
\hline \multirow[b]{2}{*}{ Variável } & \multirow[b]{2}{*}{ Categoria } & \multicolumn{2}{|c|}{ Qualidade de vida } & \multirow{2}{*}{$\begin{array}{l}\text { Total } \\
\text { № (\%) }\end{array}$} & \multirow[b]{2}{*}{$\mathbf{p}^{*}$} \\
\hline & & $\begin{array}{c}\text { Boa } \\
\text { № (\%) }\end{array}$ & $\begin{array}{c}\text { Moderada/ruim } \\
\text { № (\%) }\end{array}$ & & \\
\hline \multirow{2}{*}{$\begin{array}{l}\text { Manutenção do } \\
\text { autocuidado }\end{array}$} & Adequado & $15(57,7)$ & $11(42,3)$ & $26(100,0)$ & 0,055 \\
\hline & Inadequado & $\begin{array}{c}148 \\
(38,6)\end{array}$ & $235(61,4)$ & $383(100,0)$ & \\
\hline \multirow{3}{*}{$\begin{array}{l}\text { Gerenciamento do } \\
\text { autocuidado** }\end{array}$} & Adequado & $8(26,7)$ & $22(73,3)$ & $30(100,0)$ & 0,537 \\
\hline & Inadequado & $85(32,2)$ & $179(67,8)$ & $264(100,0)$ & \\
\hline & Adequado & $50(56,8)$ & $38(43,2)$ & $88(100,0)$ & $<0,001$ \\
\hline $\begin{array}{l}\text { Confiança no } \\
\text { autocuidado }\end{array}$ & Inadequado & $\begin{array}{c}113 \\
(35,2)\end{array}$ & $208(64,8)$ & $321(100,0)$ & \\
\hline
\end{tabular}

*p: teste de associação pelo Qui-quadrado

** Amostra de 294 pacientes (pacientes sintomáticos, conforme orientação para o uso da escala)

A Tabela 19 apresenta os resultados da análise múltipla. Foram variáveis estatisticamente e independentemente associadas à qualidade de vida relacionada à saúde, ser mau dormidor ( $O R=2,5 ; p=0,003)$, ser da classe funcional III $(O R=3,7$; $p=0,002)$, ter fadiga presente $(O R=3,3 ; p=0,009)$ e fadiga ao esforço presente $(\mathrm{OR}=8,7 ; \mathrm{p}<0,001)$ e ter inadequada confiança no autocuidado $(\mathrm{OR}=2,5 ; \mathrm{p}=$ 0,009). A idade e gênero não tiveram associações estatisticamente significativas com as escalas de autocuidado, mas se optou por deixa-las no modelo para demonstrar isso (OR $=0,6 ; p=0,089$ e $O R=1,1 p=0,959$ respectivamente). 
Tabela 19 - Resultados da análise múltipla para fatores associados à má qualidade de vida reacionada à saúde, São Paulo - 2014

\begin{tabular}{|c|c|c|c|}
\hline Variável & Categoria & OR & $\mathbf{p}^{\star}$ \\
\hline \multirow{2}{*}{ Gênero } & Masculino & 1 & 0,959 \\
\hline & Feminino & 1,1 & \\
\hline \multirow{2}{*}{ Idade } & $<60$ anos & 1 & \\
\hline & $\geq 60$ anos & 0,6 & 0,089 \\
\hline \multirow[b]{2}{*}{ Confiança no autocuidado } & Adequado & 1 & \\
\hline & Inadequado & 2.5 & 0,009 \\
\hline \multirow{2}{*}{ Padrão sono } & Bom dormidor & 1 & \\
\hline & Mau dormidor & 2,5 & 0,003 \\
\hline \multirow{4}{*}{ Classe funcional NYHA } & 1 & 1 & \\
\hline & II & 1,6 & 0,147 \\
\hline & III & 3,7 & 0,002 \\
\hline & $1 \stackrel{\circ}{\top} \mathrm{T}(0-4)$ & 1,0 & \\
\hline \multirow[t]{2}{*}{ Quantidade de medicamentos } & 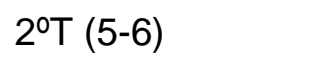 & 1,3 & 0,33 \\
\hline & $3^{\circ} \mathrm{T}(7-13)$ & 3,2 & $<0,001$ \\
\hline \multirow{2}{*}{ Fadiga ao esforço (DEFS) } & Normal & 1 & \\
\hline & Fadiga & 8,7 & $<0,001$ \\
\hline \multirow{2}{*}{ Fadiga (DUFS) } & Normal & 1 & \\
\hline & Fadiga & 3,3 & 0,009 \\
\hline
\end{tabular}

*Teste de Hosmer-Lemeshow 
Discussão 


\section{DISCUSSÃO}

Os resultados serão discutidos na sequência da sua apresentação, de acordo com os objetivos propostos: descrição das características sociodemográficas e clínicas, descrição do o padrão do sono, autocuidado e qualidade de vida relacionada à saúde e análise dos fatores associados à QVRS, identificados na regressão logística binária.

\subsection{VARIÁVEIS SOCIODEMOGRÁFICAS}

Participaram do estudo 409 pacientes com IC em tratamento ambulatorial para IC. Houve predominância do sexo masculino (54\%; Tabela 1), semelhante ao encontrado em estudos recentes que envolveram pacientes com IC (Vellone et al., 2013; Steele and Steele ,2013; Cocchieri et al., 2014; Siabani et al., 2014루;).

Observa-se que a idade média da amostra deste estudo (57,9 DP 11,6 anos; Tabela 1) é inferior à de amostras de grandes estudos prognósticos como 0 ADHERE (72,0) (Adams et al., 2005) e OPTIMIZE-HF $(73,0)$ (Gheorghiade et al., 2006), mas aproxima-se a de amostras de estudos recentes, nacionais e internacionais, com pacientes ambulatoriais com IC, em que a média de idade variou de 55,0 a 66,0 anos (Carson et al., 2009; Cruz et al. 2010 ,Santos J. et al., 2009; Nogueira et al., 2010; Redeker et al., 2010; Dickson et al., 2011; Santos M. et al., 2011; Seto et al., 2012; Avila et al., 2013; Cené et al., 2013; Steele and Steele, 2013; Siabani et al., 2014루; Lee et al., 2014루; Chu et al., 2014).

A escolaridade da amostra deste estudo foi relativamente baixa, caracterizada por tempo médio de estudo de 6,1 (DP 4,1) anos (Tabela 1), resultados semelhantes a outros estudos com amostra de brasileiros com IC (6,1 (Santos M. et al., 2011); 5,0 (Avila et al., 2013). Também foi encontrada baixa escolaridade em amostra de estudo com tailandeses (Lee et al., 2009; Shao et al., 2013르) e italianos (Vellone et al., 2013). Já em amostras de pesquisas realizadas nos Estados Unidos da América, os pacientes apresentavam melhor nível educacional (Pressler et al., 2013; Welsh et al., 2013). 
A etnia branca foi mais frequente $(60,6 \%$, Tabela 1$)$, o que é semelhante ao encontrado em outros estudos nacionais e estrangeiros. (Dickson et al., 2011; Aliti et al., 2011; Seto et al., 2012; Pressler et al., 2013; Welsh et al., 2013; Heisler et al., 2014).

No presente estudo, a convivência marital foi predominante, semelhante ao que é encontrado em outros estudos nacionais e estrangeiros (Oliveira et al., 2011;

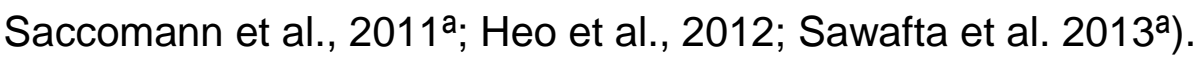

\subsection{VARIÁVEIS CLÍNICAS}

Cardiomiopatia isquêmica teve baixa frequência nessa população (11,2\%, Tabela 2), semelhante a outro estudo com amostra de pacientes brasileiros (Nogueira et al., 2010), mas diferente de outros estudos em que a frequência variou de 30 a 75 (Riegel et al., 2011; Tung et al., 2012; Avila et al., 2013; Lee et al., 2014c). Dentre as cardiomiopatias não isquêmicas, cardiomiopatia dilatada (43,9\%) apresentou maior frequência. No estudo realizado por Nogueira et al (2010), a cardiomiopatia chagásica foi mais prevalente (41\%).

Em relação a comorbidade, em nossa amostra houve maior frequência de hipertensão $(67,2 \%)$ e diabetes $(26,2 \%)$ (Tabela 3), semelhante ao descrito em outros estudos. (Nogueira et al., 2010; Naveiro-Rilo et al., 2014; Heisler et al., 2014; Bento and Brofman 2009; Siabani et al., 2014b).

Aplicando o Índice de Comorbidade de Charlson, ajustado pela idade (Chaudhry et al., 2005), a média da nossa amostra foi de 3,9, o que classifica o paciente em risco moderado de mortalidade em um ano, esse resultado foi superior ao encontrado em outros estudos(Pressler et al., 2011, 2013; Lee et al., 2013).

Classe funcional II e III foram as mais frequentes $(46,7 \%$ e $27,4 \%$, respectivamente - Tabela 2 ), resultados semelhantes aos de outros estudos com amostra ambulatorial de pacientes com IC. (Santos et al., 2011; Shao et al., 2013á; Santos M.et al., 2011; Dudas et al., 2013; Shao et al., 2013b). Vale ressaltar que no 
presente estudo não foram incluídos pacientes com classe funcional IV, visto que o interesse eram pacientes ambulatoriais (mais compensados clinicamente) e acreditávamos que pacientes com classe funcional IV (mais descompensados clinicamente) estariam internados ou em atendimento no serviço de emergência.

A média de fração de ejeção ventricular esquerda dos pacientes deste estudo foi de 40,2\% (Tabela 2), semelhante ao descrito em outros estudos (Santos J. et al. (2009), Welsh et al. (2013) e Alosco et al. (2013) e superior ao encontrado nos estudos de (Dickson et al. (2008), Castro 2010, Velone et al.(2013), Lee et al (2014a), sendo que neles houve predomínio de pacientes com maior estadiamento da IC (CFIII/IV).

O tempo de experiência com a doença, considerado fator importante para 0 autocuidado na IC (Riegel et al., 2004), teve uma grande variação (1-480 meses), sendo a mediana 65 meses (Tabela 2), o que corresponde a 5 anos, semelhante a outros estudos. (Dickson et al., 2011; Feijó and Ávila, 2012; Knafl and Riegel ,2014).

O acompanhamento multidisciplinar é importante para o tratamento adequado dos pacientes com IC e o enfermeiro tem papel fundamental nesse contexto. Segundo a III Diretriz Brasileira de Insuficiência Cardíaca o enfermeiro faz parte da base profissional de clínica de IC, com objetivo de proporcionar ações educativas aos pacientes e seus familiares, fazer detecção precoce de descompensação clínica, implementar programas de aderência e monitoramento dos sintomas e respostas ao tratamento (Bocchi et al., 2009).

$\mathrm{Na}$ amostra estudada, apenas 33,7\% dos pacientes foram atendidos por enfermeiros (Tabela 2). O número insuficiente desse profissional no local de coleta deste estudo influenciou nesse resultado. Atualmente, apenas duas enfermeiras realizam consulta de forma sistematizada para os pacientes. Como o volume de atendimento nesse ambulatório é muito grande, as enfermeiras priorizam o atendimento para aqueles pacientes que apresentam dificuldade de adesão ao tratamento medicamentoso e não medicamentoso, bem como aqueles que necessitam de otimização terapêutica. Estudos com amostras semelhantes apontam que pacientes que são atendidos por enfermeiros apresentaram diminuição na frequência de hospitalização e atendimento em serviços de emergência quando 
comparados aos pacientes que recebem acompanhamento apenas pelo médico (Agvall et al., 2013; Bento and Brofman, 2009). 
A terapia farmacológica utilizada pelos pacientes deste estudo está em consonância com as diretrizes de prática clínica para tratamento da IC. A maioria dos pacientes faziam uso de betabloqueadores $(84,1 \%)$, IECA $(48,9 \%)$ e Diuréticos $(75,1 \%)$ (Tabela 4) dados que corroboram com a literatura (Masoudi et al., 2005; Bolmsjö et al., 2013).

A terapia farmacológica para tratamento da IC tem se tornado cada vez mais complexa, com crescente número de medicamentos prescritos e esquemas de dosagem diária nem sempre simples. Terapia farmacológica da IC associada às múltiplas comorbidades que esses pacientes apresentam podem levar o indivíduo a fazer uso de mais de dez doses diárias de medicamentos. (Masoudi et al. 2005; Marti et al.,2013).

No presente estudo, os pacientes avaliados faziam em média ou uso de 5,3 tipos de medicamentos, com média de 7,6 tomadas de medicamentos por dia, chegando até 22 tomadas/dia. Esses resultados apenas enfatizam os dados de literatura que reforçam a necessidade de atuação multidisciplinar, com objetivo de direcionar o paciente para adequado manejo no autocuidado, sendo a adesão ao tratamento farmacológico uma variável importante nesse processo. Uso de fármacos variados podem ocasionar efeitos indesejáveis, cabendo aos profissionais ações capazes de prevenir esses efeitos.

Pacientes com IC sofrem vários sintomas físicos que frequentemente resultam em redução da capacidade funcional e piora na qualidade de vida, como a dispneia e fadiga e intolerância a atividade. Esses sintomas tiveram alta frequência nessa amostra, corroborando dados da literatura (Fini, 2009; Aliti et al., 2011; Santos M.et al., 2011; Darling et al., 2013; Theander et al., 2014).

Deficit cognitivo em indivíduos com IC tem sido bem documentado, com uma prevalência que varia de 25\%-80\% (Pressler, 2008; Alosco et al., 2013; Cameron et al., 2013). No entanto, as razões para essas frequências não são bem compreendidas, sendo as principais hipóteses a hipoperfusão cerebral e microêmbolos cardiogênicos que podem afetar a função cognitiva. (Vogels et al., 2007b; Torre, 2012; Dardiotis et al., 2012). Para a avaliação cognitiva foi utilizado o 
Mini Exame do Estado Mental (MEEM) por ser uma escala muito utilizada para mapear o deficit cognitivo, por ser de fácil aplicação, baixo custo e possuir sensibilidade e especificidade adequada, adotando-se o ponto de corte estratificado pelo nível de escolaridade (Brucki et al., 2003). Na prática clínica, o ponto de corte mais utilizado é o 24, apresentando alta sensibilidade e especificidade para a detecção de comprometimento cognitivo (Davis and Allen, 2013). Entretanto, diversos estudos trazem que o MEEM é influenciado pelo nível de escolaridade do indivíduo. No Brasil, outros pontos de corte têm sido recomendados, mas não existe consenso quanto ao melhor ponto de corte para população com escolaridade mais baixa. (Bertolucci et al., 1994; Brucki et al., 2003; Lourenço and Veras, 2006; Laks et al., 2007; Machado et al., 2011).

A média do escore do MEEM na amostra avaliada foi de 24,3 ( $\mathrm{pd}=4,1$ Tabela 5). Este dado difere do encontrado em estudos internacionais, que descreveram médias maiores. No estudo de Alosco et al(2013) a média do MEEM foi de 27,6 pontos, no descrito por Pressler et al. (2011) 28.2pontos; Feola et al. (2013) 27,3 pontos; Razali et al. (2014) 26.8 pontos e Cameron et al. (2013) 28,0 pontos. Porém os resultados do presente estudo se assemelha ao descrito em amostra de brasileiros (Jesus et al., 2006; Dias et al., 2011). Esta diferença pode estar relacionada ao ponto de corte utilizado nos respectivos estudos e nível de escolaridade mais elevado. A idade tem sido bem descrita como preditivo de prejuízo cognitivo, sendo que quanto mais idoso, maior a prevalência de declínio cognitivo (Dodson et al., 2013).

Na população desse estudo, a idade média foi 58 anos. Utilizando o ponto de corte por nível de escolaridade, 52,1\% dos pacientes apresentaram declínio cognitivo. Considerando as altas taxas de prevalência de deficiências cognitivas, a triagem para rastreio de comprometimento cognitivo em pacientes com IC deve tornar-se prática rotineira, com objetivo criar estratégia para o manejo da doença conforme o perfil do paciente, visto que o tratamento farmacológico e não farmacológico da IC é complexo, exigindo habilidades dependentes da cognição. $O$ gerenciamento do autocuidado envolve o reconhecimento dos sinais e sintomas, 0 julgamento se esses são relevantes ou não, a definição de uma ação em resposta a esses sinais e sintomas e a avaliação da efetividade dessas ações (Riegel et al., 2011). As decisões de autocuidado exigem processos cognitivos ou mentais usados 
para adquirir conhecimento, bem como compreensão, incluindo pensar, saber, lembrar, julgar e resolver os problemas que são extremamente importantes para o tratamento da IC; declínio cognitivo está associado ao autocuidado inadequado, aumento de hospitalização, diminuição capacidade funcional e má QVRS (Cameron et al., 2010; Pressler et al., 2010a; Alosco et al., 2013; Dodson et al. 2013).

Sintomas depressivos são comuns na insuficiência cardíaca com prevalência que varia de $9 \%$ a $60 \%$ nos estudos (referenciar). Depressão e sintomas depressivos cursam com altas taxas de morbidade, mortalidade na IC. (Adams et al. 2005; Rutledge et al., 2006; Lesman-Leegte et al., 2009b; Kato et al., 2011; Newhouse and Jiang, 2014). Em meta-análise realizada 2006 por Rutledge et al.(2006), os resultados demonstraram que pacientes com IC que apresentam sintomas depressivos são mais propensos a morrer ou experimentar um evento cardíaco em comparação com pacientes com IC sem sintomas depressivos. Neste estudo, conforme apresentado em resultados, a prevalência de sintomas depressivos avaliados por meio do CES-D, foi de $42 \%$. Esse resultado é superior ao encontrado em um estudo realizado por Lesman-Leegte et al. (2009) com 781 pacientes idosos com IC hospitalizados e 781 idosos sem IC, moradores de uma comunidade, que utilizou o CE S-D- (adotando o mesmo ponto de corte do nosso estudo) em que a prevalência de sintomas depressivos foi de $39 \%$ nos pacientes com IC e $21 \%$ idosos, o escore médio nos pacientes com IC foi de 15 (dp = 10) pontos e nos idosos sem IC foi $10(\mathrm{dp}=9)$ pontos.

Estudo realizado por van den Broek et al (2011), também utilizando o CES-D, em pacientes com IC, a prevalência de sintomas depressivos foi de $36 \%$ e nos pacientes sem IC foi de $20 \%$. As características clínicas da população desses estudo podem ter contribuído para as diferenças com os nossos resultados. No primeiro estudo, os pacientes com IC estavam hospitalizados, o que pode refletir em pior estado de saúde e no segundo estudo, a população era mais idosa.

Qualidade do sono entre pacientes com IC tem sido frequentemente descrito na literatura, utilizando-se tantas medidas objetivas, como polissonografia (vista como o padrão ouro, que reconhece o sono normal e alterado), como também medidas subjetivas. Dentre as medidas subjetivas, existem os testes e questionários de qualidade do sono, como o índice de qualidade de sono Pittsburgh para o qual 
existe descrição de sensibilidade de $89,6 \%$ e especificidade de $86,5 \%$ para a identificação de casos com distúrbio do sono (Buysse et al., 1989a)

Nesse estudo, a análise da consistência interna entre os componentes do PSQI mostrou um valor de 0,68 para o coeficiente alfa de Chronbach, indicando aceitável consistência interna do instrumento nessa amostra. Com a análise dos escores do PSQI, notou-se que a maior parte dos pacientes com IC apresentavam qualidade do sono ruim (68,9\%), sendo classificados como maus dormidores, cujo escore médio foi de 7,8 ( $\mathrm{dp}=3,7)$. Em estudo realizado com 400 pacientes ambulatoriais (Santos M. et al., 2011), com características semelhantes às características da amostra do presente estudo, também foi evidenciada alta prevalência de maus dormidores (68,5\%), com escore médio de $8,7 \quad(\mathrm{dp}=4,4)$ pontos.

Os distúrbios do sono são frequentes nessa população, com taxas que variam de 35\% a 76\% (Casida et al., 2011; Santos M. et al., 2011; Strueber et al., 2011) e geralmente estão associados à gravidade da doença, nocturia, desconforto respiratório, dificuldade para adormecer, manter o sono ou acordar muito cedo. (Redeker, 2008; Wang et al., 2010; Santos M. et al. 2011). Nosso estudo não avaliou associação do sono com outras variáveis descritas acima, mas nos itens da escala de Pittsburgh, a frequência desses sintomas (3 vezes ou mais na semana) foram elevadas (Tabela 11). A terapêutica medicamentosa de que os pacientes faziam uso também pode estar associada à má qualidade de sono, principalmente os diuréticos (Pagel, 2005; Chen et al., 2009; Riegel and Weaver 2009; Herrscher et al., 2014), visto que podem favorecer a nocturia.

Nos casos em que o distúrbio do sono é de origem respiratória, o que não foi avaliado no presente estudo, a hipoxemia tem sido apontada como mecanismo potencial também para a alteração da função cognitiva outra variável com frequência relevante entre pacientes com IC (Vogels et al., 2007b). Vale ressaltar que em nosso estudo, mais da metade dos pacientes apresentaram declínio cognitivo. Um aspecto importante para o cuidado do paciente com IC refere-se ao possível impacto negativo dos distúrbios do sono sobre o funcionamento das práticas de autocuidado devido a prejuízos na tomada de decisões (Dickson et al., 2007; Redeker 2008; Riegel and Weaver, 2009; Riegel and Weaver, 2009). 
O componente do sono com maior frequência de resposta (três vezes ou mais durante a semana) foi o transtorno do sono (Tabela 11) que teve importante contribuição da fragmentação do sono, visto que $62,3 \%$ dos pacientes responderam que acordaram no meio da noite ou de manhã, antes do horário habitual de despertar e $70,4 \%$ responderam que precisavam levantar para ir ao banheiro (Tabela 11).

Embora a grande maioria dos pacientes apresentassem má qualidade do sono, apenas $3,2 \%$ faziam uso de algum tipo de medicamento para melhorar o sono. No entanto, esse resultado deve ser interpretado com cautela porque os participantes deste estudo compuseram o grupo de pacientes elegíveis para um ensaio clínico para testar intervenções para o sono. Alguns pacientes que informaram usar medicamentos para o sono foram considerados inelegíveis e não foram incluídos na avaliação da linha de base.

Outro dado que chamou atenção foi o fato do paciente levar 300 minutos para adormecer. Esse paciente, em especial, referiu que ia deitar por volta das $20 \mathrm{~h} \mathrm{e}$ levantava-se às $6 \mathrm{~h}$, referindo ter apenas 3 horas de sono. Também importante salientar que o paciente apresentava constante fragmentação do sono, avaliada pelos relatos de ocorrência de 3 vezes ou mais por semana (pontuação máxima na escala) de necessidade de levantar para ir ao banheiro e de não conseguir respirar confortavelmente, mas, mesmo assim, relatou que sua qualidade do sono era boa.

Apenas um paciente referiu levar 5 horas para adormecer, no entanto, 23 pacientes referiram demorar duas horas ou mais para adormecer, o que reforça a necessidade de intervenções farmacológicas e não farmacológicas para essa população.

Neste estudo as médias dos escores obtidos nas escalas de manutenção, gestão e confiança no autocuidado da SCHFI versão 6.2 foram todos abaixo de 70 pontos (49,2, 40,8 e 49,2, respectivamente) que é o limite mínimo de escores indicativos de autocuidado adequado. Esses resultados são semelhantes aos de estudo com amostra de brasileiros (Avila et al., 2013) e de outras nacionalidades (Lee et al., 2009; Tung et al. 2013; Dennison et al.,2011; Dickson et al., 2014; Cocchieri et al., 2014). Esse resultado pode estar associado ao baixo nível de 
escolaridade da amostra avaliada e o fato de quase metade dos pacientes não apresentarem sintomas de descompensação (falta de ar e inchaço) no mês anterior à aplicação do instrumento. Segundo Rockwell and Riegel (2001), maior escolaridade e maior frequência e intensidade dos sintomas são preditores independentes para o autocuidado adequado.

Dos 409 pacientes deste estudo, apenas 6,4\% apresentaram autocuidado adequado na subescala manutenção do autocuidado e 21,5\% na subescala confiança no autocuidado; dos 294 pacientes que tinham apresentado sintomas no mês anterior à avaliação, 10,2\% apresentaram autocuidado adequado na subescala manejo do autocuidado. Essas frequências são inferiores às observadas em outros estudos, nos quais obtiveram proporção de 17,5\% a 65\%( Lee et al., 2009; Riegel et al. 2009a ; Cameron et al., 2010; Cocchieri et al., 2014).

Avaliando a subescala manutenção do autocuidado, cujo conteúdo trata de comportamentos para manter a estabilidade fisiológica (Riegel et al. 2009), os itens com menor pontuação foram os relacionados à atividade física (Realiza alguma atividade física e Exercita-se por $30 \mathrm{~min}$ ) e restrição de ingestão de sódio quando se alimenta fora da própria residência (Solicita alimentos com pouco sal quando come fora ou visita alguém?). Esses resultados são semelhantes aos de outros estudos, evidenciando que o baixo nível de atividade física e o consumo excessivo de sódio são comuns entre os pacientes com IC, apesar das possíveis diferenças culturais. (Britz and Dunn, 2010; Tung et al., 2012; Cocchieri et al., 2014; Siabani et al., 2014c). Embora estudos apontem os benefícios da atividade física na IC, os resultados deste estudo sugerem que os pacientes apresentam relutância em realizá-la. Muito provavelmente os fatores que contribuem para atividade física limitada são a fadiga e intolerância à atividade, respostas frequentes na IC.

A maioria dos pacientes deste estudo relatou seguir restrição ao sódio e que as suas refeições eram preparadas em suas próprias residências, mas que apresentavam dificuldade para seguir a restrição quando realizavam refeições fora de casa porque que não se sentiam confortáveis em solicitar alimentos com pouco sal quando visitavam outras pessoas. 
$\mathrm{Na}$ escala Manejo do autocuidado, que trata das respostas dos pacientes aos sintomas quando eles ocorrem, a proporção de pacientes com autocuidado adequado $(10,2 \%)$ foi superior a encontrada em amostra de pacientes tailandeses $(5,0 \%)$ (Lee et al., 2009) , mas inferior a encontrada em amostra de australianos $(12,0 \%)$ (Cameron et al.,), de italianos $(24,4 \%)$ (Cocchieri et al., 2014), de canadenses $(21,0 \%)$ (Harkness et al., 2014) e de chineses (34,9\%) (Tung et al., 2012).

O item Ingerir um diurético a mais teve um dos menores escores na escala de Manejo do autocuidado, o que pode ter contribuído para que o escore médio nessa escala tenha ficado muito abaixo do adequado, assim como o observado em outros estudos (Tung et al., 2012; Avila et al., 2013; Cocchieri et al., 2014). No ambulatório onde foi realizada esta pesquisa, assim como em outros países, ensinar sobre o uso de diurético extra não é uma prática rotineira (Tung et al., 2012; Cocchieri et al., 2014).

A rapidez com que o paciente reconhece o sintoma de IC é outro resultado deste estudo que merece destaque. O escore médio das respostas a esse item foi 1,76 ( $\mathrm{dp}=1,64$ - Tabela 14) o que é uma média baixa porque a variação possível do escore é de 0 a 4 , onde zero corresponde a "não reconheci" e 4 a "reconheci imediatamente". Esse resultado foi semelhante ao de estudo com amostra de pacientes italianos (Cocchieri et al., 2014) e sugere que os pacientes estavam pouco preparados para o autocuidado, considerando que o reconhecimento dos sintomas é o primeiro passo para a implementação de medidas para o adequado manejo dos sintomas da doença.

A proporção de pacientes com adequada Confiança no autocuidado (21,5\%) foi semelhante ao de estudos realizados em outros países: Itália $(21,2 \%)$ (Cocchieri et al., 2014) e Canadá (22,0\%) (Harkness et al., 2014). O item referente ao grau de confiança do paciente de que o que ele fazia poderia deixá-lo "... livre dos sintomas de insuficiência cardíaca?" foi o item com média de escore mais baixa, também evidenciado em outros estudos (Cocchieri et al., 2014). Se pacientes com IC não são preparados para monitorar seus sintomas de forma que reconheçam precocemente as alterações precoces, dificilmente terão confiança em sua capacidade de lidar com a doença. A confiança no autocuidado requer habilidades cognitivas que impactam 
diretamente no processo de tomada de decisão terapêutica e no desempenho do autocuidado do paciente (Vogels et al., 2007a). Vale ressaltar que neste estudo quase metade dos pacientes tinham comprometimento cognitivo.

Acredita-se que a confiança no autocuidado tenha um efeito moderador no autocuidado em diferentes desfechos como, por exemplo, na adesão (Riegel and Dickson, 2008). A implementação de programas multidisciplinares com visitas domiciliares e seguimento telefônico para que o paciente reconheça e maneje adequadamente seus sintomas é uma combinação cuja eficácia para o autocuidado pode incluir o fortalecimento da confiança do paciente no domínio de sua condição de saúde (Rodríguez-Gázquez et al.,2012; Dickson et al., 2014). No entanto, é importante considerar que a escala de Confiança no Autocuidado pode sofrer influência da desejabilidade social, o que requer cautela na interpretação dos resultados relativos a essa escala (Riegel et al., 2009a).

A média do escore total do MLWHFQ foi 34,95 (dp = 25,3 ), dimensão física $15,89(\mathrm{dp}=12,3)$ e dimensão emocional $7,89(\mathrm{dp}=7,1)$, indicando que sintomas físicos apresentam maior impacto na QVRS. Os resultados do escore total neste estudo foram semelhantes aos de outros estudos com população brasileira $(37,5$; $d p=18,4$ ) (Santos J. et al. 2009) e com população espanhola $(31,7$ e $d p=21,3$ ) (Naveiro-Rilo et al., 2014) e (37,8 e dp = 21,1) (Garin et al., 2013), cujas características da população eram semelhantes a do presente estudo, mas inferiores aos descritos em outros estudos (Cruz et al., 2010 (57.5), Carson et al., 2009 (50.8), Maric et al.,2010 (44.0) ,Wu, 2009 (39,3), Linda, 2013 (63.4). Goodman, 2013 (57.2)), realizados com amostras com classe funcional mais elevada.

Os resultados do MLQWFQ mostraram que 60,2\% dos pacientes deste estudo tinham sua qualidade de vida moderada/ruim. A presença de múltiplas comorbidades, como HAS e diabetes, comuns entre os pacientes com IC, certamente contribuiu para esse resultado que é semelhante ao de outros estudos (Fotos et al., 2013; Heo et al., 2014).

Nas questões relativas à dimensão física, as que avaliam fadiga e dispneia, mostraram pontuação média mais alta que as demais, reiterando a importância da fadiga e dispneia na restrição da qualidade de vida desses pacientes. Esses 
resultados foram semelhantes aos encontrados em estudo com população tailandesa e estadunidense (Huang et al., 2010).

Em nosso estudo, as mulheres apresentaram pior qualidade de vida relacionada à saúde em relação aos homens $(p=0,048)$. Outros estudos também demonstraram que as mulheres relatam pior qualidade de vida (Luttik et al., 2006; Oliveira et al., 2011; Sawafta et al., 2013b). No entanto, num estudo com objetivo de testar associação entre QVRS e sexo, em que as diferenças das variáveis classe funcional, fração de ejeção e situação marital foram controladas, observou-se QVRS discretamente pior entre as mulheres, mas sem significância estatística (Riegel et al., 2003).

Não houve associação entre idade ou escolaridade com QVRS neste estudo (Tabela 16), mas a literatura é controversa sobre esse tópico. Em outros estudos foram observadas associações da QVRS com idade e com escolaridade (Barbareschi et al., 2011; Sawafta et al., 2013b). No entanto, é importante observar que nos estudos que investigaram QVRS na IC, as amostras geralmente se constituíram de pacientes com idade média superior a 60 anos e com escolaridade mais elevada. Encontramos apenas um estudo que relatou associação entre idade mais avançada e boa QVRS (Heo et al., 2012). Nesse estudo, a média de idade foi 60 anos, e os pacientes tinham nível de escolaridade e classe funcional mais elevados que os do presente estudo. Possivelmente esses pacientes com maior escolaridade conseguem ter melhor assimilação sobre o processo da doença e do tratamento, e melhor autocuidado, contribuindo para melhor qualidade de vida relacionada à saúde.

Classe funcional III apresentou associação significativa para QVRS ruim, quando comparada com as classes I e II ( $p<0,001$ - Tabela 16). Os pacientes com maior gravidade HF (classe NYHA) tiveram significativamente pior QVRS ( $F=39,4$, $p<0,0001)$. Nossos resultados são consistentes com os de outro estudo em que se observou pior QVRS entre os pacientes mais sintomáticos (Pressler et al., 2010b; Santos M.et al., 2011). Com relação a FEVE, em nosso estudo, não houve associação com a QVRS. Esses resultados são consistentes com investigações anteriores (De Jong et al., 2005; Heo et al., 2008b; Peters-Klimm et al., 2010; Erceg et al. 2013). 
Com relação ao tratamento medicamentoso, tanto o número de medicamentos $(p<0,001)$ quanto o número de tomadas por dia $(p=0,002)$ apresentaram associação significativa com a QVRS (Tabela 16). Os pacientes que utilizavam 7 ou mais tipos de medicamentos e que faziam 9 ou mais tomadas de medicamentos por dia, tiveram associação com QVRS ruim. Encontramos apenas um estudo, com amostra de 136 pacientes com IC hospitalizados. Nesse estudo os pacientes utilizavam em média 6,9 ( $\mathrm{dp}=2,3)$ medicamentos, relacionados ao tratamento da IC. Número de medicamentos foi associado a pior qualidade de vida (Erceg et al., 2013). Não encontramos estudos que tenham associado quantidade e número de vezes que o paciente toma seus medicamentos com a QVRS, o que impossibilitou a comparação dos resultados.

Polifarmacia é comum nos pacientes com IC, cujo tratamento incluem drogas que reduzem a mortalidade (ex. betabloqueadores) e outras que são utilizadas para melhorar sintomas (diuréticos) (Bocchi et al. 2012). Como demonstrado no nosso estudo, a grande maioria dos pacientes possuem outras comorbidades, como hipertensão, diabetes, dislipidemia, o que aumenta ainda mais a quantidade a prescrição de medicamentos (Masoudi et al. 2005).

Incluir polifarmacia em estudos que avaliem QVRS desses pacientes é importante e ressalta ainda mais a necessidade de intervenções com essa população, levando em consideração que a complexidade do tratamento pode ser um fator de não adesão ao regime terapêutico.

Limitações na atividade física e atividades da vida diária, frequentemente estão associadas a má QVRS nos pacientes com IC. (Yaghoubi et al., 2012). Em nosso estudo houve associação significativa entre menor índice de atividade física habitual com QVRS moderada ou ruim (Tabela16). A baixa atividade física pode estar associada ao medo e insegurança dos pacientes para a sua realização.

Sintomas físicos tiveram altas frequências nos pacientes avaliados neste estudo (Tabela 2$)$ : dispneia $(83,1 \%)$, fadiga $(76,2 \%)$, fadiga ao esforço $(79,9 \%)$, nocturia (82,6\%), e todos foram significativamente associados a QVRS ( $p<0,001$ Tabela 16). Diversos estudos têm demonstrado que os sintomas limitantes da IC, como dispneia, fadiga, sintomas depressivos apresentam impacto importante sobre 
a QVRS dos pacientes com IC (Heo et al., 2008c; Faller et al,. 2009; Huang et al., 2010; Carlson et al.; Lee et al. 2014c; Naveiro-Rilo et al., 2014)

Declínio cognitivo também teve associação com má QVRS ( p 0,008 - Tabela 16). Poucos pesquisadores tem investigado se existe uma relação entre deficits cognitivos e QVRS de pacientes com IC, o que dificulta a comparação com nossos resultados. Encontramos apenas um estudo que avaliou a relação entre deficit cognitivo e QVRS, sendo utilizado vários testes neuropsicológicos, incluindo o MEEM, com uma amostra de 249 pacientes com IC (Pressler et al., 2010b). Nesse estudo, não foi encontrado associação entre deficit cognitivo com a QVRS. Esse resultado é diferente ao encontrado em nosso estudo. Possivelmente essa divergência está relacionada às diferenças entre a amostra dos dois estudos. No estudo de Pressler et al., (2010), a amostra foi constituída apenas de pacientes com FEVE menor $40 \%$ e $51 \%$ dos pacientes tinham classe funcional III e IV, na amostra do presente estudo, a FEVE foi variada e grande parte dos pacientes tinham CF II e III. A relação entre deficit cognitivo e IC vem sendo bem documentada na literatura, e um dos preditores do deficit cognitivo é o agravamento da doença (Pressler et al., 2010b). Segundo Sauvé (2009), uma das razões dos déficits cognitivos mediarem a relação entre a gravidade da IC e QVRS é porque indivíduos com tais déficits podem interpretar e relatar sintomas e QVRS de forma diferente das pessoas sem déficits (Sauvé et al., 2009).

Distúrbio no padrão do sono teve alta frequência na amostra deste estudo (68,9\% - Tabela 17) e ser mau dormidor teve associação com QVRS moderada ou ruim ( $p<0,001$ ), resultados esses consistentes com a literatura. (Chen et al., 2009; Gau et al, 2011; Santos M.et al., 2011)

Autocuidado inadequado foi associado significativamente com QVRS moderada/ruim apenas na subescala de Confiança no autocuidado, e uma fraca associação com subescala Manutenção do autocuidado ( $p=0,055$ - Tabela 18). Este resultado difere do encontrado no estudo de Vellone et al. (2013), realizada na Itália com 1.192 pacientes ambulatoriais. Nesse estudo todas as subescalas do SCHFI foram associadas à diminuição da QVRS. No entanto, as características da amostra são diferente dos pacientes do nosso estudo (pacientes mais idosos, melhor nível de escolaridade,e CF NYHA mais elevada). Já no estudo descrito por Britz and 
Dunn (2010), realizado com 30 pacientes com IC hospitalizados, também foi encontrado associação com a escala de confiança, que apresentou associação estatisticamente significante com componente físico da QVRS, sugerindo que os participantes que se sentiam mais confiantes em suas habilidades para 0 autocuidado relataram melhor qualidade de vida do que aqueles que estavam menos confiantes $(p<0,01)$ (Britz and Dunn, 2010). Segundo os autores, confiança no autocuidado pode ser um indicador de melhor qualidade de vida em pacientes com IC quando comparados com aqueles pacientes que só são capazes de completar as tarefas de manutenção de autocuidado e gerenciamento do autocuidado. Esse resultado reforça a importância de implementações de programas voltados para o autocuidado, focando intervenções que promova melhora da confiança do paciente, que segundo Riegel and Dickson (2008), a confiança na própria capacidade para controlar os sintomas e aderir a esquemas de tratamento é fator importante para o resultado do autocuidado (Riegel and Dickson, 2008).

\subsection{PREDITORES DE MÁ QVRS}

Neste estudo foram identificadas seis variáveis associadas de forma independente da má QVRS de pacientes com IC em atendimento ambulatorial: classe funcional NYHA III, fadiga substancial, fadiga ao esforço substancial, ser mau dormidor, utilizar sete ou mais tipos de medicamentos e inadequada autoconfiança no autocuidado foram determinantes independentes para a má qualidade de vida relacionada à saúde.

A IC é uma doença incapacitante e acarreta modificações no estilo de vida dos pacientes. A classificação da New York Heart Association (NYHA) é o sistema mais comumente usado para descrever o impacto da insuficiência cardíaca sobre as atividades diárias do paciente (Bennett et al., 2002) .Ela classifica os pacientes com insuficiência cardíaca em 4 categorias (I, II, III, IV), maior classe indica sintomas mais graves, limitação da atividade física, e pior estado de saúde (Holland et al., 2010).

Em estudo observacional realizado por Holland et al (2010), com 293 pacientes divididos por classe funcional, foi demonstrado maior taxa de re- 
hospitalização, pior qualidade de vida e maior taxa de mortalidade, associados com a progressão da classe funcional (Holland et al., 2010).

Neste estudo, pacientes com maior classe funcional NYHA tiveram pior QVRS (CFIII OR $=3,7 ; p=0,002$ - Tabela19), o que é consistente com a maioria dos resultados de outros estudos (Gott et al., 2006; Santos et al. (2009); Pressler et al. (2010b); Huang et al. (2010), mas difere do encontrado por Sawafta et al.(2013a).

A avaliação da classe funcional é baseada em nos principais sintomas da IC (dispneia e fadiga) e as limitações físicas da doença percebida pelo paciente. $\mathrm{Na}$ análise univariada, dispneia teve importante associação com má QVRS, quando colocada no modelo multivariado, a dispneia tirou a significância da classe funcional. Entendendo que dispneia é o principal sintoma referido pelo paciente na avaliação do estadiamento da IC, optamos por retirá-la do modelo.

Como citado anteriormente, a fadiga é um dos dois sintomas mais comuns relatados por pacientes com insuficiência cardíaca. No nosso estudo as variáveis fadiga e fadiga ao esforço mostraram ser fortes preditoras para a QVRS moderada/ruim $(O R=3,3 ; p=0,009$ e $O R=8,7 ; p=0,001$, respectivamente Tabela 19), resultado coerente com estudos anteriores (Carlson et al.,2013; Evangelista et al., 2008; Heo et al., 2009; Shah et al., 2013).

Neste estudo, ser mau dormidor foi preditor de QVRS moderada/ruim (OR = 2,5 e $p=0,003$ - Tabela 19). Diversos estudos indicam as alterações do sono como preditores de má qualidade de vida nos pacientes com insuficiência cardíaca (Broström et al.,2005; Redeker and Hilkert ,2005b; Gau et al. ,2011). No entanto, é importante ressaltar que os distúrbios respiratórios do sono e sonolência diurna destacam-se como principais fatores determinantes de má qualidade de vida. No nosso estudo, essas variáveis não foram avaliadas. Sono também é influenciado pela depressão. Alguns estudos apontam a depressão como preditor dos distúrbios do sono em pacientes com IC. Neste estudo houve significante associação entre sintomas depressivos e má qualidade de vida relacionada à saúde. Quando inserida no modelo de análise múltipla, a variável "sintomas depressivos" influenciou na significância dos problemas do sono. Como tínhamos interesse em avaliar a 
contribuição do sono para a QVRS, optamos por retirar essa variável (sintomas depressivos) do modelo.

Neste estudo, polifarmacia (7 ou mais medicamentos) também foi independentemente relacionada a má QRVS (OR = 3,2 e p < 0,001). Não encontramos outros estudos que avaliaram essa variável em relação QVRS na IC.

Os deficits de autocuidado também foram encontrados como preditores de má QVRS. O resultado desse estudo demostrou que pacientes com confiança inadequada no autocuidado apresentam maior chance de ter QRVS moderada ou ruim quando comparados com aqueles que possuem adequada confiança no autocuidado $(\mathrm{OR}=2,5 ; \mathrm{p}=0,009)$, dado que corrobora o que é encontrado na literatura (Britz and Dunn ,2010; Vellone et al., 2013).

Estudos demonstram que os pacientes com insuficiência cardíaca que têm diminuição das habilidades de autocuidado apresentam frequentes rehospitalizações e diminuição da qualidade de vida, reforçando a necessidade de programas educativos voltados para o manejo do autocuidado dos pacientes com IC.(Lee et al., 2014루; Kato et al. 2011). Os resultados do presente estudo evidenciam a necessidade de uma perspectiva que integre diversas esferas da vida no tratamento das pessoas com IC, tendo como referência o alcance da melhor QVRS possível. 
Conclusões 


\section{CONCLUSÕES}

Os resultados desta pesquisa permitem concluir que a QVRS das pessoas com IC em tratamento ambulatorial é relacionada a múltiplos fatores. Nas análises univariadas as seguintes variáveis foram associadas com qualidade de vida relacionada à saúde moderada ou ruim: ser do sexo feminino $(p=0,048)$, apresentar declínio cognitivo ( $p=0,008)$, estar em classe funcional mais elevada ( $p$ $<0,001)$, ter sintomas depressivos $(p<0,001)$, ser mau dormidor $(p<0,001)$, ter fadiga e fadiga ao esforço $(p<0,001)$, ter dispneia $(p<0,001)$, noctúria $(p<0,001)$, fazer uso de 7 ou mais tipos de medicamentos ( $p<0,001)$, fazer 9 ou mais tomadas de medicamentos por dia $(p<0,002)$, ter baixa atividade física habitual $(p<0,041)$. No modelo de análise múltipla, foram preditores independentes para a qualidade de vida relacionada à saúde moderada ou ruim: ser mau dormidor $(\mathrm{OR}=2,5$ e $\mathrm{p}=$ $0,003)$, inadequada confiança no autocuidado $(O R=2,5 ; p=0,009)$, classe funcional mais elevada ( $O R=3,7$ e $p=0,002)$, fadiga $(O R=3,3$ e $p=0,009)$ e fadiga ao esforço (OR $=8,7$ e $p=<0,001)$ e fazer uso de 7 ou mais tipos de medicamentos $(\mathrm{OR}=3,2$ e $\mathrm{p}=0,001)$. 
Limitações e implicações 


\section{LIMITAÇÕES E IMPLICAÇÕES}

\subsection{LIMITAÇÕES}

Algumas limitações devem ser consideradas na interpretação dos resultados do nosso estudo, especialmente as que se referem à amostra ter sido de conveniência, de pacientes ambulatoriais e de centro especializado em cardiologia.

A amostra deste estudo foi de pacientes em tratamento ambulatorial da IC e não foram incluídos pacientes em CF IV. Dados da literatura mostram que estadiamento mais avançado da IC é um fator preditivo para a má QVRS, de forma que os resultados aqui obtidos não podem ser extrapolados para pacientes com IC em CF IV.

O uso de uma amostra de conveniência de um único serviço, especializado em cardiologia e de ensino limita a generalização dos resultados à população de pessoas com IC. Os pacientes que chegam aos serviços especializados podem apresentar características diferentes dos demais, especialmente porque os mecanismos de acesso a esses serviços podem funcionar como uma triagem cujos critérios são variáveis e não explícitos.

A idade média dos pacientes com IC foi abaixo do comumente encontrado na literatura. Não foi possível esclarecer a razão dessa característica na amostra deste estudo e possível viés de seleção deve ser considerado na generalização dos resultados obtidos.

É importante destacar também que este estudo teve delineamento transversal, permitindo apenas mostrar associações e não uma relação temporal entre as variáveis analisadas e a QVRS como desfecho.

\subsection{IMPLICAÇÕES PARA A ASSISTENCIA, ENSINO E PESQUISA}

O enfermeiro possui papel importante na equipe multidisciplinar no manejo de pacientes com IC cujo eixo principal é promover melhor qualidade de vida. A assistência de enfermagem desses pacientes deve ser de holística e centrada no 
atendimento das necessidades individuais, tornando-se fundamental a avaliação da QVRS com objetivo de identificar as dimensões que apresentam prejuízo e potencializar as que se encontram preservadas. Conhecer os fatores que predispõem o paciente ao prejuízo na sua QVRS é importante para guiar o profissional nos aspectos mais relevantes para que o paciente tenha melhor controle da sua saúde e doença.

Educação em saúde é um dos focos de atuação do enfermeiro. Sabendo que o enfermeiro é ator importante no cenário da saúde, quanto mais precoce o conhecimento sobre os fatores que interferem na QVRS dos pacientes com IC, melhor será o direcionamento desse profissional para a busca do conhecimento e estratégias necessárias para sua segurança e atuação junto ao paciente. Os resultados dessa pesquisa serão úteis para os estudantes de graduação, para que conheçam os fatores que contribuem para a QVRS dos pacientes. Para os pacientes compreenderem a IC, e as consequências sobre sua vida, bem como para realizar um autocuidado adequado, os enfermeiros devem ser capazes de avaliar o paciente para identificar os fatores envolvidos na QVRS, de interpretá-los de forma contextualizada e de delinear intervenções que promovam a melhor QVRS desses pacientes.

Embora existam alguns estudos brasileiros voltados para programas de educação de pacientes com IC, não foi avaliado o impacto desses programas sobre a qualidade de vida relacionada à saúde, e os resultados podem não ser representativos da população com IC, visto que esses estudos foram realizados em centro especializado de atendimento ao paciente com IC, o que justifica a necessidade de mais estudos, para compreender as contribuições do autocuidado na QVRS.

Encontramos apenas um estudo que utilizou o SCHFI em população brasileira e, tratando-se de um instrumento importante para a avaliação do autocuidado sob os aspectos de manutenção, gerenciamento e confiança no autocuidado, mais estudos devem ser realizados para que seja possível investigar os fatores preditores do autocuidado nessa população para promover um programa de educação e manejo da IC, adaptado para as necessidades multifacetadas dos pacientes, que favoreçam 
o autocuidado, em todas as suas dimensões e que sejam capazes de direcionar o paciente para melhor manejo dos sintomas da IC e dessa forma, melhorar QVRS. 
Referências 


\section{REFERÊNCIAS}

Adams KF, Fonarow GC, Emerman CL, LeJemtel TH, Costanzo MR, Abraham WT, et al. Characteristics and outcomes of patients hospitalized for heart failure in the United States: rationale, design, and preliminary observations from the first 100,000 cases in the Acute Decompensated Heart Failure National Registry (ADHERE). Am Heart J [Internet]. 2005 Feb [cited 2014 Sep 24];149(2):209-16. Available from: http://www.ncbi.nlm.nih.gov/pubmed/15846257

Agvall $B$, Alehagen $U$, Dahlström $U$. The benefits of using a heart failure management programme in Swedish primary healthcare. Eur J Heart Fail [Internet]. 2013 Feb [cited 2014 Sep 8];15(2):228-36. Available from: http://www.ncbi.nlm.nih.gov/pubmed/23109650

Aliti GB, Linhares JCC, Linch GF da C, Ruschel KB, Rabelo ER. Sinais e sintomas de pacientes com insuficiência cardíaca descompensada: inferência dos diagnósticos de enfermagem prioritários. Rev Gaúcha Enferm [Internet]. Universidade Federal do Rio Grande do Sul. Escola de Enfermagem; 2011 Sep [cited 2014 Sep 29];32(3):590-5. Available from: http://www.scielo.br/scielo.php?script=sci_arttext\&pid=S1983$14472011000300022 \& \operatorname{lng}=$ en\&nrm=iso\&tlng=pt

Alosco ML, Spitznagel MB, Cohen R, Sweet LH, Colbert LH, Josephson R, et al. Reduced cognitive function predicts functional decline in patients with heart failure over 12 months. Eur J Cardiovasc Nurs [Internet]. 2013 Jun 9 [cited 2014 Sep 28];13(4):304-10. Available from: http://www.ncbi.nlm.nih.gov/pubmed/23754840

Araujo DV, Tavares LR, Veríssimo R, Ferraz MB, Paulo S, Niterói SP. Custo da Insuficiência Cardíaca no Sistema Único de Saúde Cost of Heart Failure in the Unified Health System. 2005;84:422-7.

Avila CW, Riegel B, Pokorski SC, Camey S, Silveira LCJ, Rabelo-Silva ER. Cross-cultural adaptation and psychometric testing of the brazilian version of the self-care of heart failure index version 6.2. Nurs Res Pract [Internet]. 2013 Jan; 2013:178976. Available from: http://www.pubmedcentral. nih.gov/articlerender.fcgi?artid=3791794\&tool=pmcentrez\&rendert ype=abstract

Baecke JA, Burema J, Frijters JE. A short questionnaire for the measurement of habitual physical activity in epidemiological studies. Am J Clin Nutr [Internet]. 1982 Nov [cited 2014 Sep 28];36(5):936-42. Available from: http://www.ncbi.nlm.nih.gov/pubmed/7137077

Barbareschi G, Sanderman R, Leegte IL, van Veldhuisen DJ, Jaarsma T. Educational level and the quality of life of heart failure patients: a longitudinal study. J Card Fail [Internet]. Elsevier Inc; 2011 Jan [cited 2014 Sep 19];17(1):47-53. Available from: http://www.ncbi.nlm.nih.gov/pubmed/21187264Barbosa RR, Franklin RV, Stefenoni AV, Moraes VD, Jacques TDM, Serpa RG, et al. Análise da Qualidade de Vida em Homens e Mulheres Portadores de Insuficiência Cardíaca. 2014;27(2):97-103.

Batistoni SST, Néri AL, Cupertino AP. Validade e confiabilidade da versão Brasileira da Center for Epidemiological Scale - Depression (CES-D) em idosos Brasileiros. Psico-USF (Impresso) [Internet]. Universidade São Francisco; 2010 Apr [cited 2014 Sep 28];15(1):1322. Available from: http://www.scielo.br/scielo.php?script=sci_arttext\&pid=S1413$82712010000100003 \& \operatorname{lng}=$ en\&nrm=iso\&tlng=pt 
Behlouli H, Feldman DE, Ducharme A, Frenette M, Giannetti N, Grondin F, et al. Identifying relative cut-off scores with neural networks for interpretation of the Minnesota Living with Heart Failure questionnaire. Conf Proc . Annu Int Conf IEEE Eng Med Biol Soc IEEE Eng Med Biol Soc Annu Conf [Internet]. 2009 Jan;2009:6242-6. Available from: http://www.ncbi.nlm.nih.gov/pubmed/19965089

Bekelman DB, Havranek EP, Becker DM, Kutner JS, Peterson PN, Wittstein IS, et al. Symptoms, depression, and quality of life in patients with heart failure. J Card Fail [Internet]. 2007 Oct [cited 2014 Sep 29];13(8):643-8. Available from: http://www.ncbi.nlm.nih.gov/pubmed/17923356

De Belvis AG, Avolio M, Sicuro L, Rosano A, Latini E, Damiani G, et al. Social relationships and HRQL: a cross-sectional survey among older Italian adults. BMC Public Health [Internet]. BioMed Central; 2008 Jan [cited 2014 Sep 28];8:348. Available from: /pmc/articles/PMC2569037/?report=abstract

Bennett JA, Riegel B, Bittner V, Nichols J. Validity and reliability of the NYHA classes for measuring research outcomes in patients with cardiac disease. Heart Lung [Internet]. 2002 [cited 2014 Sep 28];31(4):262-70. Available from: http://www.ncbi.nlm.nih.gov/pubmed/12122390

Bertolucci PHF, Brucki SMD, Campacci SR, Juliano Y. O Mini-Exame do Estado Mental em uma população geral: impacto da escolaridade. Arq Neuropsiquiatr [Internet]. Associação Arquivos de Neuro-Psiquiatria; 1994 Mar [cited 2014 Sep 28];52(1):01-7. Available from: http://www.scielo.br/scielo.php?script=sci_arttext\&pid=S0004-

282X1994000100001\&lng=en\&nrm=iso\&tlng=pt

Bocchi EA, Braga FGM, Ferreira SMA, Rohde LEP, Oliveira WA de, Almeida DR de, et al. III Diretriz Brasileira de Insuficiência Cardíaca Crônica. Arq Bras Cardiol [Internet]. Arquivos Brasileiros de Cardiologia; 2009 [cited 2014 Sep 28];93(1):3-70. Available from: http://www.scielo.br/scielo.php?script=sci_arttext\&pid=S0066-

$782 X 2009002000001 \&$ Ing=en\&nrm=iso\&tlng=es

Bocchi EA, Marcondes-Braga FG, Bacal F, Ferraz AS, Albuquerque D, Rodrigues D. Atualização da diretriz brasileira de insuficiência cardíaca crônica - 2012 . Arq. Bras. Cardiol. . scielo ;2012. p. 1-33.

Bolmsjö BB, Mölstad S, Östgren CJ, Midlöv P. Prevalence and treatment of heart failure in Swedish nursing homes. BMC Geriatr [Internet]. 2013 Jan [cited 2014 Sep 19];13:118. Available from: http://www.ncbi.nlm.nih.gov/pubmed/24188665

Britz J a, Dunn KS. Self-care and quality of life among patients with heart failure. J Am Acad Nurse Pract [Internet]. 2010 Sep [cited 2014 Sep 19];22(9):480-7. Available from: http://www.ncbi.nlm.nih.gov/pubmed/20854640

Bunyamin, V., Spaderna, H., \& Weidner, G. (2013). Health behaviors contribute to quality of life in patients with advanced heart failure independent of psychological and medical patient characteristics. Quality of Life Research : An International Journal of Quality of Life Aspects of Treatment, Care and Rehabilitation, 22(7), 1603-11. doi:10.1007/s11136-012-0312-6

Van den Broek KC, Defilippi CR, Christenson RH, Seliger SL, Gottdiener JS, Kop WJ. Predictive value of depressive symptoms and B-type natriuretic peptide for new-onset heart failure and mortality. Am J Cardiol [Internet]. 2011 Mar 1 [cited 2014 Sep 28];107(5):723-9. Available from: http://www.sciencedirect.com/science/article/pii/S0002914910022502 
Broström A, Johansson P, Strömberg A, Albers J, Mårtensson J, Svanborg E. Obstructive sleep apnoea syndrome - patients' perceptions of their sleep and its effects on their life situation. J Adv Nurs [Internet]. Blackwell Publishing Ltd; 2007 Feb 1;57(3):318-27. Available from: http://dx.doi.org/10.1111/j.1365-2648.2006.04110.x

Broström A, Strömberg A, Dahlström U, Fridlund B. Sleep difficulties, daytime sleepiness, and health-related quality of life in patients with chronic heart failure. J Cardiovasc Nurs;2004 [Internet]. [cited 2014 Sep 29];19(4):234-42. Available from: http://www.ncbi.nlm.nih.gov/pubmed/15326979

Brucki SMD, Nitrini R, Caramelli P, Bertolucci PHF, Okamoto IH. Sugestões para o uso do mini-exame do estado mental no Brasil. Arq Neuropsiquiatr [Internet]. Psiquiatria; 2003 Sep [cited $2014 \quad$ Sep 28];61(3B):777-81. Available from: http://www.scielo.br/scielo.php?script=sci_arttext\&pid=S0004-

$282 \times 2003000500014 \&$ Ing=en\&nrm=iso\&tlng=pt

Buysse DJ, Reynolds CF, Monk TH, Berman SR, Kupfer DJ. The Pittsburgh Sleep Quality Index: a new instrument for psychiatric practice and research. Psychiatry Res [Internet]. 1989 b May [cited 2014 Aug 29];28(2):193-213. Available from: http://www.ncbi.nlm.nih.gov/pubmed/2748771

Cameron J, Worrall-Carter L, Driscoll A, Stewart S. Measuring self-care in chronic heart failure: a review of the psychometric properties of clinical instruments. J Cardiovasc Nurs [Internet]. 2009 [cited 2014 Sep 29];24(6):E10-22. Available from: http://www.ncbi.nlm.nih.gov/pubmed/19786882

Cameron J, Worrall-Carter L, Page K, Riegel B, Lo SK, Stewart S. Does cognitive impairment predict poor self-care in patients with heart failure? Eur $\mathrm{J}$ Heart Fail [Internet]. 2010 May [cited 2014 Sep 19];12(5):508-15. Available from: http://www.ncbi.nlm.nih.gov/pubmed/20354031

Cameron J, Worrall-Carter L, Page K, Stewart S, Ski CF. Screening for mild cognitive impairment in patients with heart failure: Montreal cognitive assessment versus mini mental state exam. Eur J Cardiovasc Nurs [Internet]. 2013 Jun [cited 2014 Sep 11];12(3):252-60. Available from: http://www.ncbi.nlm.nih.gov/pubmed/22514141

Carlson B, Pozehl B, Hertzog M, Zimmerman L, Riegel B. Predictors of overall perceived health in patients with heart failure. J Cardiovasc Nurs [Internet]. NIH Public Access; [cited 2014 Sep 29];28(3):206-15. Available from: /pmc/articles/PMC3396769/?report=abstract

Carson P, Tam SW, Ghali JK, Archambault WT, Taylor A, Cohn JN, et al. Relationship of quality of life scores with baseline characteristics and outcomes in the African-American heart failure trial. J Card Fail [Internet]. Elsevier Inc; 2009 Dec [cited 2014 Sep 19];15(10):835-42. Available from: http://www.ncbi.nlm.nih.gov/pubmed/19944359

Carvalho VO, Guimarães GV, Carrara D, Bacal F, Bocchi EA. Validação da versão em português do Minnesota Living with Heart Failure Questionnaire. Arq. Bras. Cardiol. 2009. p. 39-44.

Casida JM, Marcuccilli L, Peters RM, Wright S. Lifestyle adjustments of adults with long-term implantable left ventricular assist devices: A phenomenologic inquiry. Hear Lung J Acute Crit Care. 2011;40:511-20. 
Cené CW, Haymore LB, Dolan-Soto D, Lin F-C, Pignone M, Dewalt DA, et al. Self-care confidence mediates the relationship between perceived social support and self-care maintenance in adults with heart failure. J Card Fail [Internet]. NIH Public Access; 2013 Mar 1 [cited 2014 Sep 16];19(3):202-10. Available from: /pmc/articles/PMC3596888/?report=abstract

Charlson ME, Pompei P, Ales KL, MacKenzie CR. A new method of classifying prognostic comorbidity in longitudinal studies: development and validation. J Chronic Dis [Internet]. 1987 Jan [cited 2014 Jul 10];40(5):373-83. Available from: http://www.ncbi.nlm.nih.gov/pubmed/3558716

Chaudhry S, Jin L, Meltzer D. Use of a self-report-generated Charlson Comorbidity Index for predicting mortality. Med Care [Internet]. 2005 Jun [cited 2014 Sep 29];43(6):607-15. Available from: http://www.ncbi.nlm.nih.gov/pubmed/15908856

Chen H-M, Clark AP, Tsai L-M, Chao Y-FC. Self-reported Sleep Disturbance of Patients With Heart Failure in Taiwan. Nurs Res [Internet]. 2009;58(1). Available from: http://journals.Iww.com/nursingresearchonline/Fulltext/2009/01000/Self_reported_Sleep_Dist urbance_of_Patients_With.8.aspx

Chu SH, Lee WH, Yoo JS, Kim SS, Ko IS, Oh EG, et al. Factors affecting quality of life in Korean patients with chronic heart failure. Jpn J Nurs Sci [Internet]. 2014 Jan [cited 2014 Sep 28];11(1):54-64. Available from: http://www.ncbi.nlm.nih.gov/pubmed/24460602

Chung ML, Moser DK, Lennie T a, Frazier SK. Perceived social support predicted quality of life in patients with heart failure, but the effect is mediated by depressive symptoms. Qual Life Res [Internet]. 2013 Sep [cited 2014 Sep 25];22(7):1555-63. Available from: http://www.pubmedcentral.nih.gov/articlerender.fcgi?artid=3568459\&tool=pmcentrez\&rendert ype=abstract

Cocchieri A, Riegel B, D'Agostino F, Rocco G, Fida R, Alvaro R, et al. Describing self-care in Italian adults with heart failure and identifying determinants of poor self-care. Eur $\mathrm{J}$ Cardiovasc Nurs [Internet]. 2014 Jan 9 [cited 2014 Sep 19]; Available from: http://www.ncbi.nlm.nih.gov/pubmed/24366984

Comín-Colet J, Enjuanes C, González G, Torrens A, Cladellas M, Meroño O, et al. Iron deficiency is a key determinant of health-related quality of life in patients with chronic heart failure regardless of anaemia status. Eur J Heart Fail [Internet]. 2013 Oct [cited 2014 Sep 13];15(10):1164-72. Available from: http://www.pubmedcentral.nih.gov/articlerender.fcgi?artid=3782146\&tool=pmcentrez\&rendert ype=abstract

Cruz FDD, Issa VS, Ayub-Ferreira SM, Chizzola PR, Souza GEC, Moreira LFP, et al. Effect of a sequential education and monitoring programme on quality-of-life components in heart failure. Eur J Heart Fail. 2010;12:1009 15

Dardiotis E, Giamouzis G, Mastrogiannis D, Vogiatzi C, Skoularigis J, Triposkiadis F, et al. Cognitive impairment in heart failure. Cardiol. Res. Pract. 2012.

Darling C, Saczynski JS, McManus DD, Lessard D, Spencer F a, Goldberg RJ. Delayed hospital presentation in acute decompensated heart failure: clinical and patient reported factors. Heart Lung [Internet]. Elsevier Inc; 2013 [cited 2014 Sep 13];42(4):281-6. Available from: 
http://www.pubmedcentral.nih.gov/articlerender.fcgi?artid=3706507\&tool=pmcentrez\&rendert ype=abstract

Davis KK, Allen JK. Identifying cognitive impairment in heart failure: a review of screening measures. Heart Lung [Internet]. Elsevier Inc; 2013 [cited 2014 Sep 28];42(2):92-7. Available from: http://www.ncbi.nlm.nih.gov/pubmed/23260324

Delvaux K, Lefevre J, Philippaerts R, Dequeker J, Thomis M, VanreuseL B, et al. Bone mass and lifetime physical activity in Flemish males: a 27-year follow-up study. Med Sci Sports Exerc [Internet]. 2001 Nov 1 [cited 2014 Sep 28];33(11):1868-75. Available from: http://europepmc.org/abstract/MED/11689737

Dennison CR, McEntee ML, Samuel L, Johnson BJ, Rotman S, Kielty A, et al. Adequate health literacy is associated with higher heart failure knowledge and self-care confidence in hospitalized patients. J Cardiovasc Nurs [Internet]. [cited 2014 Sep 29];26(5):359-67. Available from: http://www.pubmedcentral.nih.gov/articlerender.fcgi?artid=3116982\&tool=pmcentrez\&rendert ype $=$ abstract

Dias IA, Santos LS, Ferreira LN. Avaliação da independência funcional e estado mental de pacientes com insuficiência cardíaca congestiva. 2011;144-55.

Dickson V V, Tkacs N, Riegel B. Cognitive influences on self-care decision making in persons with heart failure. Am Heart J [Internet]. 2007 Sep [cited 2014 Sep 23];154(3):42431. Available from: http://www.ncbi.nlm.nih.gov/pubmed/17719284

Dickson VV, Buck H, Riegel B. A qualitative meta-analysis of heart failure self-care practices among individuals with multiple comorbid conditions. J Card Fail [Internet]. Elsevier Inc; 2011 May [cited $2014 \quad$ Sep 19];17(5):413-9. Available from: http://www.ncbi.nlm.nih.gov/pubmed/21549299

Dickson VV, Deatrick J a, Riegel B. A typology of heart failure self-care management in nonelders. Eur J Cardiovasc Nurs [Internet]. 2008 Sep [cited 2014 Sep 19];7(3):171-81. Available from: http://www.ncbi.nlm.nih.gov/pubmed/18178132

Dickson VV, Melkus GD, Katz S, Levine-Wong A, Dillworth J, Cleland CM, et al. Building skill in heart failure self-care among community dwelling older adults: results of a pilot study. Patient Educ Couns [Internet]. 2014 Aug [cited 2014 Sep 29];96(2):188-96. Available from: http://www.sciencedirect.com/science/article/pii/S0738399114001797

Dodson J a, Truong T-TN, Towle VR, Kerins G, Chaudhry SI. Cognitive impairment in older adults with heart failure: prevalence, documentation, and impact on outcomes. Am J Med [Internet]. Elsevier Inc.; 2013 Feb [cited 2014 Sep 28];126(2):120-6. Available from: http://www.pubmedcentral.nih.gov/articlerender.fcgi?artid=3553506\&tool=pmcentrez\&rendert ype=abstract

Dudas K, Olsson L-E, Wolf A, Swedberg K, Taft C, Schaufelberger M, et al. Uncertainty in illness among patients with chronic heart failure is less in person-centred care than in usual care. Eur J Cardiovasc Nurs [Internet]. 2013 Dec [cited 2014 Sep 19];12(6):521-8. Available from: http://www.ncbi.nlm.nih.gov/pubmed/23303766

Dunlay SM, Eveleth JM, Shah ND, McNallan SM, Roger VL. Medication adherence among community-dwelling patients with heart failure. [Internet]. Mayo Clin. Proc. 2011. p. 273-81. Available

from: 
http://www.pubmedcentral.nih.gov/articlerender.fcgi?artid=3068886\&tool=pmcentrez\&rendert ype=abstract

Erceg P, Despotovic N, Milosevic DP, Soldatovic I, Zdravkovic S, Tomic S, et al. Healthrelated quality of life in elderly patients hospitalized with chronic heart failure. Clin Interv Aging [Internet]. 2013 Jan;8:1539-46. Available from: http://www.pubmedcentral. nih.gov/articlerender.fcgi?artid=3832382\&tool=pmcentrez\&rendert ype=abstract

Evangelista LS, Moser DK, Westlake C, Pike N, Ter-Galstanyan A, Dracup K. Correlates of fatigue in patients with heart failure. Prog Cardiovasc Nurs [Internet]. NIH Public Access; 2008 Jan [cited 2014 Sep 28];23(1):12-7. Available from: /pmc/articles/PMC2891443/?report=abstract

Evenson KR, Rosamond WD, Cai J, Diez-Roux A V, Brancati FL. Influence of retirement on leisure-time physical activity: the atherosclerosis risk in communities study. Am J Epidemiol [Internet]. 2002 Apr 15 [cited 2014 Sep 28];155(8):692-9. Available from: http://www.ncbi.nlm.nih.gov/pubmed/11943686

Faller H, Störk S, Schuler M, Schowalter M, Steinbüchel T, Ertl G, et al. Depression and disease severity as predictors of health-related quality of life in patients with chronic heart failure--a structural equation modeling approach. J Card Fail [Internet]. 2009 May [cited 2014 Sep 28];15(4):286-292.e2. Available from: http://www.ncbi.nlm.nih.gov/pubmed/19398075

Farinatti P. Apresentação de uma Versão em Português do Compêndio de Atividades Físicas: uma contribuição aos pesquisadores e profissionais em Fisiologia do. Rev Bras Fisiol Exerc [Internet]. 2003 [cited 2014 Sep 28]; Available from: http://xa.yimg.com/kq/groups/18719196/1191340261/name/Comp\%2525C3\%2525AAndio\% 2Bde\%2Batividades\%2Bf\%2525C3\%2525ADsicas\%2B-

\%2Buma\%2Bcontribui\%2525C3\%2525A7\%2525C3\%2525A30\%2Baos\%2Bpesquisadores\% 2Be\%2Bprofissionais\%2Bem\%2Bfisiologia\%2Bdo\%2Bexerc\%2525C3\%2525ADcio.pdf

Feijó MK, Ávila CW. Adaptação transcultural e validação da European Heart Failure Selfcare Behavior Scale para o português do Brasil. 2012;20(5).

Feola M, Garnero S, Vallauri P, Salvatico L, Vado A, Leto L, et al. Relationship between Cognitive Function, Depression/Anxiety and Functional Parameters in Patients Admitted for Congestive Heart Failure. Open Cardiovasc Med J [Internet]. Bentham Science Publishers; 2013 Jan [cited 2014 Sep 29];7:54-60. Available from: /pmc/articles/PMC3772569/?report=abstract

Fletcher A, Gore S, Jones D, Fitzpatrick R, Spiegelhalter D, Cox D. Quality of life measures in health care. II: Design, analysis, and interpretation. BMJ [Internet]. 1992 Nov 7 [cited 2014 Oct 1];305(6862):1145-8. Available from:

http://www.pubmedcentral.nih.gov/articlerender.fcgi?artid=1883654\&tool=pmcentrez\&rendert ype=abstract

Fini $A$, Cruz $D$ de ALM da. Characteristics of fatigue in heart failure patients: a literature review . Rev. Latino-Americana Enferm. . scielo ; 2009. p. 557-65.

Fini A, Cruz D de ALM da. Propriedades psicométricas da Dutch Fatigue Scale e Dutch Exertion Fatigue Scale: versão brasileira. Rev Bras Enferm [Internet]. Associação Brasileira de Enfermagem; 2010 Apr [cited 2014 Sep 28];63(2):216-21. Available from: http://www.scielo.br/scielo.php?script=sci_arttext\&pid=S0034-

$71672010000200008 \& \operatorname{lng}=$ en\&nrm=iso\&tlng=pt 
Florindo AA, Latorre M do RD de O, Jaime PC, Tanaka T, Zerbini CA de F. Metodologia para a avaliação da atividade física habitual em homens com 50 anos ou mais. Rev Saude Publica [Internet]. Faculdade de Saúde Pública da Universidade de São Paulo; 2004 Apr [cited 2014 Sep 28];38(2):307-14. Available from: http://www.scielo.br/scielo.php?script=sci_arttext\&pid=S0034-

$89102004000200022 \& \operatorname{lng}=$ en\&nrm=iso\&tlng $=p t$

Folstein MF, Folstein SE, McHugh PR. "Mini-mental state". A practical method for grading the cognitive state of patients for the clinician. J Psychiatr Res [Internet]. 1975 Nov [cited 2014 Jul 9];12(3):189-98. Available from: http://www.ncbi.nlm.nih.gov/pubmed/1202204

Fotos N V, Giakoumidakis K, Kollia Z, Galanis P, Copanitsanou P, Pananoudaki E, et al. Health-related quality of life of patients with severe heart failure. A cross-sectional multicentre study. Scand J Caring Sci [Internet]. 2013 Sep [cited 2014 Sep 19];27(3):686-94. Available from: http://www.ncbi.nlm.nih.gov/pubmed/23004008

Bento VFR, Brofman PRS. Impacto da consulta de enfermagem na frequência de internações em pacientes com insuficiência cardíaca em Curitiba - Paraná . Arq. Bras. Cardiol. . scielo ; 2009. p. 490-6.

Gallicchio L, Hoffman SC, Helzlsouer KJ. The relationship between gender, social support, and health-related quality of life in a community-based study in Washington County, Maryland. Qual Life Res [Internet]. 2007 Jun [cited 2014 Sep 28];16(5):777-86. Available from: http://www.ncbi.nlm.nih.gov/pubmed/17286195

Garin O, Ferrer M, Pont À, Wiklund I, Van Ganse E, Vilagut G, et al. Evidence on the global measurement model of the Minnesota Living with Heart Failure Questionnaire. Qual Life Res [Internet]. 2013 Dec [cited 2014 Sep 19];22(10):2675-84. Available from: http://www.ncbi.nlm.nih.gov/pubmed/23677481

Gastelurrutia P, Lupón J, Altimir S, de Antonio M, González B, Cabanes R, et al. Effect of fragility on quality of life in patients with heart failure. Am J Cardiol [Internet]. $2013 \mathrm{Dec} 1$ [cited 2014 Sep 29];112(11):1785-9. Available from: http://www.ncbi.nlm.nih.gov/pubmed/24012028

Gau F-Y, Chen X-P, Wu H-Y, Lin M-L, Chao Y-FC. Sleep-related predictors of quality of life in the elderly versus younger heart failure patients: a questionnaire survey. Int $\mathrm{J}$ Nurs Stud [Internet]. 2011 Apr [cited 2014 Aug 27];48(4):419-28. Available from: http://www.sciencedirect.com/science/article/pii/S0020748910002397

Gheorghiade M, Abraham WT, Albert NM, Greenberg BH, O'Connor CM, She L, et al. Systolic blood pressure at admission, clinical characteristics, and outcomes in patients hospitalized with acute heart failure. JAMA [Internet]. 2006 Nov 8 [cited 2014 Sep 29];296(18):2217-26. Available from: http://www.ncbi.nlm.nih.gov/pubmed/17090768

Godoy HL, Silveira JA, Segalla E, Almeida DR. Hospitalização e mortalidade por insuficiência cardíaca em hospitais públicos no município de São Paulo. Arq. Bras. Cardiol. 2011. p. 402-7.

Gonçalves B, Fagulha T. The Portuguese Version of the Center for Epidemiologic Studies Depression Scale (CES-D). Eur J Psychol Assess [Internet]. 2004 Jan 1 [cited 2014 Sep 28];20(4):339-48. Available from: http://www.researchgate.net/publication/232590404_The_Portuguese_Version_of_the_Cent er_for_Epidemiologic_Studies_Depression_Scale_(CES-D) 
Goodman H, Firouzi A, Banya W, Lau-Walker M, Cowie MR. Illness perception, self-care behaviour and quality of life of heart failure patients: a longitudinal questionnaire survey. Int $\mathrm{J}$ Nurs Stud [Internet]. 2013 Jul [cited 2014 Aug 31];50(7):945-53. Available from: http://www.ncbi.nlm.nih.gov/pubmed/23211796

Gott M, Barnes S, Parker C, Payne S, Seamark D, Gariballa S, et al. Predictors of the quality of life of older people with heart failure recruited from primary care. Age Ageing [Internet]. 2006 Mar [cited 2014 Sep 19];35(2):172-7. Available from: http://www.ncbi.nlm.nih.gov/pubmed/16495294

Harkness K, Heckman GA, Akhtar-Danesh N, Demers C, Gunn E, McKelvie RS. Cognitive function and self-care management in older patients with heart failure. Eur J Cardiovasc Nurs [Internet]. 2014 Jun [cited 2014 Sep 29];13(3):277-84. Available from: http://www.ncbi.nlm.nih.gov/pubmed/23733350

Heidenreich P a, Trogdon JG, Khavjou O a, Butler J, Dracup K, Ezekowitz MD, et al. Forecasting the future of cardiovascular disease in the United States: a policy statement from the American Heart Association. Circulation [Internet]. 2011 Mar 1 [cited 2014 Jul 14];123(8):933-44. Available from: http://www.ncbi.nlm.nih.gov/pubmed/21262990

Heisler M, Halasyamani L, Cowen ME, Choi H, Mase R, Piette JD, et al. NIH Public Access. 2014;6(2):246-53.

Heo S, Doering L V, Widener J, Moser DK. Predictors and effect of physical symptom status on health-related quality of life in patients with heart failure. Am J Crit Care [Internet]. $2008 \mathrm{a}$ Mar;17(2):124-32. Available from: http://www.ncbi.nlm.nih.gov/pubmed/18310649

Heo S, Lennie TA, Okoli C, Moser DK. Quality of life in patients with heart failure: ask the patients. Heart Lung [Internet]. NIH Public Access; 2009 Jan [cited 2014 Sep 28];38(2):1008. Available from: file://C:/Users/AnaPaula/Documents/Mestrado/artigos discuss\%E3o/Heo S 2009.htm

Heo S, Moser DK, Chung ML, Lennie T a. Social status, health-related quality of life, and event-free survival in patients with heart failure. Eur J Cardiovasc Nurs [Internet]. 2012 Jun [cited 2014 Sep 28];11(2):141-9. Available from: http://www.pubmedcentral. .nih.gov/articlerender.fcgi?artid=4084695\&tool=pmcentrez\&rendert ype=abstract

Heo S, Moser DK, Pressler SJ, Dunbar SB, Kim J, Ounpraseuth S, et al. Dose-dependent relationship of physical and depressive symptoms with health-related quality of life in patients with heart failure. Eur J Cardiovasc Nurs [Internet]. 2013 Oct [cited 2014 Oct 1];12(5):45460. Available from: http://www.ncbi.nlm.nih.gov/pubmed/23283567

Heo S, Moser DK, Pressler SJ, Dunbar SB, Mudd-Martin G, Lennie T a. Psychometric Properties of the Symptom Status Questionnaire-Heart Failure. J Cardiovasc Nurs [Internet]. 2014 Mar 3 [cited 2014 Sep 19];00(0):1-9. Available from: http://www.ncbi.nlm.nih.gov/pubmed/24598550

Herrscher TE, Akre H, Overland B, Sandvik L, Westheim AS. Clinical predictors of sleep apnoea in heart failure outpatients. Int J Clin Pract [Internet]. 2014 Jun [cited 2014 Sep 29];68(6):725-30. Available from: http://www.ncbi.nlm.nih.gov/pubmed/24548330 
Hill LR, Klauber MR, Salmon DP, Yu ES, Liu WT, Zhang M, et al. Functional status, education, and the diagnosis of dementia in the Shanghai survey. Neurology [Internet]. 1993 Jan [cited 2014 Sep 28];43(1):138-45. Available from: http://www.ncbi.nlm.nih.gov/pubmed/8423878

Hodges P. Factors impacting readmissions of older patients with heart failure. Crit Care Nurs Q [Internet]. 2009;32:33-43; quiz 44-5. Available from: http://www.ncbi.nlm.nih.gov/pubmed/19077807

Holland R, Rechel B, Stepien K, Harvey I, Brooksby I. Patients' self-assessed functional status in heart failure by New York Heart Association class: a prognostic predictor of hospitalizations, quality of life and death. J Card Fail [Internet]. Elsevier; 2010 Feb 1 [cited 2014 Sep 28];16(2):150-6. Available from: /pmc/articles/PMC2817782/?report=abstract

Huang T-Y, Moser DK, Hwang S-L, Lennie T a, Chung M, Heo S. Comparison of healthrelated quality of life between American and Taiwanese heart failure patients. J Transcult Nurs [Internet]. 2010 Jul [cited 2014 Sep 28];21(3):212-9.

Hulley SB, Cumming SR, Browner WS, Grady DG, Hearst NB, Newman TB. Delineando a pesquisa clínica: uma abordagem epidemiológica. Artmed; 2008 [cited 2014 Sep 28]; Available from: http://bases.bireme.br/cgibin/wxislind.exe/iah/online/? IsisScript=iah/iah.xis\&src=google\&base=LILACS\&lang=p\&nextA ction=Ink\&exprSearch=591606\&indexSearch=ID

Jesus P a P, Vieira-de-Melo RM, Reis FJFB, Viana LC, Lacerda A, Dias JS, et al. Cognitive dysfunction in congestive heart failure: transcranial Doppler evidence of microembolic etiology. Arq Neuropsiquiatr [Internet]. 2006 Jun;64(2A):207-10. Available from: http://www.ncbi.nlm.nih.gov/pubmed/16791357

De Jong M, Moser DK, Chung ML. Predictors of health status for heart failure patients. Prog Cardiovasc Nurs [Internet]. 2005 Jan;20(4):155-62. Available from: http://www.ncbi.nlm.nih.gov/pubmed/16276138

Jovicic A, Holroyd-Leduc JM, Straus SE. Effects of self-management intervention on health outcomes of patients with heart failure: a systematic review of randomized controlled trials. BMC Cardiovasc Disord. 2006;6:43.

Kato N, Kinugawa K, Seki S, Shiga T, Hatano M, Yao A, et al. Quality of Life as an Independent Predictor for Cardiac Events and Death in Patients With Heart Failure. Circ J [Internet]. $2011 \quad$ [cited 2014 Sep 19];75(7):1661-9. Available from: http://joi.jlc.jst.go.jp/JST.JSTAGE/circj/CJ-10-1308?from=CrossRef

Van Kerrebroeck P, Abrams P, Chaikin D, Donovan J, Fonda D, Jackson S, et al. The standardisation of terminology in nocturia: report from the Standardisation Sub-committee of the International Continence Society. Neurourol Urodyn [Internet]. 2002 Jan [cited 2014 Sep 28];21(2):179-83. Available from: http://www.ncbi.nlm.nih.gov/pubmed/11857672

Knafl GJ, Riegel B. What puts heart failure patients at risk for poor medication adherence? Patient Prefer Adherence [Internet]. 2014 Jan;8:1007-18. Available from: http://www.pubmedcentral.nih.gov/articlerender.fcgi?artid=4109641\&tool=pmcentrez\&rendert ype=abstract

De la Torre JC. Cardiovascular risk factors promote brain hypoperfusion leading to cognitive decline and dementia. Cardiovasc Psychiatry Neurol [Internet]. 2012 Jan [cited 2014 Aug 27];2012:367516. 
http://www.pubmedcentral.nih.gov/articlerender.fcgi?artid=3518077\&tool=pmcentrez\&rendert ype=abstract

Lainscak M, Blue L, Clark AL, Dahlström U, Dickstein K, Ekman I, et al. Self-care management of heart failure: Practical recommendations from the patient care committee of the heart failure association of the European society of cardiology. Eur $\mathrm{J}$ Heart Fail. 2011;13:115-26.

Laks J, Baptista EMR, Contino ALB, Paula EO de, Engelhardt E. Mini-Mental State Examination norms in a community-dwelling sample of elderly with low schooling in Brazil . Cad. Saúde Pública . scielo ; 2007. p. 315-9.

Lee CS, Mudd JO, Hiatt SO, Gelow JM, Chien C, Riegel B. Trajectories of heart failure selfcare management and changes in quality of life. Eur J Cardiovasc Nurs [Internet]. $2014 \mathrm{a}$ Jun 30 [cited 2014 Sep 19]; Available from: http://www.ncbi.nlm.nih.gov/pubmed/24982435

Lee CS, Suwanno J, Riegel B. The relationship between self-care and health status domains in Thai patients with heart failure. Eur $\mathrm{J}$ Cardiovasc Nurs [Internet]. European Society of Cardiology; 2009 Oct [cited 2014 Sep 19];8(4):259-66. Available from: http://www.pubmedcentral. nih.gov/articlerender.fcgi?artid=2757500\&tool=pmcentrez\&rendert ype=abstract

Lee KS, Lennie T a, Warden S, Jacobs-Lawson JM, Moser DK. A comprehensive symptom diary intervention to improve outcomes in patients with HF: a pilot study. J Card Fail [Internet]. Elsevier Inc; 2013 Sep [cited 2014 Sep 28];19(9):647-54. Available from: http://www.ncbi.nlm.nih.gov/pubmed/24054342

Lee KS, Lennie T a, Wu J-R, Biddle MJ, Moser DK. Depressive symptoms, health-related quality of life, and cardiac event-free survival in patients with heart failure: a mediation analysis. Qual Life Res [Internet]. 2014 c Aug [cited 2014 Sep 19];23(6):1869-76. Available from: http://www.ncbi.nlm.nih.gov/pubmed/24488573

Lesman-Leegte I, Jaarsma T, Coyne JC, Hillege HL, Van Veldhuisen DJ, Sanderman R. Quality of life and depressive symptoms in the elderly: a comparison between patients with heart failure and age- and gender-matched community controls. J Card Fail [Internet]. Elsevier Inc.; 2009 Feb [cited 2014 Sep 19];15(1):17-23. Available from: http://www.ncbi.nlm.nih.gov/pubmed/19181289

Lindesay J, Jagger C, Mlynik-Szmid A, Sinorwala A, Peet S, Moledina F. The Mini-Mental State Examination (MMSE) in an elderly immigrant Gujarati population in the United Kingdom. Int J Geriatr Psychiatry [Internet]. 1997 Dec [cited 2014 Sep 28];12(12):1155-67. Available from: http://www.ncbi.nlm.nih.gov/pubmed/9444539

Lourenço RA, Veras RP. Mini-Exame do Estado Mental: características psicométricas em idosos ambulatoriais . Rev. Saúde Pública . scielo ; 2006. p. 712-9.

Luttik ML, Jaarsma T, Veeger N, van Veldhuisen DJ. Marital status, quality of life, and clinical outcome in patients with heart failure. Heart Lung [Internet]. 2006 [cited 2014 Sep 29];35(1):3-8. Available from: http://www.ncbi.nlm.nih.gov/pubmed/16426930

Machado JC, Ribeiro R de CL, Cotta RMM, Leal PF da G. Declínio cognitivo de idosos e sua associação com fatores epidemiológicos em Viçosa, Minas Gerais . Rev. Bras. Geriatr. e Gerontol. . scielo ; 2011. p. 109-21. 
Mahler DA, Weinberg DH, Wells CK, Feinstein AR. The measurement of dyspnea. Contents, interobserver agreement, and physiologic correlates of two new clinical indexes. Chest [Internet]. 1984 Jun [cited 2014 Sep 28];85(6):751-8. Available from: http://www.ncbi.nlm.nih.gov/pubmed/6723384

Maric B, Kaan A, Araki Y, Ignaszewski A, Lear S a. The use of the Internet to remotely monitor patients with heart failure. Telemed J E Health [Internet]. 16(1):26-33. Available from: http://www.ncbi.nlm.nih.gov/pubmed/20070163

Marti CN, Georgiopoulou V V, Giamouzis G, Cole RT, Deka A, Tang WHW, et al. Patientreported selective adherence to heart failure self-care recommendations: a prospective cohort study: the Atlanta Cardiomyopathy Consortium. Congest Heart Fail [Internet]. [cited 2014 Sep 29];19(1):16-24. Available from: http://www.pubmedcentral.nih.gov/articlerender.fcgi?artid=3519965\&tool=pmcentrez\&rendert ype=abstract

Masoudi F a, Baillie C a, Wang Y, Bradford WD, Steiner JF, Havranek EP, et al. The complexity and cost of drug regimens of older patients hospitalized with heart failure in the United States, 1998-2001. Arch Intern Med [Internet]. 2005 Oct 10;165(18):2069-76. Available from: http://www.ncbi.nlm.nih.gov/pubmed/16216996

McAlister FA, Stewart S, Ferrua S, McMurray JJJ V. Multidisciplinary strategies for the management of heart failure patients at high risk for admission: A systematic review of randomized trials. J. Am. Coll. Cardiol. 2004. p. 810-9.

Mesquita ET, Jorge AJL. Tratamento da insuficiência cardíaca com fração de ejeção normal. Arq. Bras. Cardiol. 2010. p. 414-26.

Moser DK, Heo S, Lee KS, Hammash M, Riegel B, Lennie TA, et al. "It could be worse ... lot"s worse!' Why health-related quality of life is better in older compared with younger individuals with heart failure. Age Ageing [Internet]. Oxford University Press; 2013 Sep 1 [cited 2014 Sep 28];42(5):626-32. Available from: /pmc/articles/PMC3745088/?report=abstract

Naveiro-Rilo JC, Diez-Juárez MD, Flores-Zurutuza L, Rodríguez-García MÁ, RebolloGutiérrez F, Romero Blanco A. [Quality of life in patients with heart failure: the perspective of primary health care]. Gac Sanit [Internet]. 2014 [cited 2014 Sep 19];26(5):436-43. Available from: http://www.ncbi.nlm.nih.gov/pubmed/22342047

Newhouse A, Jiang W. Heart failure and depression. Heart Fail Clin [Internet]. 2014 Apr [cited 2014 Sep 28];10(2):295-304. Available from: http://www.sciencedirect.com/science/article/pii/S1551713613001153

Nogueira PR, Rassi S, Corrêa K de S. Perfil epidemiológico, clínico e terapêutico da insuficiência cardíaca em hospital terciário. Arq. Bras. Cardiol. 2010. p. 392-8.

Oliveira BG, Abreu MNS, Abreu CDG, Rocha MODC, Ribeiro AL. Health-related quality of life in patients with Chagas disease. Rev Soc Bras Med Trop [Internet]. 2011 Apr [cited 2014 Sep 19];44(2):150-6. Available from: http://www.scielo.br/scielo.php?script=sci_arttext\&pid=S0037-

$86822011000200005 \&$ Ing=en\&nrm=iso\&tIng=en

Pagel JF. Medications and their effects on sleep. Prim Care Clin Off Pract. Elsevier; 2005;32(2):491-509. 
Peters-Klimm F, Kunz CU, Laux G, Szecsenyi J, Müller-Tasch T. Patient- and providerrelated determinants of generic and specific health-related quality of life of patients with chronic systolic heart failure in primary care: a cross-sectional study. Health Qual Life Outcomes [Internet]. BioMed Central; 2010 Jan [cited 2014 Sep 29];8:98. Available from: /pmc/articles/PMC2945966/?report=abstract

Pressler SJ. Cognitive functioning and chronic heart failure: a review of the literature (2002July 2007). J Cardiovasc Nurs [Internet]. 2008 [cited 2014 Sep 29];23(3):239-49. Available from: http://www.ncbi.nlm.nih.gov/pubmed/18437066

Pressler SJ, Kim J, Riley P, Ronis DL, Gradus-Pizlo I. Memory dysfunction, psychomotor slowing, and decreased executive function predict mortality in patients with heart failure and low ejection fraction. J Card Fail [Internet]. 2010 a Sep [cited 2014 Sep 29];16(9):750-60. Available from: http://www.pubmedcentral.nih.gov/articlerender.fcgi?artid=2929394\&tool=pmcentrez\&rendert ype=abstract

Pressler SJ, Martineau A, Grossi J, Giordani B, Koelling TM, Ronis DL, et al. Healthcare resource use among heart failure patients in a randomized pilot study of a cognitive training intervention. Heart Lung [Internet]. Elsevier Inc; 2013 [cited 2014 Sep 28];42(5):332-8. Available from: http://www.pubmedcentral.nih.gov/articlerender.fcgi?artid=3781586\&tool=pmcentrez\&rendert ype=abstract

Sauvé MJ, et al. Cognitive deficits and health-related quality of life in chronic heart failure. [Internet]. J. Cardiovasc. Nurs. 2010b. p. 189-98. Available from: http://www.pubmedcentral.nih.gov/articlerender.fcgi?artid=2922930\&tool=pmcentrez\&rendert ype=abstract

Pressler SJ, Therrien B, Riley PL, Chou C-C, Ronis DL, Koelling TM, et al. Nurse-Enhanced Memory Intervention in Heart Failure: the MEMOIR study. J Card Fail [Internet]. Elsevier Inc; 2011 Oct [cited 2014 Sep 19];17(10):832-43. Available from: http://www.pubmedcentral. nih.gov/articlerender.fcgi?artid=3227743\&tool=pmcentrez\&rendert ype=abstract

Quan H, Parsons GA, Ghali WA. Assessing accuracy of diagnosis-type indicators for flagging complications in administrative data. J Clin Epidemiol [Internet]. 2004 Apr [cited 2014 Sep 16];57(4):366-72. Available from: http://www.ncbi.nlm.nih.gov/pubmed/15135837

Rabelo ER, Aliti GB, Domingues FB, Ruschel KB, Brun A de O. What to teach to patients with heart failure and why: the role of nurses in heart failure clinics. Rev Lat Am Enfermagem [Internet]. Escola de Enfermagem de Ribeirão Preto / Universidade de São Paulo; 2007 Feb [cited 2014 Sep 28];15(1):165-70. Available from: http://www.scielo.br/scielo.php?script=sci_arttext\&pid=S0104$11692007000100024 \&$ Ing =en\&nrm=iso\&tIng=pt

Razali R, Jean-Li L, Jaffar A, Ahmad M, Shah SA, Ibrahim N, et al. Is the Bahasa Malaysia version of the Montreal Cognitive Assessment (MoCA-BM) a better instrument than the Malay version of the Mini Mental State Examination (M-MMSE) in screening for mild cognitive impairment $(\mathrm{MCl})$ in the elderly? Compr Psychiatry [Internet]. Elsevier Inc.; 2014 Jan [cited 2014 Sep 28];55 Suppl 1:S70-5. Available from: http://www.ncbi.nlm.nih.gov/pubmed/24314103

Rector TS, Tschumperlin LK, Kubo SH, Bank AJ, Francis GS, McDonald KM, et al. Use of the Living With Heart Failure questionnaire to ascertain patients' perspectives on 
improvement in quality of life versus risk of drug-induced death. J Card Fail [Internet]. 1995 Jun [cited 2014 Sep 28];1(3):201-6. Available from: http://www.ncbi.nlm.nih.gov/pubmed/9420652

Redeker NS. Sleep Disturbance in People With Heart Failure: Implications for Self-care. J Cardiovasc Nurs [Internet]. 2008;23(3). Available from: http://journals.Iww.com/jcnjournal/Fulltext/2008/05000/Sleep_Disturbance_in_People_With_ Heart_Failure_.9.aspx

Redeker NS, Hilkert R. Sleep and quality of life in stable heart failure. J Card Fail. 2005 b;11:700-4.

Redeker NS, Muench U, Zucker MJ, Walsleben J, Gilbert M, Freudenberger R, et al. Sleep disordered breathing, daytime symptoms, and functional performance in stable heart failure. Sleep [Internet]. American Academy of Sleep Medicine; 2010 Apr 1 [cited 2014 Sep 29];33(4):551-60. Available from: /pmc/articles/PMC2849795/?report=abstract

Riegel B, Carlson B, Moser DK, Sebern M, Hicks FD, Roland V. Psychometric testing of the self-care of heart failure index. J Card Fail [Internet]. 2004 Aug [cited 2014 Sep 5];10(4):35060. Available from: http://linkinghub.elsevier.com/retrieve/pii/S1071916403008017

Riegel B, Dickson VV. A situation-specific theory of heart failure self-care. J Cardiovasc Nurs [Internet]. 2008 [cited 2014 Sep 29];23(3):190-6. Available from: http://www.ncbi.nlm.nih.gov/pubmed/18437059

Riegel B, Driscoll A, Suwanno J, Moser DK, Lennie TA, Chung ML, et al. Heart failure selfcare in developed and developing countries. J Card Fail [Internet]. 2009 a Aug [cited 2014 Sep 29];15(6):508-16. Available from: http://www.pubmedcentral.nih.gov/articlerender.fcgi?artid=2745342\&tool=pmcentrez\&rendert ype=abstract

Riegel B, Lee CS, Dickson VV. Self care in patients with chronic heart failure. Nat Rev Cardiol [Internet]. Nature Publishing Group; 2011 Nov [cited 2014 Sep 12];8(11):644-54. Available from: http://www.ncbi.nlm.nih.gov/pubmed/21769111

Riegel B, Moser DK, Anker SD, Appel LJ, Dunbar SB, Grady KL, et al. State of the science: Promoting self-care in persons with heart failure: A scientific statement from the american heart association. Circulation. 2009b. p. 1141-63.

Riegel B, Moser DK, Carlson B, Deaton C, Armola R, Sethares K, et al. Gender differences in quality of life are minimal in patients with heart failure. J Card Fail [Internet]. 2003 Feb [cited 2014 Sep 19];9(1):42-8. Available from: http://www.ncbi.nlm.nih.gov/pubmed/12612872

Riegel B, Weaver TE. Poor sleep and impaired self-care: towards a comprehensive model linking sleep, cognition, and heart failure outcomes. Eur J Cardiovasc Nurs [Internet]. Elsevier B.V.; 2009 Dec [cited 2014 Sep 19];8(5):337-44. Available from: http://www.pubmedcentral.nih.gov/articlerender.fcgi?artid=2788056\&tool=pmcentrez\&rendert ype=abstract

Rockwell JM, Riegel B. Predictors of self-care in persons with heart failure. Heart Lung [Internet]. $2001 \quad$ [cited 2014 Sep 20];30(1):18-25. Available from: http://www.ncbi.nlm.nih.gov/pubmed/11174364 
Rodríguez-Gázquez M de los Á, Arredondo-Holguín E, Herrera-Cortés R. Effectiveness of an educational program in nursing in the self-care of patients with heart failure: randomized controlled trial. Rev Lat Am Enfermagem [Internet]. [cited 2014 Sep 29];20(2):296-306. Available from: http://www.ncbi.nlm.nih.gov/pubmed/22699730

Roger VL. Epidemiology of heart failure. Circ Res [Internet]. 2013 Aug 30 [cited 2014 Aug 17];113(6):646-59. Available from: http://www.ncbi.nlm.nih.gov/pubmed/23989710

Rutledge T, Reis V a, Linke SE, Greenberg BH, Mills PJ. Depression in heart failure a metaanalytic review of prevalence, intervention effects, and associations with clinical outcomes. $J$ Am Coll Cardiol [Internet]. 2006 Oct 17 [cited 2014 Sep 25];48(8):1527-37. Available from: http://www.ncbi.nlm.nih.gov/pubmed/17045884

Saccomann ICR, Cintra FA, Gallani MCBJ. Qualidade de vida relacionada à Saúde em Idosos com Insuficiência cardíaca: avaliação com instrumento específico [Internet]. Acta Paul. Enferm. 2011a. p. 179-84. Available from: http://www.scielo.br/scielo.php?script=sci_arttext\&pid=S0103$21002011000200004 \&$ Ing=pt\&nrm=iso\&tlng=pt

Santos JJA dos, Plewka JEA, Brofman PRS. Quality of life and clinical indicators in heart failure: a multivariate analysis. Arq Bras Cardiol [Internet]. 2009 Aug [cited 2014 Sep 28];93(2):159-66. Available from: http://www.ncbi.nlm.nih.gov/pubmed/19838494

Santos MA dos, Cruz D de ALM da, Barbosa RL. Fatores associados ao padrão de sono em pacientes com insuficiência cardíaca [Internet]. Rev Esc Enferm USP. 2011. p. 1105-12. Available from: http://www.scielo.br/scielo.php?script=sci_arttext\&amp $/ n p i d=S 0080$ 62342011000500011

Santos Eficácia de medidas de Higiene do sono e fototerapia no sono e qualidade de vida de pacientes com insuficiência cardíaca - ensaio clínico. (Projeto de Pesquisa ), Universidade de São Paulo.

Sauvé MJ, Lewis WR, Blankenbiller M, Rickabaugh B, Pressler SJ. Cognitive impairments in chronic heart failure: a case controlled study. J Card Fail [Internet]. 2009 Feb [cited 2014 Sep 20];15(1):1-10. Available from: http://www.ncbi.nlm.nih.gov/pubmed/19181287

Sawafta FJS, Road HK, Chen X. Quality of Life of Chinese Heart Failure Patients and Their Family Caregivers Tongji Medical Collage- Huazhong University of science and technology Tongji Medical Collage- Huazhong University of science and technology. 2013 ;3(2):77-88.

Servantes DM, Pelcerman A, Salvetti XM, Salles AF, de Albuquerque PF, de Salles FCA, et al. Effects of home-based exercise training for patients with chronic heart failure and sleep apnoea: a randomized comparison of two different programmes. Clin Rehabil [Internet]. 2012 Jan [cited 2014 Sep 28];26(1):45-57. Available from: http://www.ncbi.nlm.nih.gov/pubmed/21937519

Seto E, Leonard KJ, Cafazzo JA, Barnsley J, Masino C, Ross HJ. Mobile phone-based telemonitoring for heart failure management: a randomized controlled trial. J Med Internet Res [Internet]. JMIR Publications Inc.; 2012 Jan [cited 2014 Sep 11];14(1):e31. Available from: /pmc/articles/PMC3374537/?report=abstract

Shah AB, Udeoji DU, Baraghoush A, Bharadwaj P, Yennurajalingam S, Schwarz ER. An evaluation of the prevalence and severity of pain and other symptoms in acute 
decompensated heart failure. J Palliat Med [Internet]. 2013 Jan [cited 2014 Sep 29];16(1):87-90. Available from: http://www.ncbi.nlm.nih.gov/pubmed/23272674

Shao J-H, Chang AM, Edwards H, Shyu Y-IL, Chen S-H. A randomized controlled trial of self-management programme improves health-related outcomes of older people with heart failure. J Adv Nurs [Internet]. 2013 Nov [cited 2014 Sep 8];69(11):2458-69. Available from: http://www.ncbi.nlm.nih.gov/pubmed/23488859

Siabani S, Leeder SR, Davidson PM, Najafi F, Hamzeh B, Solimani A, et al. Translation and Validation of the Self-care of Heart Failure Index Into Persian. J Cardiovasc Nurs [Internet]. 2014 C Jan 14 [cited 2014 Sep 19];00(00):1-5. Available from: http://www.ncbi.nlm.nih.gov/pubmed/24434822

Son Y-J, Song Y, Nam S, Shin W-Y, Lee S-J, Jin D-K. Factors associated with health-related quality of life in elderly Korean patients with heart failure. J Cardiovasc Nurs [Internet]. 2012 [cited $2014 \quad$ Sep 28];27(6):528-38. Available from: http://www.ncbi.nlm.nih.gov/pubmed/22343211

Steele LL, Steele JR. Heart Failure Outcomes Based on Race and Gender of Patients in a Medically Undeserved Area. J Immigr Minor Health [Internet]. 2013 Aug 22 [cited 2014 Sep 28]; Available from: http://www.ncbi.nlm.nih.gov/pubmed/23975013

Strueber M, O'Driscoll G, Jansz P, Khaghani A, Levy WC, Wieselthaler GM. Multicenter evaluation of an intrapericardial left ventricular assist system. J Am Coll Cardiol. 2011;57:1375-82.

Theander K, Hasselgren M, Luhr K, Eckerblad J, Unosson M, Karlsson I. Symptoms and impact of symptoms on function and health in patients with chronic obstructive pulmonary disease and chronic heart failure in primary health care. Int $\mathrm{J}$ Chron Obstruct Pulmon Dis [Internet]. $2014 \quad$ Jan;9:785-94. Available from: http://www.pubmedcentral.nih.gov/articlerender.fcgi?artid=4111648\&tool=pmcentrez\&rendert ype=abstract

Tiesinga LJ, Dassen TW, Halfens RJ. DUFS and DEFS: development, reliability and validity of the Dutch Fatigue Scale and the Dutch Exertion Fatigue Scale. Int J Nurs Stud [Internet]. 1998 [cited 2014 Sep 28];35(1-2):115-23. Available from: http://www.ncbi.nlm.nih.gov/pubmed/9695018

Tung $\mathrm{H}-\mathrm{H}$, Chen S-C, Yin W-H, Cheng $\mathrm{C}-\mathrm{H}$, Wang T-J, Wu S-F. Self care behavior in patients with heart failure in Taiwan. Eur J Cardiovasc Nurs [Internet]. 2012 Jun [cited 2014 Sep 28];11(2):175-82. Available from: http://www.ncbi.nlm.nih.gov/pubmed/21382750

Tung H-H, Lin C-Y, Chen K-Y, Chang C-J, Lin Y-P, Chou C-H. Self-management intervention to improve self-care and quality of life in heart failure patients. Congest Heart Fail [Internet]. 2013 [cited 2014 Sep 21];19(4):E9-E16. Available from: http://www.ncbi.nlm.nih.gov/pubmed/23279120

Vellone E, Riegel B, D'Agostino F, Fida R, Rocco G, Cocchieri A, et al. Structural equation model testing the situation-specific theory of heart failure self-care. J Adv Nurs [Internet]. 2013 Nov [cited 2014 Sep 22];69(11):2481-92. Available from: http://www.ncbi.nlm.nih.gov/pubmed/23521633

Vogels RLC, Oosterman JM, van Harten B, Scheltens P, van der Flier WM, Schroeder-Tanka $\mathrm{JM}$, et al. Profile of cognitive impairment in chronic heart failure. J Am Geriatr Soc [Internet]. 2007 a Nov [cited 2014 Aug 14];55(11):1764-70. Available from: http://www.ncbi.nlm.nih.gov/pubmed/17727641 
Vogels RLC, Scheltens P, Schroeder-Tanka JM, Weinstein HC. Cognitive impairment in heart failure: a systematic review of the literature. Eur J Heart Fail [Internet]. 2007 b May [cited 2014 Sep 29];9(5):440-9. Available from: http://www.ncbi.nlm.nih.gov/pubmed/17174152

Wahle C, Adamopoulos C, Ekundayo OJ, Mujib M, Aronow WS, Ahmed A. A propensitymatched study of outcomes of chronic heart failure (HF) in younger and older adults. Arch Gerontol Geriatr [Internet]. NIH Public Access; 2009 Jan [cited 2014 Sep 28];49(1):165-71. Available from: /pmc/articles/PMC2685163/?report=abstract

Wang T-J, Lee S-C, Tsay S-L, Tung H-H. Factors influencing heart failure patients' sleep quality. J Adv Nurs [Internet]. 2010 Aug [cited 2014 Sep 29];66(8):1730-40. Available from: http://www.ncbi.nlm.nih.gov/pubmed/20557385

Welsh D, Lennie TA, Marcinek R, Biddle MJ, Abshire D, Bentley B, et al. pilot study results. 2013;12(1):1-14.

Yaghoubi A, Tabrizi J-S, Mirinazhad M-M, Azami S, Naghavi-Behzad M, Ghojazadeh M. Quality of life in cardiovascular patients in iran and factors affecting it: a systematic review. J Cardiovasc Thorac Res [Internet]. 2012 Jan [cited 2014 Oct 2];4(4):95-101. Available from: http://www.pubmedcentral. nih.gov/articlerender.fcgi?artid=3825371\&tool=pmcentrez\&rendert ype $=$ abstract

Yeh GY, McCarthy EP, Wayne PM, Stevenson LW, Wood MJ, Forman D, et al. Tai chi exercise in patients with chronic heart failure: a randomized clinical trial. Arch Intern Med [Internet]. 2011 Apr 25 [cited 2014 Sep 28];171(8):750-7. Available from: http://www.pubmedcentral.nih.gov/articlerender.fcgi?artid=3277798\&tool=pmcentrez\&rendert ype=abstract

Zambroski CH, Moser DK, Bhat G, Ziegler C. Impact of symptom prevalence and symptom burden on quality of life in patients with heart failure. Eur J Cardiovasc Nurs [Internet]. 2005 Sep [cited 2014 Sep 16];4(3):198-206. Available from: http://www.ncbi.nlm.nih.gov/pubmed/15916924

The World Health Organization quality of life assessment (WHOQOL): Position paper from the World Health Organization. Soc Sci Med [Internet]. 1995 Nov [cited 2014 Sep 23];41(10):1403-9. Available from: http://www.sciencedirect.com/science/article/pii/027795369500112K 
Anexos 


\title{
ANEXOS
}

\author{
ANEXO A
}

\section{TERMO de Consentimento LivRe E Esclarecido}

\section{I - DADOS DE IDENTIFICAÇÃO dO SUJEITO DE PESQUISA}

Nome do participante

Documento de Identidade $\mathrm{N}^{\circ}$ Sexo $M \square \quad F \square$

Data de Nascimento I

Endereço

Cidade CEP Telefone

\section{II - DADOS SOBRE A PESQUISA CIENTÍFICA}

TítULo DA PESQUISA: Eficácia de medidas de higiene do sono e fototerapia no sono e qualidade de vida de pacientes com Insuficiência Cardíaca - ensaio clínico

Pesquisador: Mariana Alvina dos Santos

CARGO/ Função: Enfermeira

INSCRIÇÃo CONSELHO REGIONAL :105.649

\section{LOCAL DA PESQUisa:}

\section{AvALIAÇÃO de RISCO DA PESQUISA:}

Sem risco X Risco mínimo $\square \quad$ Risco baixo $\square \quad$ Risco médio $\square \quad$ Risco maior $\square$

(probabilidade de que o indivíduo sofra algum dano como consequência imediata ou tardia do estudo)

DURAÇÃO DA PESQUISA: 11/2012 a 06/2013

\section{III - REGISTRO DAS EXPLICAÇÕES DO PESQUISADOR AO PACIENTE OU SEU REPRESENTANTE LEGAL SOBRE A PESQUISA}

O senhor (a) está sendo convidado a participar da Pesquisa: Eficácia de medidas de higiene do sono e fototerapia no sono e qualidade de vida de pacientes com Insuficiência Cardíaca - ensaio clínico. A seguir, alguns esclarecimentos sobre a mesma:

1) Um sono satisfatório é um dos principais meios para que possamos desempenhar as atividades do dia-a-dia com qualidade. Sendo assim, o objetivo desta pesquisa é conhecer o efeito do uso de intervenções não farmacológicas (que não usam medicamentos) na melhora no padrão de sono em pacientes com insuficiência cardíaca.

2) Para isto, será necessário que o senhor(a) responda um questionário com perguntas sobre o seu sono, seu dia-a-dia e outras questões relacionadas a outros sintomas sobre sua doença, em 4 (quatro) encontros programados com o pesquisador no Ambulatório de Insuficiência Cardíaca do IDPC.

3) Os resultados deste estudo ajudarão na prescrição de cuidados para um sono de melhor qualidade em pacientes com insuficiência cardíaca, melhorando assim sua qualidade de vida. 
1) A qualquer tempo vocês, participantes deste estudo, poderão ter acesso às informações sobre a pesquisa, seus procedimentos, riscos e benefícios, inclusive para tirar dúvidas pelos telefones/endereços abaixo citados.

2) A participação nesta pesquisa é voluntária e a pessoa que participar poderá retirar o consentimento a qualquer momento e, portanto, pode deixar de participar do estudo, sem acarretar prejuízos ao tratamento médico.

3) Os participantes não serão identificados garantindo-se o sigilo das respostas, que permanecerão confidenciais. Este estudo não trará riscos ou prejuízos ao seu tratamento. E os resultados obtidos serão divulgados em revistas e eventos científicos.

\section{V - INFORMAÇÕES DE NOMES, ENDEREÇOS E TELEFONES DOS RESPONSÁVEIS PELO ACOMPANHAMENTO DA PESQUISA, PARA CONTATO EM CASO DE INTERCORRÊNCIAS CLÍNICAS E REAÇÕES ADVERSAS}

Acredito ter sido suficientemente esclarecido em relação ao projeto: "Eficácia de medidas de higiene do sono e fototerapia no sono e qualidade de vida de pacientes com Insuficiência Cardíaca ensaio clínico."

Discuti com a enfermeira Mariana Alvina dos Santos sobre minha decisão em participar nesse estudo. Ficam claros para mim quais são os propósitos do estudo, os procedimentos a serem realizados, seus desconfortos e riscos, as garantias de confidencialidade e de esclarecimentos permanentes. Ficou claro também que minha participação é isenta de despesas e que tenho garantia do acesso a tratamento hospitalar quando necessário. Concordo voluntariamente em participar deste estudo e poderei retirar o meu consentimento a qualquer momento, antes ou durante o mesmo, sem penalidades ou prejuízo ou perda de qualquer benefício que eu possa ter adquirido, ou no meu atendimento neste Serviço. Este Termo será assinado em duas vias, sendo que uma ficará em minha posse e a outra com a pesquisadora.

São Paulo, de de 20

Assinatura do sujeito de pesquisa

Declaro que obtive de forma apropriada e voluntária o Consentimento Livre e Esclarecido deste paciente.

Escola de Enfermagem da USP (EE-USP)

Pesquisadora: Mariana Alvina dos Santos

Av. Dro Enéas de Carvalho Aguiar, 419 sala 314

Telefone: (11)-9475 7261
Comitê de Ética em Pesquisa da EEUP

E-mail: edipesq@usp.br Telefone: (11)-3061 7548 


\section{ANEXO B \\ INSTRUMENTO PARA SELEÇÃO DOS PARTICIPANTES DA PESQUISA}

Nome:

$\mathrm{RH}:$ Número Prontuário Ambulatório:

DATA DA COLETA:

\section{CheKLIST dos Critérios de PARTICIPAÇÃo}

1. Regularmente matriculado no Ambulatório de IC do IDPC

2. Idade maior ou igual a 18 anos

3. Diagnóstico confirmado de IC classe funcional I, II ou II

4. Clinicamente em condições de participar da entrevista

5. Ausência doenças psiquiátricas, oncológicas, infecciosas com repercussão no estado geral, ou doenças endócrino-metabólicas sem tratamento (por exemplo, diabetes mellitus ou doenças tireoidianas)

7. Pós-operatório recente (até 60 dias de pós operatório) de qualquer intervenção cirúrgica

8. Faz tratamento farmacológico/não farmacológico para melhora do sono

9. Tem contato telefônico

10. Atende aos critérios de Participação

$\begin{array}{ll}\square \text { Sim } & \square \text { Não } \\ \square \text { Sim } & \square \text { Não } \\ \square \text { Sim } & \square \text { Não } \\ \square \text { Sim } & \square \text { Não } \\ \square \text { Sim } & \square \text { Não } \\ & \\ \square \text { Sim } & \square \text { Não } \\ \square \text { Sim } & \square \text { Não } \\ \square \text { Sim } & \square \text { Não } \\ \square \operatorname{Sim} & \square \text { Não }\end{array}$




\section{ANEXO C - INSTRUMENTOS DE COLETA DE DADOS}

\begin{tabular}{|l|l|}
\hline INSTRUMENTO DE COLETA DE DADOS & $\mathrm{N}^{\circ}$ pcte no \\
AVALIAÇÃO INICIAL & estudo: \\
RH: & IC:_- \\
\hline
\end{tabular}

Data da avaliação:

Avaliador:

Telefones para contato:

Identificação

Nome:

Gênero: $1 \square$ M $2 \square F$ Idade: DN: Naturalidade: Procedência:

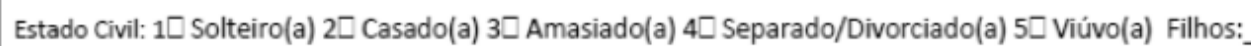

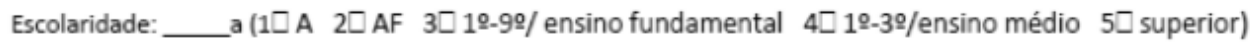
Profissão: $1 \square$ Do Lar 2ॅEstudante $\square$

Situação Trabalhista: $1 \square$ Empregado $2 \square$ Desempregado $3 \square$ Aposentado $4 \square$ Auxilio Doença $5 \square$ Pensionista

\section{Investigação Clínica}

Diagnóstico Médico Principal (motivo pelo qual é acompanhado no serviço):

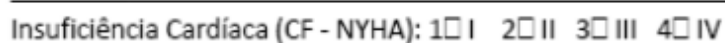

\section{ANTECEDENTES PESSOAIS}

1[ Nega ou desconhece AP além da Insuficiência Cardiaca

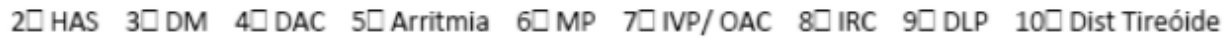

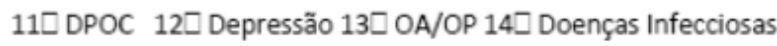

$15 \square$ Neoplasias $\square$

$16 \square$ AVEi / h prévio? Há _ a - $\square$ sem seqüela $\square$ com seqüela: \cognitiva \motora $\square$

Tratamentos Anteriores:

Clínicos:

Cirúrgicos: 
Terapia Medicamentosa

¿Não usa: \não foi prescrito \controle inadequado $\square$ NREF $\square$ NMED

\begin{tabular}{|c|c|c|c|c|c|}
\hline $\begin{array}{l}\text { Quais medicamentos o } \mathrm{Sr}(\text { a) usou na última } \\
\text { semana? (Incluir medicaçōes para o sono) }\end{array}$ & Dose & $\begin{array}{c}, n^{\circ} \text { de } \\
\text { tomadas } \\
\text { por dia }\end{array}$ & Via & $\begin{array}{c}\text { Há quanto tempo } \\
\text { usa cada } \\
\text { medicamento? }\end{array}$ & $\begin{array}{c}\text { O Sr(a) usa o } \\
\text { medicamento conforme } \\
\text { foi prescrito? }\end{array}$ \\
\hline 1 & & & & & $1 \square \mathrm{Näo} 2 \square \mathrm{sim}$ \\
\hline 2 & & & & & $1 \square \mathrm{Nä \circ} 2 \square \mathrm{sim}$ \\
\hline 3 & & & & & $1 \square \mathrm{Nä \circ} 2 \square \mathrm{sim}$ \\
\hline 4 & & & & & $1 \square \mathrm{Não} 2 \square \mathrm{sim}$ \\
\hline 5 & & & & & $1 \square$ Não $2 \square \mathrm{sim}$ \\
\hline 6 & & & & & $1 \square$ Não $2 \square \mathrm{sim}$ \\
\hline 7 & & & & & $1 \square$ Não $2 \square \mathrm{sim}$ \\
\hline 8 & & & & & $1 \square$ Não $2 \square \mathrm{sim}$ \\
\hline 9 & & & & & $1 \square$ Não $2 \square \mathrm{sim}$ \\
\hline 10 & & & & & $1 \square$ Não $2 \square \mathrm{sim}$ \\
\hline
\end{tabular}

\section{DISPNÉIA}

O Sr.(a) senta falta de ar? 1โNão $2 \square \operatorname{Sim}$ - Quando o Sr (a) sente falta de ar?

1 1. pequenos esforços (caminhar no plano, tomar banho ou ficar de pé)

$2 \square$ médios esforços (subir pequenos aclives, subir menos que 3 lances de escada ou carregando volumes leves no plano)

$3 \square$ grandes esforços (subir grandes aclives, subir mais que 3 lances de escada)

$4 \square$ intensos esforços (Carregar volumes muito pesados no plano, pesos leves em aclives ou correndo)

\section{NOCTÚRIA}

O Sr.(a) acorda durante a noite para ir ao banheiro ? 1] Não $2 \square$ Sim - com qual frequências? $1 \square 1 \mathrm{X} /$ noite $2 \square 2 \mathrm{X} /$ noite $3 \square 3 \mathrm{X} /$ noite $4 \square 4 \mathrm{X}$ ou mais /noite

\section{TABAGISMO}

O Sr (a) fuma atualmente? 1 1 Sim (Quantos maços por dia: Há quantos anos fuma $2 \square$ Não

Parou de fumar nos últimos 12 meses? $1 \square \operatorname{sim} 2 \square$ não Se sim, há quanto tempo? 
ÍNDICE DE QUALIDADE DE SONO DE PITTSBURGH (PSQI-BR) (Buysse et al., 1989)

\begin{tabular}{|c|c|c|c|c|}
\hline \multicolumn{5}{|c|}{$\begin{array}{l}\text { 1. Durante o último mês, quando você geralmente foi para a cama à noite? } \\
\text { Hora usual de deitar: } \\
\text { 2. Durante o último mês, quanto tempo (em minutos) você geralmente levou para dormir à noite? } \\
\text { Número em minutos: } \\
\text { 3. Durante o último mês, quando você geralmente levantou de manhã? } \\
\text { Hora usual de levantar: } \\
\text { 4. Durante o último mês, quantas horas de sono você teve por noite? (Este pode ser diferente do número de horas } \\
\text { que você ficou na cama). } \\
\text { Horas de sono por noite: }\end{array}$} \\
\hline $\begin{array}{l}\text { 5. Durante o último mês, com que frequência você teve } \\
\text { dificuldade de dormir porque você... }\end{array}$ & $\begin{array}{c}\text { Nenhuma no } \\
\text { último me̊s } \\
(0)\end{array}$ & $\begin{array}{c}\text { Menos de } \\
1 \mathrm{x} / \mathrm{sem} \\
(1)\end{array}$ & $\begin{array}{l}1 \text { ou } 2 \\
x / \text { sem } \\
(2)\end{array}$ & $\begin{array}{c}3 \text { ou mais } \\
\text { x/sem } \\
\text { (3) }\end{array}$ \\
\hline \multicolumn{5}{|l|}{ a) Não conseguiu adormecer em até 30 minutos } \\
\hline \multicolumn{5}{|l|}{ b) Acordou no meio da noite ou de manhã cedo } \\
\hline \multicolumn{5}{|l|}{ c) Precisou levantar para ir ao banheiro } \\
\hline \multicolumn{5}{|l|}{ d) Não conseguiu respirar confortavelmente } \\
\hline \multicolumn{5}{|l|}{ e) Tossiu ou roncou forte } \\
\hline \multicolumn{5}{|l|}{ f) Sentiu muito frio } \\
\hline \multicolumn{5}{|l|}{ g) Sentiu muito calor } \\
\hline \multicolumn{5}{|l|}{ h)Teve sonhos ruins } \\
\hline \multicolumn{5}{|l|}{ h) Teve dor } \\
\hline \multicolumn{5}{|l|}{$\begin{array}{l}\text { j) Outra(s) razão(ס̃es), por favor descreva, incluindo a } \\
\text { frequência com que esse problema atrapalha seu sono: }\end{array}$} \\
\hline $\begin{array}{l}\text { 6. Durante o último mès, como você classificaria a qualidade do } \\
\text { seu sono de uma maneira geral? }\end{array}$ & Muito boa $(0)$ & Boa (1) & Ruim (2) & $\begin{array}{l}\text { Muito ruim } \\
\text { (3) }\end{array}$ \\
\hline \multicolumn{5}{|l|}{$\begin{array}{l}\text { 7. Durante o último mês, com que frequência você tomou } \\
\text { medicamento (prescrito ou "por conta própria") para lhe ajudar } \\
\text { a dormir? }\end{array}$} \\
\hline \multicolumn{5}{|l|}{$\begin{array}{l}\text { 8. No último mês, com que frequência você teve dificuldade de } \\
\text { ficar acordado enquanto dirigia, comia ou participava de uma } \\
\text { atividade social (festa, reunião de amigos, trabalho, estudo)? }\end{array}$} \\
\hline \multicolumn{5}{|l|}{$\begin{array}{l}\text { 9. Durante o último mês, quão problemático foi para você manter } \\
\text { o entusiasmo (ânimo) para fazer as coisas (suas atividades } \\
\text { habituais)? }\end{array}$} \\
\hline \multicolumn{5}{|c|}{ Componente 1: Resp questão 6 ( Mto boa=0; Boa=1; Ruim=2;Mto ruim=3) $\quad$ C1: } \\
\hline \multicolumn{5}{|c|}{ Componente 2: Resp questão $2(\leq 15 \mathrm{mim}=0 ; 16-30 \mathrm{~min}=1 ; 31-60 \mathrm{~min}=2 ;>60 \mathrm{~min}=3)+5 \mathrm{a}$} \\
\hline \multicolumn{5}{|c|}{ Atribua à pontuação: $0=0 ; 1-2=1 ; 3-4=2 ; 5-6=3$ ) } \\
\hline \multirow{2}{*}{\multicolumn{5}{|c|}{$\begin{array}{l}\text { Componente 3: Resp questão } 4 \text { ( }>7 \mathrm{~h}=0 ; 6-7 \mathrm{~h}=1 ; 5-6 \mathrm{~h}=2 ;<5 \mathrm{~h}=3) \\
\text { Componente } 4 \text { : (total horas dormidas }) \div(\text { total de horas na cama) } \times 100\end{array}$}} \\
\hline Componente $4:$ (total horas dormidas $) \div($ total de horas na cama) $\times 100$ & & & & \\
\hline \multicolumn{2}{|l|}{ Atribua: $>85 \%=0 ; 75-84 \%=1 ; 65-74 \%=2 ;<65 \%=3$} & C4: & & \\
\hline \multicolumn{2}{|l|}{ Componente 5: Soma respostas $5 b-5 j(0=0 ; 1-9=1 ; 10-18=2 ; 19-27=3)$} & C5: & & \\
\hline \multicolumn{2}{|c|}{ Componente 6: Resposta questão 7 (0 vezes $=0 ;<1$ vez $=1 ; 1-2$ vezes $=2 ; 3$ ou + vezes $=3$ ) } & C6: & & \\
\hline \multicolumn{2}{|l|}{ Componente 7: Soma questão 8 e $9(0=0 ; 1-2=1 ; 3-4=2 ; 5-6=3)$} & C7: & & \\
\hline PSQI: $\leq 5$ bom dormidor PSQI: > 5 mau dormidor & Soma $7 \mathrm{co}$ & mponentes & & \\
\hline
\end{tabular}




\section{Qualidade de VIDA - Minessota Living With Heart FaILURe Questionnaire (Rector \& Cohn, 1992) \\ (Tradução Para o PoRtuguês Carrara, 2001)}

\section{DURANTE O ÚLTIMO MÊS SEU PROBLEMA CARDÍACO O IMPEDIU DE VIVER COMO VOCÊ QUERIA POR QUÊ?}

\begin{tabular}{|c|c|c|c|c|c|c|c|c|}
\hline & & & 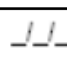 & $-1-1$ & $-1 /-$ & $-I_{-}$ & $-1-1$ & $-1-4$ \\
\hline & & Pré & $6 m$ & $12 \mathrm{~m}$ & $18 \mathrm{~m}$ & $24 \mathrm{~m}$ & $36 \mathrm{~m}$ & $48 \mathrm{~m}$ \\
\hline 1. & Causou inchaço em seus tornozelos e pernas & () & () & () & () & () & () & () \\
\hline 2. & Obrigando você a sentar ou deitar para descansar durante o di & $\mathrm{dia}()$ & () & () & () & () & () & () \\
\hline 3. & Tornando sua caminhada e subida de escadas difícil & () & () & () & () & () & () & () \\
\hline 4. & Tornando seu trabalho doméstico difícil & () & () & () & () & () & () & () \\
\hline 5. & Tornando suas saídas de casa difícil & () & () & () & () & () & () & () \\
\hline 6. & Tornando dificil domir bem a noite & () & () & () & () & () & () & () \\
\hline & Tornando seus relacionamentos ou atividades com familiares & & & & & & & \\
\hline & e amigos dificil & () & () & () & () & () & () & () \\
\hline 8. & Tornando seu trabalho para ganhar a vida dificil & () & () & () & () & () & () & () \\
\hline 9. & Tornando seus passatempos, esportes e diversa̋o difícil & () & () & () & () & () & () & () \\
\hline 10. & Tornando sua atividade sexual difícil & () & () & () & () & () & () & () \\
\hline 11. & Fazendo você comer menos as comidas que você gosta & () & () & () & () & () & () & () \\
\hline 12. & Causando falta de ar & () & () & () & () & () & () & () \\
\hline 13. & Deixando você cansado, fatigado ou com pouca energia & () & () & () & () & () & () & () \\
\hline 14. & Obrigando você a ficar hospitalizado & () & () & () & () & () & () & () \\
\hline & Fazendo você gastar dinheiro com cuidados médicos & () & () & () & () & () & () & () \\
\hline & Causando a você efeitos colaterais das medicaçốes & () & () & () & () & () & () & () \\
\hline 17. & Fazendo você sentir-se um peso para familiares e amigos & () & () & () & () & () & () & () \\
\hline 18. & Fazendo você sentir uma falta de auto controle na sua vida & () & () & () & () & () & () & () \\
\hline 19. & Fazendo você se preocupar & () & () & () & () & () & () & () \\
\hline & Tornando difícil você concentrar-se ou lembrar-se das coisas & () & () & () & () & () & () & () \\
\hline & Fazendo você sentir-se deprimido & () & () & () & () & () & () & () \\
\hline & $\begin{array}{l}\text { MUITO } \\
\text { POUCO }\end{array}$ & & & & & & EMAIS & \\
\hline & 1 & 3 & & 4 & & & 5 & \\
\hline
\end{tabular}




\section{MINI-EXAME DO ESTADO MENTAL}

(Folstein, Folstein \& McHugh, 1.975)

Paciente:

Data da Avaliação: I _ Avaliador:

\section{ORIENTAÇÃO}

. Dia da semana (1 ponto) .......................................

- Dia do mês (1 ponto) ........................................

- Mês (1 ponto) ...............................................

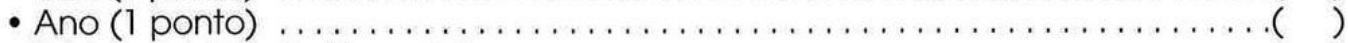

- Hora aproximada (1 ponto) ...................................

- Local específico (aposento ou setor) (1 ponto) ....................... ( )

- Instituição (residência, hospital, clínica) (1 ponto) ....................

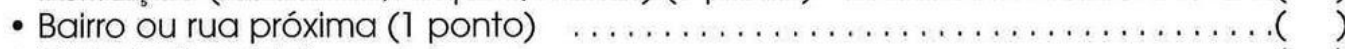

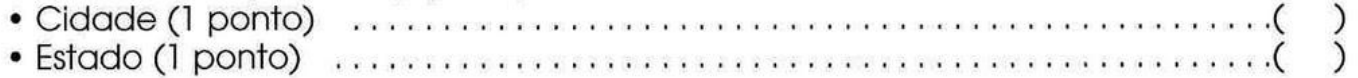

\section{MEMÓRIA IMEDIATA}

- Fale 3 palavras não relacionadas. Posteriormente pergunte ao paciente pelas 3 palavras. Dê 1 ponto para cada resposta correta Depois repita as palavras e certifique-se de que o paciente as aprendeu, pois mais adiante você irá perguntá-las novamente.

\section{ATENÇÃO E CÁLCULO}

- (100 - 7) sucessivos, 5 vezes sucessivamente

(1 ponto para cada cálculo correto)

(alternativamente, soletrar MUNDO de trás para frente)

\section{EVOCAÇÃO}

- Pergunte pelas 3 palavras ditas anteriormente (1 ponto por palavra)

\section{LINGUAGEM}

- Nomear um relógio e uma caneta (2 pontos)

- Repetir "nem aqui, nem ali, nem lá) (1 ponto)

- Comando: "pegue este papel com a mão direita dobre ao meio e coloque no chão ( 3 ptos $) \ldots \ldots \ldots \ldots \ldots \ldots \ldots \ldots \ldots$ ( )

- Ler e obedecer: "feche os olhos" (1 ponto) ........................

- Escrever uma frase (1 ponto) ..................................

- Copiar um desenho (1 ponto)

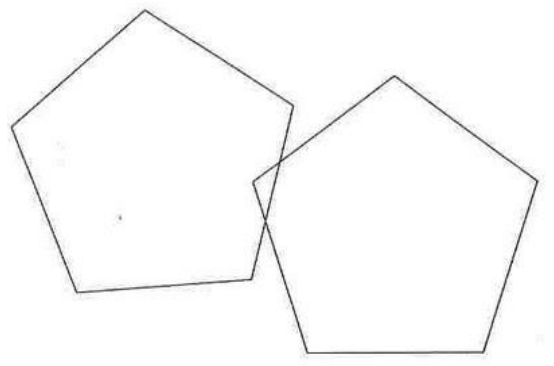


ESCALA DE AUTOCUIDADO PARA PACIENTES COM INSUFICIÊNCIA CARDÍACA EAC-IC (ÀVILA ET AL. 2011)

\begin{tabular}{|c|c|c|c|c|}
\hline \multicolumn{5}{|c|}{$\begin{array}{l}\text { Pense em como você tem se sentido no último mês ou desde a última vez em que conversamos ao completar } \\
\text { esses itens. } \\
\text { SEÇÃO A:_Segue abaixo uma lista de orientações normalmente dadas às pessoas com insuficiência cardiaca. Com } \\
\text { que frequência você realiza as seguintes atividades? }\end{array}$} \\
\hline & $\begin{array}{l}\text { Nunca ou } \\
\text { raramente }\end{array}$ & Às vezes & Frequentemente & $\begin{array}{l}\text { Sempre ou } \\
\text { diariamente }\end{array}$ \\
\hline 1. Você se pesa? & 1 & 2 & 3 & 4 \\
\hline 2. Verifica se os seus tornozelos estão inchados? & 1 & 2 & 3 & 4 \\
\hline $\begin{array}{l}\text { 3.Tenta evitar ficar doente (por exemplo: vacinar-se } \\
\text { contra a gripe, evitar contato com pessoas } \\
\text { doentes)? }\end{array}$ & 1 & 2 & 3 & 4 \\
\hline 4. Realiza alguma atividade fisica? & 1 & 2 & 3 & 4 \\
\hline $\begin{array}{l}\text { 5.É assiduo nas consultas com médico ou } \\
\text { enfermeiro? }\end{array}$ & 1 & 2 & 3 & 4 \\
\hline 6. Ingere uma dieta com pouco sal? & 1 & 2 & 3 & 4 \\
\hline 7. Exercita-se por 30 minutos? & 1 & 2 & 3 & 4 \\
\hline $\begin{array}{l}\text { 8. Esquece-se ou deixa de tomar algum de seus } \\
\text { medicamentos? }\end{array}$ & 1 & 2 & 3 & 4 \\
\hline $\begin{array}{l}\text { 9. Solicita alimentos com pouco sal quando come } \\
\text { fora ou visita alguém? }\end{array}$ & 1 & 2 & 3 & 4 \\
\hline $\begin{array}{l}\text { 10. Usa um sistema (caixa de comprimido, } \\
\text { lembretes) para ajudá-lo a lembrar de seus } \\
\text { medicamentos? }\end{array}$ & 1 & 2 & 3 & 4 \\
\hline
\end{tabular}

SEÇÃO B:Muitos pacientes têm sintomas devido à sua insuficiência cardiaca. Dificuldade em respirar e tornozelos inchados são sintomas comuns de insuficiência cardiaca.

No mês passado, você teve problemas para respirar ou tornozelos inchados? Circule uma das opções: 0) Não 1) Sim

11. Se teve problemas para respirar ou tornozelos inchados no último mês... (circule um número)

\begin{tabular}{|l|c|c|c|c|c|c|}
\hline & $\begin{array}{c}\text { Não tive } \\
\text { tais } \\
\text { sintomas }\end{array}$ & $\begin{array}{c}\text { Não } \\
\text { reconheci }\end{array}$ & $\begin{array}{c}\text { Demorei muito } \\
\text { para } \\
\text { reconhecer }\end{array}$ & $\begin{array}{c}\text { Demorei um } \\
\text { pouco para } \\
\text { reconhecer }\end{array}$ & $\begin{array}{c}\text { Reconheci } \\
\text { rapidamente }\end{array}$ & $\begin{array}{c}\text { Reconheci } \\
\text { imediatamente }\end{array}$ \\
\hline $\begin{array}{l}\text { Com que rapidez você os } \\
\text { reconheceu como um } \\
\text { sintoma de insuficiência } \\
\text { cardiaca? }\end{array}$ & N/A & 0 & 1 & 2 & 3 & 4 \\
\hline
\end{tabular}


Abaixo estão os recursos que são utilizados por pessoas com insuficiência cardiaca. Se você tem dificuldade para respirar ou inchaço nos tornozelos, qual a probabilidade de você tentar um destes recursos? (circule um número para cada um dos recursos)

\begin{tabular}{|l|c|c|c|c|}
\hline & Improvável & $\begin{array}{c}\text { Pouco } \\
\text { provável }\end{array}$ & $\begin{array}{c}\text { Provável } \\
\text { Muito } \\
\text { provável }\end{array}$ \\
\hline 12. Reduzir o sal na sua dieta & 1 & 2 & 3 & 4 \\
\hline 13. Reduzir a ingestão de líquidos & 1 & 2 & 3 & 4 \\
\hline 14. Ingerir um diurético a mais & 1 & 2 & 3 & 4 \\
\hline $\begin{array}{l}\text { 15. Contatar seu médico ou enfermeiro para } \\
\text { orientação }\end{array}$ & 1 & 2 & 3 & 4 \\
\hline
\end{tabular}

16. Pense em um dos recursos acima que você tentou na última vez em que teve dificuldade para respirar ou tornozelos inchados, (circule um número)

\begin{tabular}{|l|c|c|c|c|c|}
\hline & $\begin{array}{c}\text { Eu não } \\
\text { tentei nada }\end{array}$ & $\begin{array}{c}\text { Não tenho } \\
\text { certeza }\end{array}$ & $\begin{array}{c}\text { Tenho } \\
\text { pouca } \\
\text { certeza }\end{array}$ & $\begin{array}{c}\text { Tenho } \\
\text { certeza }\end{array}$ & $\begin{array}{c}\text { Tenho } \\
\text { absoluta } \\
\text { certeza }\end{array}$ \\
\hline $\begin{array}{l}\text { Você tem certeza de que este recurso o } \\
\text { ajudou? }\end{array}$ & 0 & 1 & 2 & 3 & 4 \\
\hline
\end{tabular}

\section{SEÇÃO C:}

De maneira geral, você está confiante sobre:

\begin{tabular}{|c|c|c|c|c|}
\hline & $\begin{array}{l}\text { Não } \\
\text { confiante }\end{array}$ & $\begin{array}{l}\text { Um pouco } \\
\text { confiante }\end{array}$ & $\begin{array}{c}\text { Muito } \\
\text { confiante }\end{array}$ & $\begin{array}{c}\text { Extremam } \\
\text { ente } \\
\text { confiante }\end{array}$ \\
\hline 1. Estar livre dos sintomas de insuficiência cardiaca? & 1 & 2 & 3 & 4 \\
\hline 2. Seguir o tratamento recomendado? & 1 & 2 & 3 & 4 \\
\hline 3. Avaliar a importância de seus sintomas? & 1 & 2 & 3 & 4 \\
\hline 4. Reconhecer alterações na saúde, caso elas ocorram? & 1 & 2 & 3 & 4 \\
\hline 5. Fazer algo que possa aliviar seus sintomas? & 1 & 2 & 3 & 4 \\
\hline 6. Avaliar se um medicamento funciona? & 1 & 2 & 3 & 4 \\
\hline
\end{tabular}




\section{FADIGA}

\section{DUFS - Auto Relato Adaptado}

(Tiesinga et al., 1998)

Os sintomas da fadiga estão descritos na próxima página. Pedimos que você indique o quanto você apresenta de cada um desses sintomas. Marque um $\mathrm{X}$ em um dos cinco quadradinhos entre não e sim, sendo que o não significa que esta situação não ocorre com você e o sim significa que a situação ocorre sempre. Por favor, não deixe de responder sobre nenhum sintoma.

Abaixo há dois exemplos que lhe darão uma ideia de como responder às questões. Em quase todas as questões o aparece o termo ultimamente; ele se refere aos últimos 3 a 6 meses. Exemplos:

$$
\text { NÃO }<-1->S I M
$$

Ultimamente, você tem dito para si mesmo(a) que as coisas não são tão ruins ?

[Se, por exemplo, tem sido raro você dizer isso para si mesmo(a) ultimamente, marque o segundo quadradinho da esquerda para a direita]

Ultimamente, você tem evitado situações dificeis?

[Se, por exemplo, você sempre evita situações dificeis,

marque o quadradinho da extrema direita]

1 Ultimamente você tido uma sensação forte $e$ constante de falta de energia?

2 Ultimamente você tem observado que precisa de mais energia para dar conta das suas tarefas diárias?

3 Ultimamente você tem se sentido sem disposição para fazer as coisas?

4 Ultimamente você tem acordado com a sensação de estar exausto e desgastado?

5 Ultimamente você tem tido necessidade de descansar mais?

6 Ultimamente você tem conseguido fazer suas atividades do dia-a-dia?

7 Ultimamente seu interesse por sexo, sua vontade de ter relações sexuais diminuiu?

8 Tem sido mais dificil se concentrar em uma coisa por muito tempo?

Nunca Raramente Pouco Frequentemente Sempre

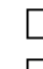




\section{DEFS - Auto Relato AdAPTAdo}

(Tiesinga et al., 1998)

Na próxima página são listadas várias atividades do dia-a-dia. Pedimos que você descreva o quanto essas atividades são atualmente fatigantes para você. Marque um $X$ em um dos cinco quadradinhos entre não e sim, sendo que o não significa que a atividade não lhe causa fadiga e o sim significa que essa atividade é extremamente fatigante. Por favor, não deixe de responder nenhuma questão.

Abaixo há dois exemplos que dão uma ideia de como responder as questões.

Exemplos:

Você acha fatigante preparar sanduíches?

[Se, por exemplo, você acha que essa atividade é

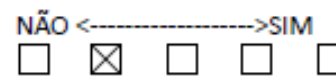

só um pouco fatigante, marque o segundo quadradinho.]

Você acha fatigante por e tirar a roupa?

[Se, por exemplo, você acha que essa atividade é extremamente fatigante, marque o quadradinho da extrema direita]

NÃO $<->$ SIM

Nunca Raramente Pouco Frequentemente Sempre

1 Você acha fatigante caminhar por 10 minutos?

2 Você acha fatigante caminhar por meia hora?

3 Você acha fatigante ficar em pé embaixo do chuveiro?

4 Você acha fatigante subir e descer escadas?

5 Você acha fatigante sair para comprar alguma coisa?

6 Você acha fatigante recolher o lixo da casa?

7 Você acha fatigante passar o aspirador na casa?

8 Você acha que visitar outras pessoas, em geral, é fatigante?

9 Você acha fatigante participar de encontros sociais especiais, como uma festa de aniversário?






\section{Questionário de atividade Física habitual}

(Baecke 1982)

Por favor, circule a resposta apropriada para cada questão:

Nos últimos 12 meses:

1) Qual tem sido sua principal ocupação?

135

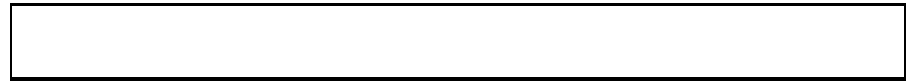

2) No trabalho eu sento:

nunca / raramente / algumas vezes / freqüentemente / sempre

3) No trabalho eu fico em pé:

nunca / raramente / algumas vezes / freqüentemente / sempre

4) No trabalho eu ando:

nunca / raramente / algumas vezes / freqüentemente / sempre

5) No trabalho eu carrego carga pesada:

nunca / raramente / algumas vezes / freqüentemente / sempre

6) Após o trabalho eu estou cansado:

muito freqüentemente / freqüentemente / algumas vezes / raramente / nunca

7) No trabalho eu suo:

$\begin{array}{lllll}5 & 4 & 3 & 2 & 1\end{array}$

muito freqüentemente / freqüentemente / algumas vezes / raramente / nunca

8) Em comparação com outros da minha idade eu penso que meu trabalho é fisicamente: $\quad \begin{array}{lllll}5 & 4 & 3 & 2 & 1\end{array}$ muito mais pesado/ mais pesado / tão pesado quanto / mais leve / muib mais leve 
9) Vợe pratica ou praficou esporte ou exercicio fisico nos últimos 12 meses: sim / nâo

Qual esporte ou exercicio fisico você pratica ou praticou mais freqüentemente?

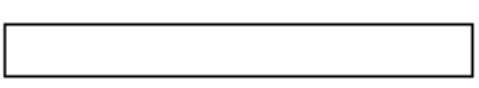

- quantas horas por semana?

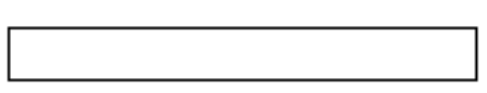

- quantos meses por ano?

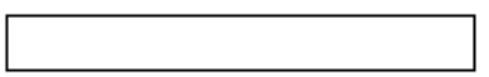

Se você faz um fez segundo esporte ou exercicio fisico, qual o tipo?:

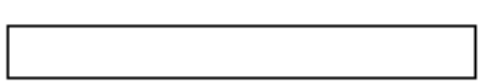

- quantos meses por ano?
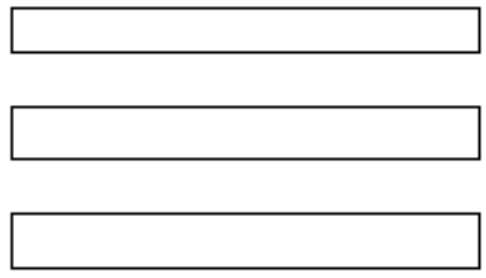

10) Em comparaçẫo com outros da minha idade eu penso que minha atividade fisica durante as horas de lazer é: muito maior / maior / a mesma / menor / muito menor

11) Durante as horas de lazer eu suo: muito freqüentemente / freqüentemente / algumas vezes / raramente / nunca

12) Durante as horas de lazer eu pratico esporte ou exercicio fisico: nunca / raramente / algumas vezes / freqüentemente / muito freqüentemente

13) Durante as horas de lazer eu vejo televisāo:

nunca / raramente / algumas vezes / freqüentemente / muito freqüentemente

14) Durante as horas de lazer eu ando:

nunca / raramente / algumas vezes / freqüentemente / muito freqüentemente

$<1 \quad 1-2 \quad 2-3 \quad 3-4 \quad>4$

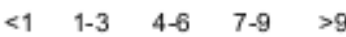

$<1 \quad 1-2 \quad 2-3 \quad 3-4 \quad>4$

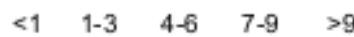
15) Durante as horas de lazer eu ando de bicicleta:
nunca / raramente / algumas vezes / freqüentemente / muito freqüentemente

16) Durante quantos minutos por día você anda a pé ou de bicideta indo e voltando do trabalho, escola ou compras? $<5 / 5-15 / 16-30 / 31-45 />45$

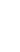


CES-D

(Batistoni et al., 2007)

Instruções: Segue abaixo uma lista de tipos de sentimentos e comportamentos. Solicitamos que você assinale a frequência com que tenha se sentido dessa maneira durante a semana passada

\begin{tabular}{|c|c|c|c|c|}
\hline DURANTE A ÚLTIMA SEMANA & $\begin{array}{c}\text { Raramente } \\
\text { (menos que } 1 \text { dia) } \\
0\end{array}$ & $\begin{array}{c}\text { Durante pouco } \\
\text { tempo } \\
\text { (1 ou } 2 \text { dias) } \\
1\end{array}$ & $\begin{array}{c}\text { Durante um tempo } \\
\text { moderado } \\
\text { (de } 3 \text { a } 4 \text { dias) } \\
2\end{array}$ & $\begin{array}{c}\text { Durante a maior } \\
\text { parte do tempo } \\
\text { (de } 5 \text { a } 7 \text { dias) } \\
3\end{array}$ \\
\hline \multicolumn{5}{|l|}{$\begin{array}{l}\text { 01. Senti-me incomodado com } \\
\text { coisas que habitualmente não } \\
\text { me incomodam }\end{array}$} \\
\hline \multicolumn{5}{|l|}{$\begin{array}{l}\text { 02. Não tive vontade de comer, } \\
\text { tive pouco apetite }\end{array}$} \\
\hline \multicolumn{5}{|l|}{$\begin{array}{l}\text { 03. Senti não conseguir } \\
\text { melhorar meu estado de ânimo } \\
\text { mesmo com a ajuda de } \\
\text { familiares e amigos }\end{array}$} \\
\hline \multicolumn{5}{|l|}{$\begin{array}{l}\text { 04. Senti-me, comparando-me } \\
\text { às outras pessoas, tendo tanto } \\
\text { valor quanto a maioria delas }\end{array}$} \\
\hline \multicolumn{5}{|l|}{$\begin{array}{l}\text { 05. Senti dificuldade em me } \\
\text { concentrar no que estava } \\
\text { fazendo }\end{array}$} \\
\hline \multicolumn{5}{|l|}{ 06. Senti-me deprimido } \\
\hline \multicolumn{5}{|l|}{$\begin{array}{l}\text { 07. Senti que tive de fazer } \\
\text { esforço para dar conta das } \\
\text { minhas tarefas habituais }\end{array}$} \\
\hline \multicolumn{5}{|l|}{$\begin{array}{l}\text { 08. Senti-me otimista com } \\
\text { relação ao futuro }\end{array}$} \\
\hline \multicolumn{5}{|l|}{$\begin{array}{l}\text { 09. Considerei que a minha vida } \\
\text { tinha sido um fracasso }\end{array}$} \\
\hline \multicolumn{5}{|l|}{ 10. Senti-me amedrontado } \\
\hline \multicolumn{5}{|l|}{$\begin{array}{l}\text { 11. Meu sono não foi } \\
\text { repousante }\end{array}$} \\
\hline \multicolumn{5}{|l|}{ 12. Estive feliz } \\
\hline \multicolumn{5}{|l|}{ 13. Falei menos que o habitual } \\
\hline \multicolumn{5}{|l|}{ 14. Senti-me sozinho } \\
\hline \multicolumn{5}{|l|}{$\begin{array}{l}\text { 15. As pessoas não foram } \\
\text { amistosas comigo }\end{array}$} \\
\hline \multicolumn{5}{|l|}{ 16. Aproveitei minha vida } \\
\hline \multicolumn{5}{|l|}{ 17. Tive crises de choro } \\
\hline \multicolumn{5}{|l|}{ 18. Senti-me triste } \\
\hline \multicolumn{5}{|l|}{$\begin{array}{l}\text { 19. Senti que as pessoas não } \\
\text { gostavam de mim }\end{array}$} \\
\hline $\begin{array}{l}\text { 20. Não consegui levar adiante } \\
\text { minhas coisas }\end{array}$ & & & & \\
\hline
\end{tabular}

SOMATÓRIA:

CES-D $\geq 16$ PONTOS: SINTOMAS DEPRESSIVOS 
ANEXO D - PARECER CONSUBSTANCIADO DO CEP- EEUSP

\author{
ESCOLA DE ENFERMAGEM DA \\ UNIVERSIDADE DE SÃO \\ PAULO - EEUSP
}

\title{
PARECER CONSUBSTANCIADO DO CEP
}

\section{DADOS DO PROJETO DE PESQUISA}

Título da Pesquisa: Eficácia de medidas de higiene do sono e fototerapia no sono e na qualidade de vida de pacientes com insuficiência cardíaca - ensaio clínico

Pesquisador: Mariana Alvina dos Santos

Área Temática:

Versão: 1

CAAE: 09844712.7 .0000 .5392

Instituição Proponente: Escola de Enfermagem da Universidade de São Paulo - EEUSP

\section{DADOS DO PARECER}

Número do Parecer: 145.630

Data da Relatoria: $13 / 11 / 2012$

Apresentação do Projeto:

O enfermeiro pode exercer papel fundamental no cuidado ao paciente com IC (insuficiência cardíaca) ao ensinar-Ihes habilidades que promovam o

autocuidado, bem como incentivar a adesão ao tratamento. Quando as condições clínicas estão sob controle e o paciente tem habilidades

serão testadas três intervenções não farmacológicas quanto à eficácia para melhorar o sono e qualidade de vida de pacientes com insuficiência cardíaca (IC). O estudo será realizado no Ambulatório de Insuficiência Cardíaca do Instituto Dante Pazzanese

de Cardiologia (IDPC), localizado no Município de São Paulo. Para estimar o tamanho da amostra, foi assumido que os três tratamentos

apresentarão efeitos semelhantes, e melhorarão o Pittsburg Sleep Quality Index (PSQI) dos maus dormidores em média 4 unidades de escore,

comparado à ausência de efeito no Grupo Controle. E usando dados de desvio padrão do escore do PSQI observados por Currie (2002) (3,8),

estimou-se um efeito de 0,455 , que resulta em tamanho amostral de 88 indivíduos, para um nível crítico de $5 \%$ e poder de $95 \%$. Como se estima

perda de até $20 \%$ no acompanhamento dos pacientes ao longo do estudo, sugere-se uma amostra total de 108 indivíduos divididos igualmente nos

4 grupos propostos (27 por grupo) 


\section{ESCOLA DE ENFERMAGEM DA \\ UNIVERSIDADE DE SÃO Q Platoformo PAULO - EEUSP}

adequadas para a gestão do seu estado de saúde, a qualidade de vida pode ser melhorada. Sendo assim, as intervenções de enfermagem que

aliviem as respostas aos problemas de saúde que prejudicam e reduzem o bem-estar do paciente com IC devem ser exploradas

Objetivo da Pesquisa:

Objetivo geral

Testar a efetividade da terapia de higiene do sono, da fototerapia e da terapia combinada (higiene do sono + fototerapia) para melhorar o sono de pacientes com IC em acompanhamento ambulatorial.

Objetivos especificos

¿Avaliar a associação de variáveis clínicas e demográficas selecionadas com o padrão de sono e qualidade de vida de pacientes com IC

¿ Estimar a validade da dimensão fisica do Minessota Living with Heart Failure Questionaire (MLHFQ) para avaliar a dispneia, a fadiga e fadiga ao esforço dos pacientes com IC.

Avaliação dos Riscos e Beneficios:

Acredita-se que o uso das intervenções propostas trará beneficios relacionados à melhora do padrão de sono e da qualidade de vida dos pacientes

com insuficiência cardiaca, podendo ser incorporada como possibilidade terapêutica pelos profissionais de saúde para essa clientela.

Comentários e Considerações sobre a Pesquisa:

Pesquisa bem elaborada

Considerações sobre os Termos de apresentação obrigatória:

Bem escrito, detalhado em linguagem acessivel e em formulário proprio, constam no TCLE as orientações da Resolução 196/96

Recomendações:

Nao há.

Conclusões ou Pendências e Lista de Inadequações:

Trabalho bem elaborado. Não há óbices éticos.

Situação do Parecer:

Aprovado

Necessita Apreciação da CONEP:

Não

Endereço: Av. Dr Enéas de Carvalho Aguiar, 419

Bairro: Cerqueira Cesa

UF: SP Municipio: SAO PAULO

Telefone: (11)3061-7548 Fax: (11)3061-7548 E-mail: edipesq@usp.br 


\section{ESCOLA DE ENFERMAGEM DA \\ UNIVERSIDADE DE SÃO \\ Platoformo \\ PAULO - EEUSP}

Considerações Finais a critério do CEP:

SAO PAULO, 13 de Novembro de 2012

Assinador por:

Celia Maria Sivalli Campos

(Coordenador)

Endereço: Av. Dr Enéas de Carvalho Aguiar, 419

Bairro: Cerqueira Cesar $\quad$ CEP: $05.403-000$

UF: SP Municipio: SAO PAULO

Telefone: (11)3061-7548 $\quad$ Fax: (11)3061-7548

E-mail: edipesq@usp.br 


\section{ANEXO E - PARECER CONSUBSTANCIADO DO CEP}

\section{INSTITUTO DANTE \\ PAZZANESE DE CARDIOLOGIA \\ PARECER CONSUBSTANCIADO DO CEP \\ Elaborado pela Instituição Coparticipante}

\section{DADOS DO PROJETO DE PESQUISA}

Título da Pesquisa: Eficácia de medidas de higiene do sono e fototerapia no sono e na qualidade de vida de pacientes com insuficiência cardiaca - ensaio clínico

Pesquisador: Mariana Alvina dos Santos

Área Temática:

Versäo: 1

CAAE: 09844712.7 .0000 .5392

Instituição Proponente: Escola de Enfermagem da Universidade de São Paulo - EEUSP

\section{DADOS DO PARECER}

Número do Parecer: 155.322

Data da Relatoria: $27 / 11 / 2012$

Apresentação do Projeto:

Adequado

Objetivo da Pesquisa:

Adequado

Avaliação dos Riscos e Benefícios:

Adequado

Comentários e Considerações sobre a Pesquisa:

Atende as solicitação do CEP

Consideraçöes sobre os Termos de apresentação obrigatória:

Elaborar as declarações obrigatórias.

Recomendaçöes:

1) Anexar autorização do setor onde será realizada a pesquisa

2) TCLE - colocar os contatos do Instituto Dante Pazzanese (setor responsável) e do Comitê de Ética em Pesquisa do IDPC.

3) Apresentar relatório parcial e final.

Conclusões ou Pendências e Lista de Inadequações:

Entregar declarações assinadas pelos responsáveis. 
INSTITUTO DANTE PAZZANESE DE CARDIOLOGIA

Situação do Parecer:

Aprovado

Necessita Apreciação da CONEP:

Não

Consideraçōes Finais a critério do CEP:

Protocolo avaliado e aprovado por este Comitê de Ética em Pesquisa em reunião ordinária realizada no dia 27 de novembro de 2012.

Atender as recomendações.

27 de Novembro de 2012

Assinador por:

Pedro Silvio Farsky

(Coordenador)

Endereço: Av. Dr. Dante Pazzanese N. ${ }^{\circ} 500$, Torre $6^{\circ}$ andar

Bairro: CEP: $04.012-909$

UF: SP Município:

Telefone: (115)085--6040 Fax: (115)085--6040 E-mail: cep@dantepazzanese.org.br 